University of Rhode Island

DigitalCommons@URI

Open Access Dissertations

2014

\title{
IMPACTS OF MANAGEMENT ON FISHERIES DIVERSITY AS A FACTOR AFFECTING SOCIAL RESILIENCE IN COMMUNITIES OF THE SOUTHERN NEW ENGLAND REGION
}

Tarsila Seara

University of Rhode Island, tarseara@gmail.com

Follow this and additional works at: https://digitalcommons.uri.edu/oa_diss

\section{Recommended Citation}

Seara, Tarsila, "IMPACTS OF MANAGEMENT ON FISHERIES DIVERSITY AS A FACTOR AFFECTING SOCIAL RESILIENCE IN COMMUNITIES OF THE SOUTHERN NEW ENGLAND REGION" (2014). Open Access Dissertations. Paper 137.

https://digitalcommons.uri.edu/oa_diss/137

This Dissertation is brought to you for free and open access by DigitalCommons@URI. It has been accepted for inclusion in Open Access Dissertations by an authorized administrator of DigitalCommons@URI. For more information, please contact digitalcommons-group@uri.edu. 
IMPACTS OF MANAGEMENT ON FISHERIES DIVERSITY AS A FACTOR AFFECTING SOCIAL RESILIENCE IN COMMUNITIES OF THE SOUTHERN NEW ENGLAND REGION

By

TARSILA SEARA

A DISSERTATION SUBMITED IN PARTIAL FULFILLMENT OF THE REQUIREMENTS FOR THE DEGREE OF

DOCTOR OF PHILOSOPHY

IN

MARINE AFFAIRS

UNIVERSITY OF RHODE ISLAND 


\section{DOCTOR OF PHILOSOPHY DISSERTATION}

OF

TARSILA SEARA

\section{APPROVED:}

Dissertation Committee:

Major Professor Richard B. Pollnac

Tracey M. Dalton

John J. Poggie

Robert S. Pomeroy

Nasser H Zawia

DEAN OF THE GRADUATE SCHOOL 


\begin{abstract}
The present research aims at examining potential impacts of fisheries management on the diversity of species exploited by fishermen in Southern New England, and examining the relationship between this diversity and the resilience of fishermen and, consequently, communities in adapting to changes in their social and physical environments. One way fishermen are able to adapt to environmental and socio-economic changes is through diversification of the catch. The current study argues that certain management plans, especially those focused on limited entry strategies, have been reducing fishermen's adaptive flexibility, therefore reducing fishermen's resilience and that of their communities. Two hypotheses were developed: 1) the diversity of species landed by fishing vessels homeported in the studied communities has decreased through time as a consequence of management practices; and 2) A decrease in diversity and flexibility in the fisheries has the potential to negatively affect fishermen's individual well-being as well as their resilience to changes in the fishery. In order to test these hypotheses, two research methods were used: structured surveys and analyses of secondary data of fishery landings for the ports studied. A total of 157 interviews were conducted with fishermen from the ports of Point Judith, Rhode Island, New Bedford and Fairhaven, Massachusetts, and the Cape Cod region of Massachusetts, more specifically the ports of Chatham, Harwich Port, Hyannis, and Provincetown. Results of analyses show that fishermen perceived a significant reduction in fishery diversity to have occurred as a result of regulations, despite the fact that analyses involving landings data showed a significant decline in
\end{abstract}


diversity only for New Bedford and a slight declining trend for New Bedford and Cape Cod when trawl gear landings were analyzed separately. The latter results can be in part explained by the analyses of landings fluctuation for some of the most important species in the studied region, suggesting that diversification has occurred, possibly as a means of adaptation to change. Qualitative data obtained from surveys suggest that impacts on fishery diversity have a negative effect on fishermen's resilience. Results from this study have the potential to contribute to the enhancement of knowledge and stimulate important future research about aspects of adaptability in fishing communities specifically with regard to their impact on future policy strategies. 


\section{ACKNOWLEDGEMENTS}

I would like to express my utmost gratitude to my advisor Dr. Richard Pollnac. During the five years that I have been his student, he has given me immensurable support and useful advice, and has also become a very important person in my life. I owe so much to his belief in me. P, I admire you professionally and personally and I have learned a lot from you. Thank you.

I would like to thank Lisa Colburn for the enormous help and support, and especially for being so understanding and allowing so much flexibility in my working hours so that I could finish writing my dissertation. I am incredibly grateful for the opportunities and for everything I learned during all the years I have been working under your supervision. Thank you.

I would like thank Robert Pomeroy for believing in my potential and helping open up the first door that brought me here. Thank you.

A big thank you to Angela, whom without I would not have been able to finish fieldwork on time, for making those mornings at the docks a lot more fun and hilarious at times. Thanks!

I would like to thank Changhua for sharing her experiences as a Marine Affairs PhD student with me and for answering so many of my silly questions. Xie Xie.

I would like to thank my family for their love and immense support in every step of the way. Especially my parents Paula and Antonio, grandparents Paulo and Yara, and sister Flora, who have always believed in me and contributed so much to my life achievements. Obrigada. 
I would like to thank Graeme, my love and companion who had to put up with so much during this process. Thank you for being there for me, thank you for all the kind words and thank you for reminding me that we stand on a giant blue rock, floating on an infinite universe. I love you.

So many people were important during my research process, but I would not have been able to do it without the help of the fishermen who were kind enough to take the time to answer my questions. Thank you. 
For Pedro and Julia, whom I hope to inspire. 


\section{TABLE OF CONTENTS}

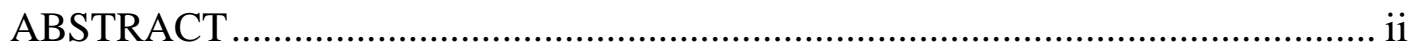

ACKNOWLEDGEMENTS ........................................................................... iv

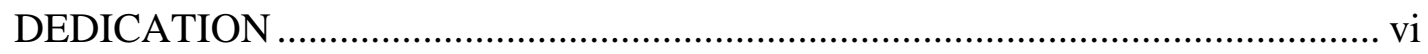

TABLE OF CONTENTS ............................................................................. vii

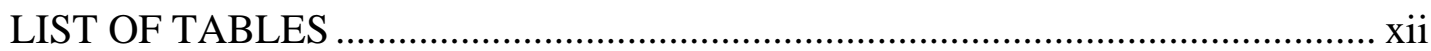

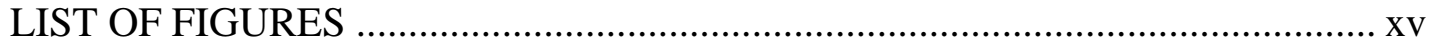

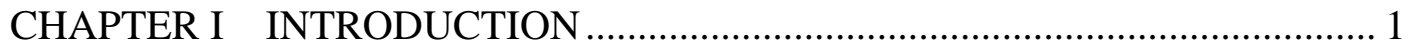

1.1. Theoretical background and statement of the problem.............................. 1

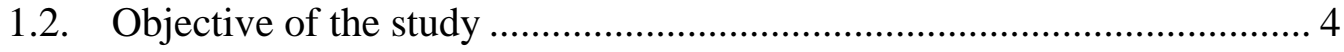

1.3. Research question and hypotheses ........................................................ 4

1.3.1. Research question ....................................................................... 4

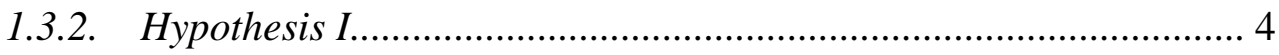

1.3.3. Hypothesis II ....................................................................... 5

1.4. The ports and regions ............................................................................ 5

1.4.1. Point Judith, Rhode Island .......................................................... 5

1.4.2. New Bedford, Massachusetts ............................................................ 10

1.4.3. Cape Cod, Massachusetts ............................................................... 14

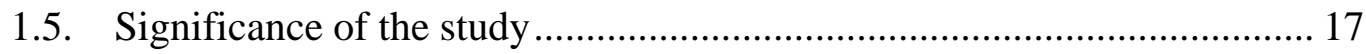

CHAPTER II LITERATURE REVIEW ........................................................... 20

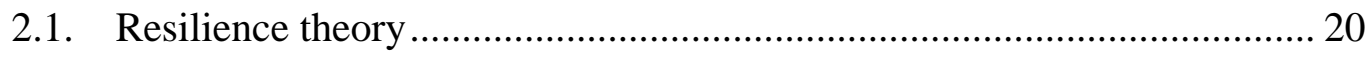

2.2. Resilience of fishing communities........................................................... 28 
2.3. Diversity and 'adaptive flexibility' of fishing communities .

2.4. Fisheries management in New England - an overview of two important stocks............................................................................. 41

2.4.1. Groundfish fishery............................................................. 41

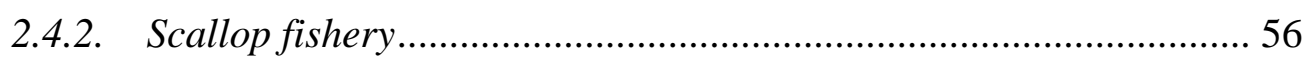

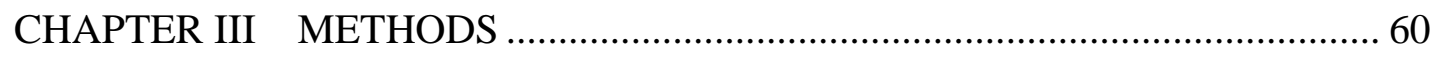

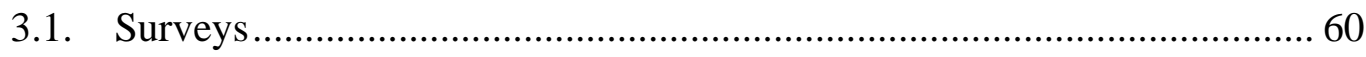

3.1.1. Participants and sampling design........................................... 60

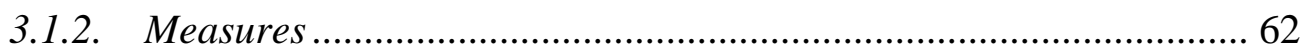

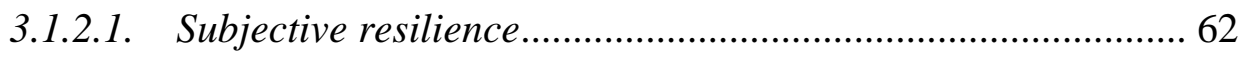

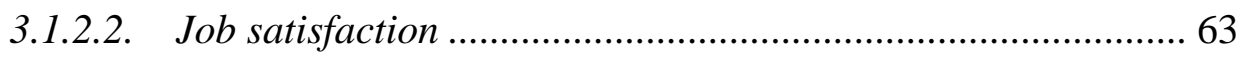

3.2. Post-survey supplementary question.................................................. 65

3.2.1. Participants and sampling design for supplementary questions ..... 65

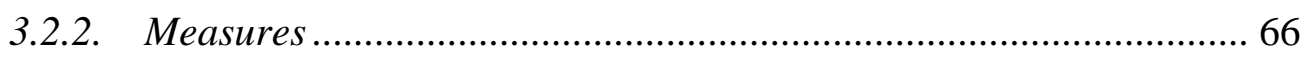

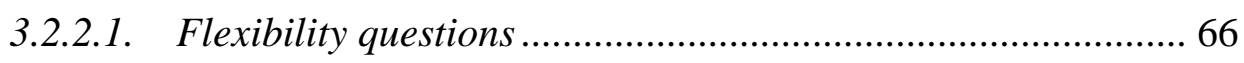

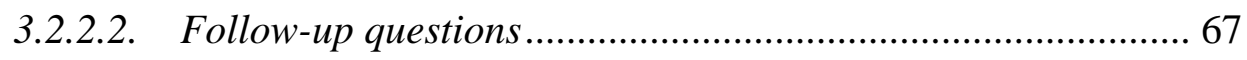

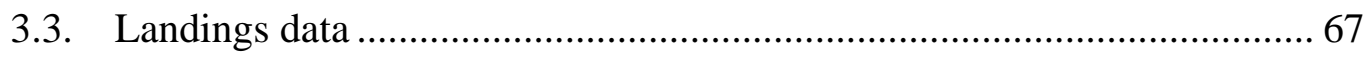

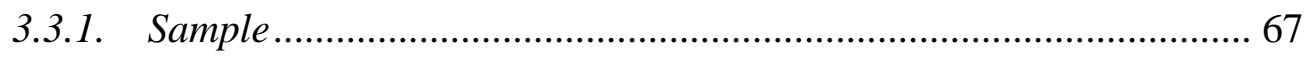

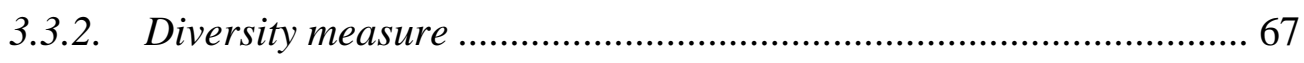

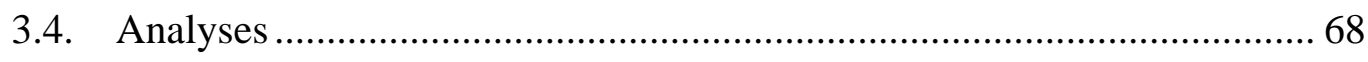

CHAPTER IV ANALYSES AND RESULTS ............................................. 69

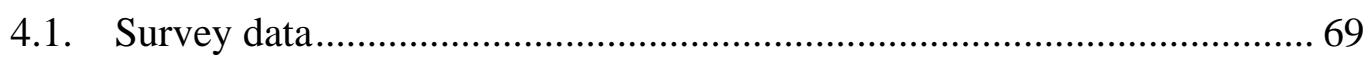

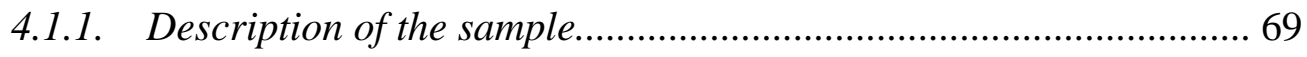

4.1.1.1. Age and education........................................................... 69 


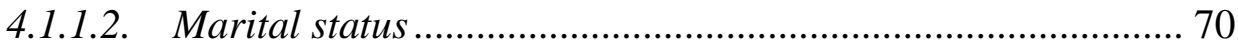

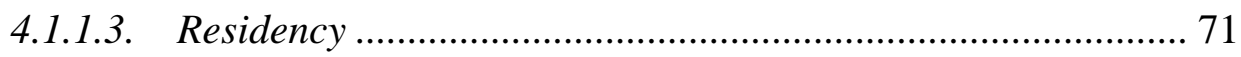

4.1.1.4. Occupations besides fishing ..................................................... 71

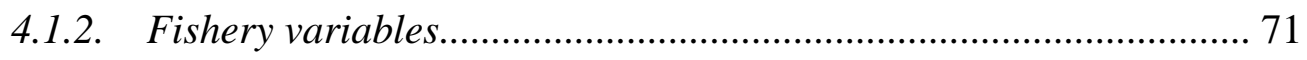

4.1.2.1. Fishing experience ……………….......................................... 71

4.1.2.2. Familial involvement in fishing.............................................. 73

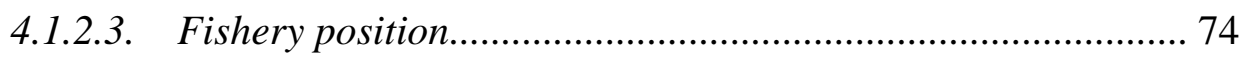

4.1.3. Characteristics of current fishing activity ....................................... 75

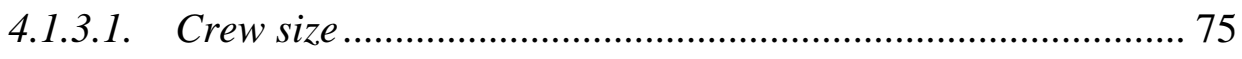

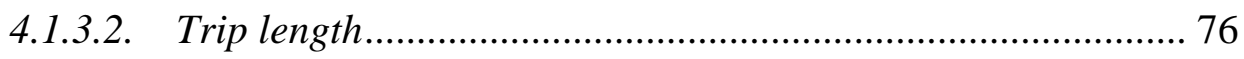

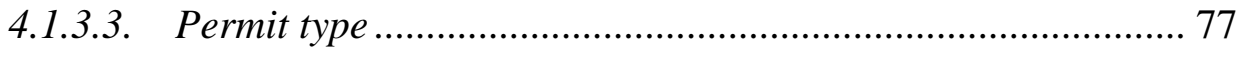

4.1.3.4. Annual income from fishing ................................................... 77

4.1.3.5. Gear types ........................................................................... 79

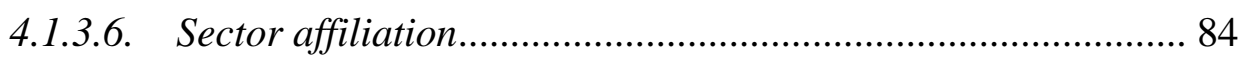

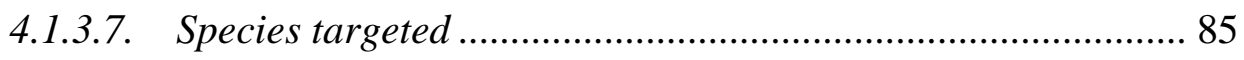

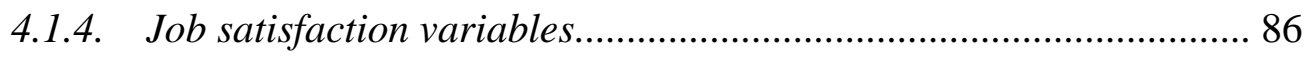

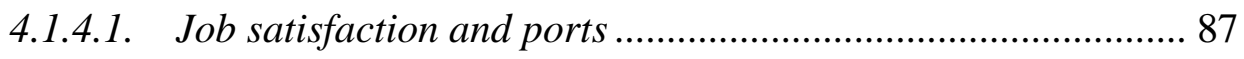

4.1.4.2. Job satisfaction and gear types ............................................. 88

4.1.4.3. Additional job satisfaction questions ....................................... 88

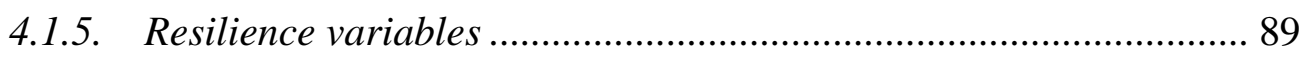

4.1.5.1. Resilience and ports ................................................................ 90

4.1.5.2. Resilience and gear types........................................................ 91

4.1.6. Correlations between variables ................................................... 92 
4.1.7. Changes in catch composition .................................................. 97

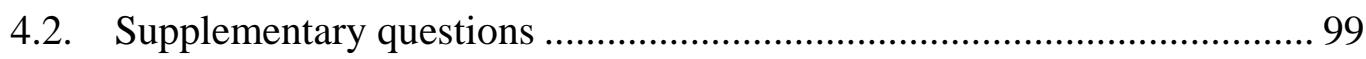

4.2.1. Description of the sample.......................................................... 99

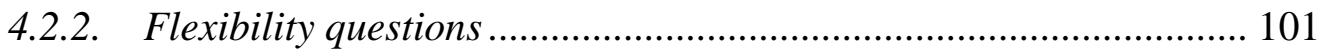

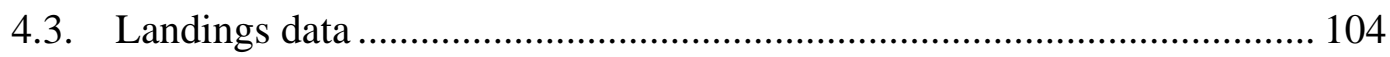

4.3.1. Overall characteristics of the fleet................................................ 104

4.3.2. Diversity analyses ................................................................ 106

4.3.3. Species landings fluctuation..................................................... 107

CHAPTER V DISCUSSION AND CONCLUSIONS ….................................. 117

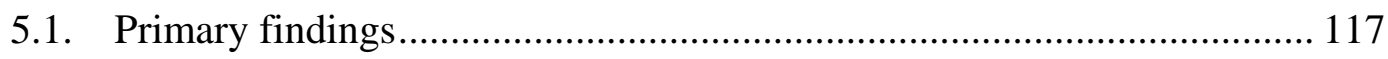

5.1.1. Additional characterization of the ports ....................................... 118

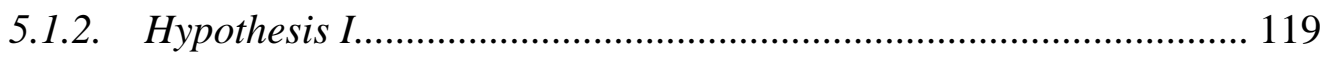

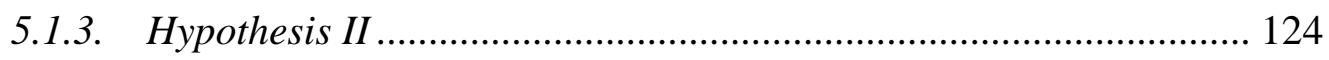

5.2. Other potentially important findings............................................... 127

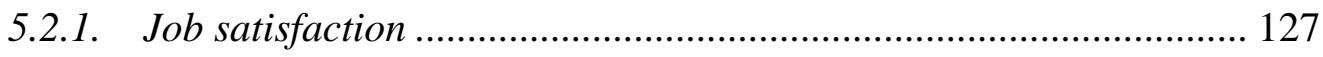

5.2.2. Correlations between variables ................................................ 129

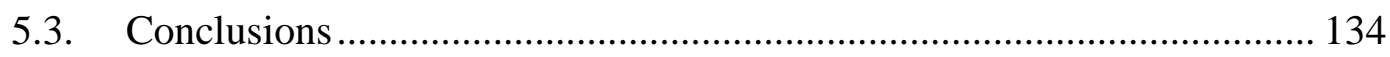

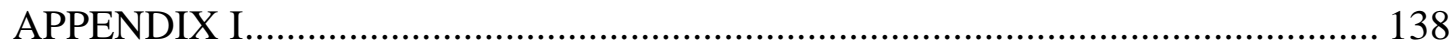

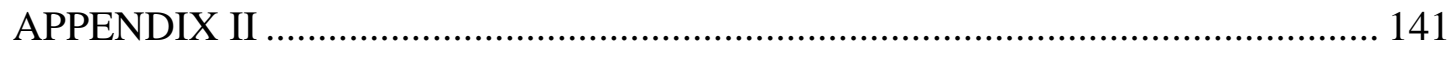

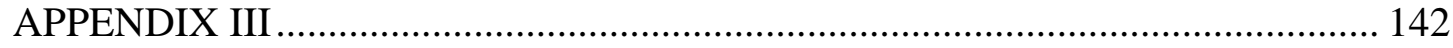

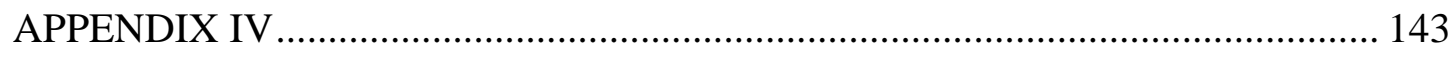

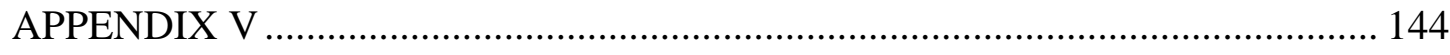

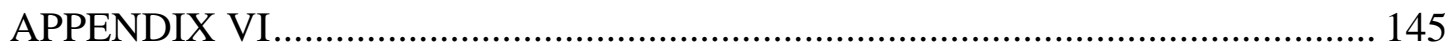




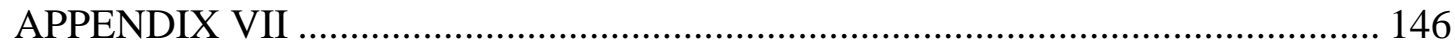

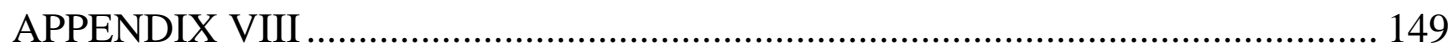

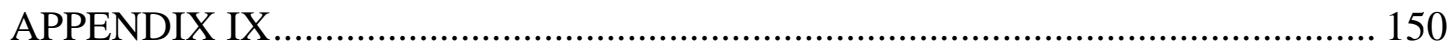

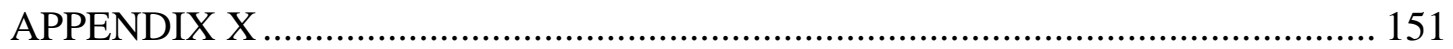

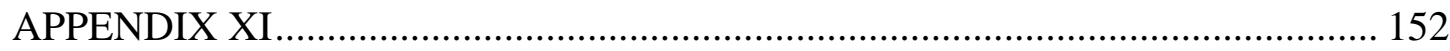

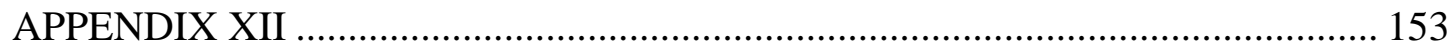

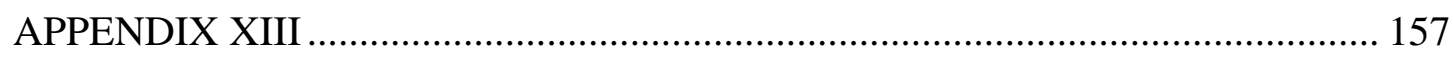

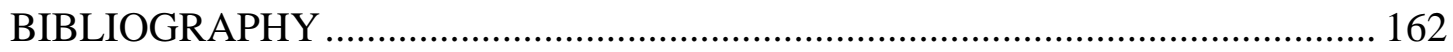




\section{LIST OF TABLES}

Table 1. Volume (lb) and value for significant species landed in Narragansett (ports of Point Judith and Jerusalem) in 2012 (Data extracted from NMFS databases)

Table 2. Volume (lb) and value for significant species landed in New Bedford in 2012 (Data extracted from NMFS databases)

Table 3. Volume (lb) and value for significant species landed in the Cape Cod region (Hyannis (Barnstable), Chatham, Harwich Port, and Provincetown in 2012 (Data extracted from NMFS databases).

Table 4. Statements developed by Marshal and Marshal (2007) to measure levels of subjective resilience.

Table 5. Items derived from the twenty-two scale developed by Pollnac and Poggie (1980) to measure levels of job satisfaction.

Table 6. Results of basic statistics regarding years of age and education for each port studied and for all three ports combined.

Table 7. Results of basic statistics regarding years of experience fishing, years of experience in current port, and years of experience on current boat for each port

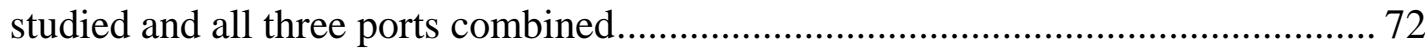

Table 8. Results of basic statistics involving the number of generations involved in fishing for each port and all three ports combined

Table 9. Results of basic statistics regarding number of relatives involved in fishing and number of relatives fishing on the same boat for each port studied and all three ports combined

Table 10. Distribution of the different fishery positions in the sample across the three ports studied and all ports combined.

Table 11. Results of basic statistics for crew size for each port and all three ports combined

Table 12. Results of basic statistics for trip length in days for each port and all three ports combined

Table 13. Frequencies for presence of federal permits on boats in the overall sample and in each port studied .... 
Table 14. Categories for annual income (based on Census 2010) and respective codes.

Table 15. Results of basic statistics for annual income (in categories) for each port and all three ports combined

Table 16. Frequencies for primary gear type found in the overall sample 80

Table 17. Frequencies for primary gear type found in New Bedford.....

Table 18. Frequencies for primary gear type found in Point Judith 81

Table 19. Frequencies for primary gear type found in Cape Cod.

Table 20. Frequencies of secondary gear types found in the overall sample of fishermen who used more than one gear type.

Table 21. Frequencies for secondary gear type used by fishermen who used more than one gear type in New Bedford

Table 22. Frequencies of secondary gear types used by fishermen who used more than one gear type in Point Judith.

Table 23. Frequencies of secondary gear types used by fishermen who used more than one gear type in Cape Cod

Table 24. All combinations of primary (rows) and secondary (columns) gear types and respective frequencies of occurrence found for fishermen who used multiple gear types in New Bedford

Table 25. All combinations of primary (rows) and secondary (columns) gear types and respective frequencies of occurrence found for fishermen who used multiple gear types in Point Judith

Table 26. All combinations of primary (rows) and secondary (columns) gear types and respective frequencies of occurrence found for fishermen who used multiple gear types in Cape Cod

Table 27. Results of a factor analysis involving the nine job satisfaction variables (Varimax rotation).

Table 28. Distribution of gear types by transformed category by port.....

Table 29. Results of a factor analysis involving the twelve resilience variables (Varimax rotation). 
Table 30. Mean standardized values for the three resilience components for each port studied

Table 31. Mean standardized values for the components Ability to Cope and Perception of Risk for each transformed gear type

Table 32. Results of a factor analysis involving demographic and fishing related variables (Varimax rotation) 94

Table 33. Matrix of correlations between components of demographic and fishing related variables and components of job satisfaction and resilience. 96

Table 34. Results of basic statistics for age, education, and fishing experience for the supplementary questionnaire sample

Table 35. Frequencies for fishery positions in the supplementary questionnaire sample 100

Table 36. Frequencies of gear types used by the overall sample of fishermen interviewed using the supplementary questionnaire

Table 37. Results of a paired sample t test comparing levels of perceived flexibility with regard to the diversity of species fishermen can exploit today and when respondent first began fishing

Table 38. Results of a paired sample t test comparing levels of perceived flexibility with regard to the diversity of gear types fishermen can use today and when respondent first began fishing

Table 39. Reasons believed by fishermen interviewed using the supplementary questionnaire to have influenced their flexibility to exploit different species and/or use multiple gear types.

Table 40. Incidence of landings between 1994 and 2012 using the most common gear types in the three ports studied 105 


\section{LIST OF FIGURES}

Figure 1. Map showing the location of the village of Galilee, where the port of Point Judith, RI, is located (adapted from maps.google.com) ................................... 6

Figure 2. Map showing the location of New Bedford (adapted from maps.google.com)

Figure 3. Map showing the location of Cape Cod and the four ports that are the focus of the present study: Hyannis, Harwich Port, Chatham, and Provincetown (adapted from maps.google.com)...

Figure 4. Panarchy model proposed by Gunderson and Holling (2002) (Adapted from www.peopleandplace.net) 25

Figure 5. Relationships between the human and natural environments and the resilience of coastal communities

Figure 6. Chart showing the distribution of fishery positions across the three ports studied

Figure 7. Histogram of the frequencies of trip length in days reported by the fishermen interviewed comparing the three ports studied

Figure 8. Histogram comparing the distribution of income categories across the three ports studied

Figure 9. Heurist model reflecting the statistically significant correlations found between the components of demographic and fishing related variables and components of job satisfaction and resilience.

Figure 10. Chart of the distribution of fishery positions found among fishermen in the supplementary questionnaire sample

Figure 11. Results of an analysis of variance involving the three ports analyzed comparing the average number of gear types reported by vessels across the time period studied

Figure 12. Results of an analysis of variance involving the three ports analyzed comparing average Shannon Index score across the time period studied

Figure 13. Results of an analysis of variance for New Bedford and Cape Cod comparing average Shannon scores through time for multispecies (trawl) gear users only 
Figure 14. Charts showing results for analyses of variance for landings of the group including the species cod, winter flounder, yellowtail flounder, and haddock between 1994 and 2012 for the three ports studied

Figure 15. Charts showing results for analyses of variance for landings of the group including the species red fish, pollock, and Atlantic halibut between 1994 and 2012 for the three ports studied

Figure 16. Charts showing results for analyses of variance for landings of the group including the species monkfish, witch founder, and American plaice founder between 1994 and 2012 for the three ports studied

Figure 17. Charts showing results for analyses of variance for landings of the group including the species summer flounder, scup, black sea bass, loligo squid, tilefish, and hakes between 1994 and 2012 for the three ports studied....

Figure 18. Charts showing results for analyses of variance for landings of the group including the species butterfish and ilex squid between 1994 and 2012 for the three ports studied

Figure 19. Charts showing results for analyses of variance for landings of the group including the species wolf fish and dogfish between 1994 and 2012 for the three ports studied 


\section{CHAPTER I}

\section{INTRODUCTION}

Chapter I provides an introduction to the problem that will be investigated in the present study in the context of the theoretical background that led to the development of the main research question and two hypotheses, which are also described in this chapter. Moreover, this chapter provides a characterization of the fishing ports and areas studied as well as the projected significance of the study.

\subsection{Theoretical background and statement of the problem}

The past few decades have been marked by an increased emphasis on the importance of understanding social impacts of management in fishing communities (see Colburn et al. 2006 for historical overview). In 1996, the enactment of the Sustainable Fisheries Act during reauthorization of the Magnuson-Stevens Act, implemented National Standard 8 (NS8), calling for the consideration of community impacts and emphasizing the importance of fishing resources for communities (Magnuson Fishery Conservation and Management Act of 1996). This initiative contributed to the development of social impact assessments for fisheries management plans as well as to an increase in research effort in the field of fisheries social sciences with regard to the impacts of management on coastal communities (Olson 2006, Sharp and Lach 2003, Pollnac et al. 2008). According to Colburn et al. (2006) the passage of NS8 required the body governing fisheries in the U.S. to "consider how fishing- 
dependent communities can adapt and sustain their engagement in marine resources harvesting and processing in the face of complex pressures” (2006: 234).

There is enough evidence in the literature to support the idea that knowledge concerning aspects of community and individual resilience gives managers the opportunity to foresee potential consequences of external change events (pressure), such as new policies, and thus choose options that balance social and economic costs with sustainability goals (see Marshall and Marshall 2007, Coulthard 2012). For that reason, there have been increased theoretical efforts to apply the concept of resilience to fisheries management practices in an attempt to maximize the ability of fishing communities to adapt and deal with change (Adger 2000, Carpenter et al. 2001, Marshall and Marshall 2007).

Fishing communities in the Northeast Region of the U.S. have been the focus of intense and complex changes in the past few decades. Fish stock declines have resulted in the implementation of strict and intricate regulations, often the cause of frustration and conflict between fishermen and policy-makers. During the past decade the increased popularity of limited access programs in the fisheries led to dramatic structural changes in the fishing industry and consequently in traditional fishing communities. One way fishermen can adapt to changes (e.g. stock and market fluctuations, management restrictions) is by diversifying their fishing activity. This idea is supported by a great deal of research, especially in the fields of 'portfolio,' 'livelihood,' and 'risk management' (Allison and Ellis 2001, Marschke and Berkes 2006, Béné 2009, Ha and van Dijk 2013, Cinner et al. 2010, Sethi 2010, Kasperski and 
Holland 2013). A diverse catch composition is also believed to be related to better conservation practices in the fishery (Murray et al. 2010).

The means and ability to exploit an array of different resources at different times of the year constitutes part of the adaptive tools fishermen have to overcome change and guarantee a stable flow of income. In other words, diversity of catch functions to maintain adaptive flexibility and help ensure long term survival in the face of adversities. This idea is especially relevant in the context of fishing communities because aspects of job satisfaction among fishermen have been shown to create reluctance to leave the occupation even when income is minimal (Pollnac et al. 2001, Pollnac et al. 2008, Pollnac and Poggie 2008), reinforcing the need for 'withinfishery diversification' (e.g. diversify species, gear, and fishing grounds) as opposed to ‘out-fishery diversification’ (i.e. seek alternative occupation) (Ha and van Djik 2013).

Conventional policy strategies used to manage the fisheries in the U.S. are, generally, not aimed at maintaining diversity of catch composition (Rammel and van der Bergh 2010). In fact, the majority of the regulations being implemented to control the fishing activities in the U.S. today have a negative influence on the diversity of resources individual fishermen can exploit. For example, limited access to a number of fisheries makes it difficult for new entrants; qualification for permits based on historical catch motivates fishermen to continuously exploit given species in order to maintain their licenses; and bureaucratic constraints to the process make short term decisions about target species virtually impossible. This inability to diversify is likely to hinder fishermen's adaptability and consequently have negative effects on their resilience and that of entire communities highly dependent on fishing resources. 


\subsection{Objective of the study}

Primarily, the present research aims at examining potential impacts of fisheries management on the diversity of species exploited by fishermen (catch composition) in southern New England, specifically Point Judith, Rhode Island, New Bedford, and the Cape Cod region in Massachusetts, and examining the relationship between this diversity and the resilience of fishers and, consequently, communities in adapting to changes in their social and physical environments. At the individual fisherman level, this study aims at analyzing the relationships between subjective resilience and job satisfaction variables to investigate if fishermen's high levels of occupational attachment influence their perception of their ability to adapt to changes.

\subsection{Research question and hypotheses}

\subsubsection{Research question:}

Have management practices affected New England fisheries by decreasing fishery diversity and flexibility thus negatively affecting individual and community resilience?

\subsubsection{Hypothesis I:}

Diversity of species landed (catch composition) by fishing vessels homeported in Point Judith, Rhode Island, New Bedford and Cape Cod, Massachusetts, has decreased through time as a consequence of management practices. A decrease in flexibility to exploit different species is expected to have been more significant for 
multispecies fishermen, who have been subjected to the most dramatic changes in management in the past years.

\subsubsection{Hypothesis II:}

A decrease in diversity and flexibility to exploit different species in the fisheries has the potential to negatively affect fishermen's individual well-being as well as their resilience to changes in the fishery. Impacts on resilience are expected to affect more significantly multispecies fishermen.

\subsection{The ports and regions}

\subsubsection{Point Judith, Rhode Island}

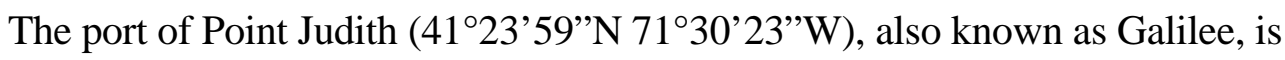
located on Point Judith Cape, in the town of Narragansett, Rhode Island. The port is located in the village of Galilee, which borders the village of Point Judith to the east and the village of Jerusalem, home to a small fishing port, to the west across the Point Judith channel (figure 1). 


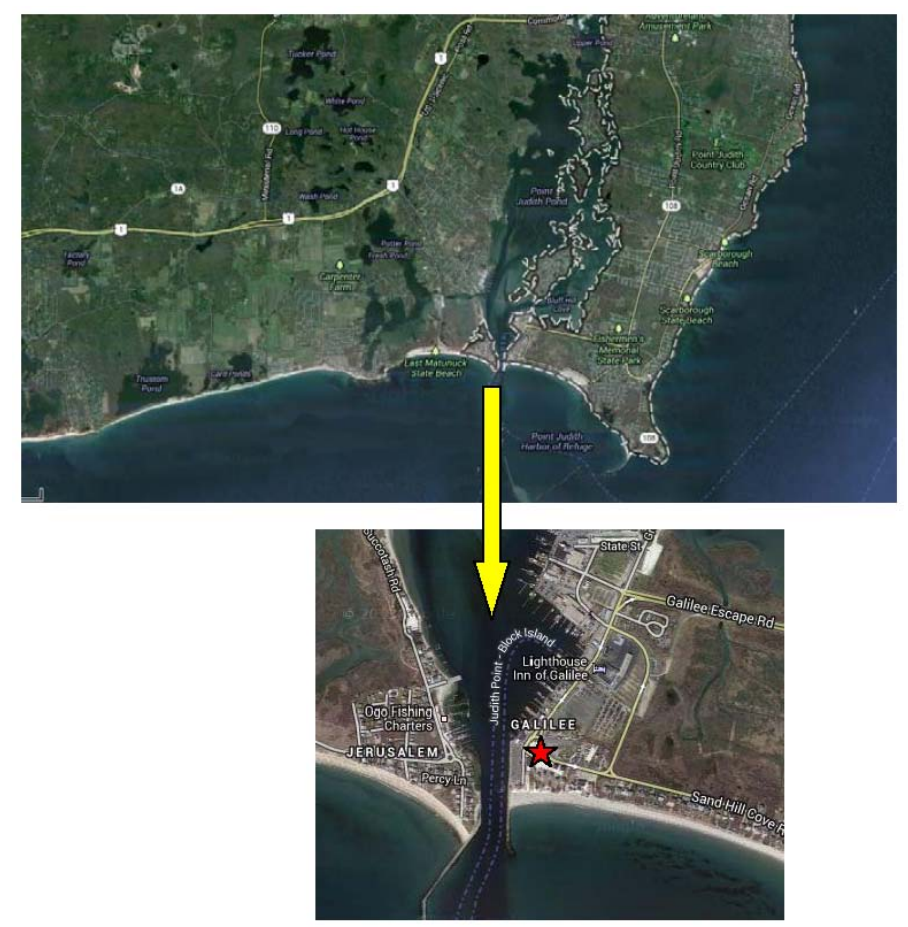

Figure 1. Map showing the location of the village of Galilee, where the port of Point Judith, RI, is located (adapted from maps.google.com)

Fishing has been an important economic and subsistence activity in Rhode Island since the early stages of the state's development. Although in the beginning fishing was practiced mainly as a way to complement agricultural activities in the offseason, the first recorded commercial fishing operations in Rhode Island date back to the 1700s (Gersuny and Poggie 1973). The first commercial and subsistence fishermen in the state relied mainly on simple techniques such as hook-and-line, floating fish traps, and beach seines (Hall-Arber et al. 2001).

Throughout the 1800s, New England fisheries underwent several changes brought by the use of new technology. In Point Judith, records dating from the $19^{\text {th }}$ century show the introduction of new fishing techniques such as trolling, lobster traps, and barrel traps. Although steamships had been successfully introduced in the fisheries at the time, by 1885 Point Judith’s fishing industry was comprised entirely of a couple of sailboats and approximately 130 rowboats (Gersuny and Poggie 1973). 
Nonetheless, the Rhode Island fishery was gaining strength, and the state's fishing industry was expanding beyond the local market. Point Judith’s fishermen hauled their catch on a regular basis to Newport where a steamship service was offered to transport local catch to be sold the next morning in New York markets (Gersuny and Poggie 1973).

Point Judith has been Rhode Island's largest and most fruitful fishing port for many decades, ranking numerous times among the East Coast’s most productive fishery landing sites. The rise of Point Judith into becoming the most important fishing port in the state of Rhode Island was the result of two large construction projects finalized in the late 1800s and early 1900s. The first project, accomplished in 1889, involved the construction of a "harbor of refuge," that consisted in the placement of three extensive breakwaters totaling more than 11,800 feet (Gersuny and Poggie 1974).

The other large intervention that contributed to the success of Point Judith was the dredging of the channel into Point Judith Pond. Shifting sand deposits at the pond's outlet to the sea obstructed navigation, limiting the access of large steamship boats into the harbor. Although the motivation for improving the port was not primarily related to the fishing industry, impacts of the two interventions on the productivity of the local fisheries were evident: records show that landings increased from 300 tons in 1895 to 3000 tons in 1935 (Gersuny and Poggie 1973).

In 1935, major improvements were made to the Port of Galilee. The government expended $\$ 300,000$ U.S. dollars with the construction of two piers and the dredging of a thirty-five acre anchorage basin inside the pond, in a project which 
partially aimed at providing jobs during difficult times for the U.S. economy.

Subsequent to these improvements, fish landings increased drastically reaching a total of 17,000 tons in 1945 (Gersuny and Poggie 1974). The fishing industry continued to prosper in the following decades, and despite capital shortage associated with the World War II, both tonnage and value of catch continued to rise, reaching a record of 142 million pounds in 1957 (Gersuny and Poggie 1974).

The extremely large landings observed for the periods that followed the early 1930s can be associated with the introduction of the first large trawlers in the New England fisheries. As inshore menhaden stocks plummeted, technologies allowing efficient pursuit of fish farther from shore became available. The otter trawler became the primary method in the early 1930s, employed in the capture of mostly whiting and red hake (Hall-Arber et al. 2001).

In 1947 the Point Judith Fishermen's Cooperative Association was created as a means to look out for the economic interests of the local fishermen. As the fleet grew and transformed from a shore fishery into a vessel fishery, private interests in the receiving and transporting of the catch subjected the fishermen to manipulation by the fish-market middlemen who charged the highest possible prices to handle the catch. Therefore, in order to protect their interests, sixty-five local fishermen formed the cooperative that eliminated the need for the outside middlemen and put the fishermen at an advantage in the market for fish products (Marshall 1973).

Although the cooperative ensured higher fish prices and therefore higher incomes for the fishermen, gross landings of many important species began to decline after 1960. As a response to this decline, Rhode Island fisheries went through a phase 
of diversification in species, in an effort to maintain a relatively stable amount and value of total landings. As part of this diversification process, offshore lobstering was introduced in the early 1960s (Doeringer et al. 1986). By the end of the 1980s decreases in stocks coupled with increases in costs for fishing supplies and boat insurance began to have impacts on the Rhode Island fishing industry. The Fishermen's Cooperative closed in 1994.

Despite these issues, the successful implementation of the off-shore fleet in Point Judith sealed the future of the port as number one in the state of Rhode Island and one of the most important landing sites in the U.S. East Coast. As of 2012, Point Judith was ranked number 26 in the country in terms of total value of catch - 42.6 million U.S. dollars (NOAA 2013a).

Point Judith is characterized by diverse fishing activities. The state's marine fisheries are divided into three major sectors: shellfish, lobster, and finfish. The shellfish sector includes oysters, soft shell clams, and most importantly, quahogs. The lobster sector is primarily comprised of the highly valued American lobster with some crabs as well. The finfish sector targets a variety of pelagic and bottom species of fish including winter, yellowtail and summer flounder, striped bass, black sea bass, scup, butterfish, squid, whiting, skate, and dogfish. A wide range of gear including otter trawl nets, floating fish traps, lobster traps, gillnets, fish pots, rod and reel, and clam rakes are used to harvest these species (NOAA 2006a). Table 1 shows volume in pounds and value for significant species landed in Narragansett (ports of Point Judith and Jerusalem) in 2012. As of May 2013, NMFS (National Marine Fisheries Service) databases show a total of 138 vessels homeported in Narragansett. 
Table 1. Volume (lb) and value for significant species landed in Narragansett (ports of Point Judith and Jerusalem) in 2012 (Data extracted from NMFS databases)

\begin{tabular}{lrr}
\hline Species landed & Volume (lb) & Value (\$) \\
\hline Butterfish/mackerel/squid & $10,288,046$ & $10,953,170^{*}$ \\
Herring & $8,041,013$ & 837,841 \\
Summer flounder/scup/black sea bass & $7,640,762$ & $9,573,142$ \\
Skates & $7,564,113$ & $1,214,620$ \\
Small mesh groundfish $^{* *}$ & $2,923,827$ & $1,542,453$ \\
Other $^{\dagger}$ & $2,722,669$ & $2,919,533$ \\
Lobster $^{*}$ & $1,632,977$ & $7,202,125$ \\
Large mesh groundfish $^{\dagger \dagger}$ & 874,765 & $1,521,289$ \\
Monkfish & 822,400 & $2,050,070$ \\
Dogfish & 500,941 & 75,847 \\
Bluefish & 452,541 & 279,088 \\
Scallops & 417,145 & $4,054,071$ \\
Surf clam/ocean quahog & 10,336 & 10,336 \\
Tilefish & 7,185 & 13,876 \\
Salmon & 0 & 0 \\
Red crab & 0 & 0 \\
\hline Total & $\mathbf{4 3 , 8 9 8 , 7 2 0}$ & $\mathbf{4 2 , 2 4 7 , 4 6 1}$
\end{tabular}

*Values in red represent the five most important species in terms of value landed

** Silver hake (whiting), red hake, and offshore hake

${ }^{\dagger}$ Species not federally managed

${ }^{++}$Atlantic cod, haddock, pollock, yellowtail flounder, witch flounder, winter flounder, windowpane flounder, American plaice, Atlantic halibut, redfish, ocean pout, and white hake

\subsubsection{New Bedford, Massachusetts}

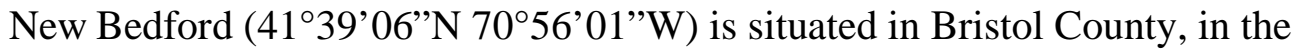
southeastern section of the state of Massachusetts. The city is bordered by Dartmouth on the west, Freetown on the north, Fairhaven and Acushnet on the east, and Buzzards Bay on the south. New Bedford Harbor is situated at the mouth of the Acushnet River, which flows south into Buzzards Bay and the Atlantic Ocean (figure 2). The harbor has a hurricane barrier, built in the 1960s by the Army Corps of Engineers, with gates 150 feet tall to protect the fishing fleet, docks, and town from storm surge. 


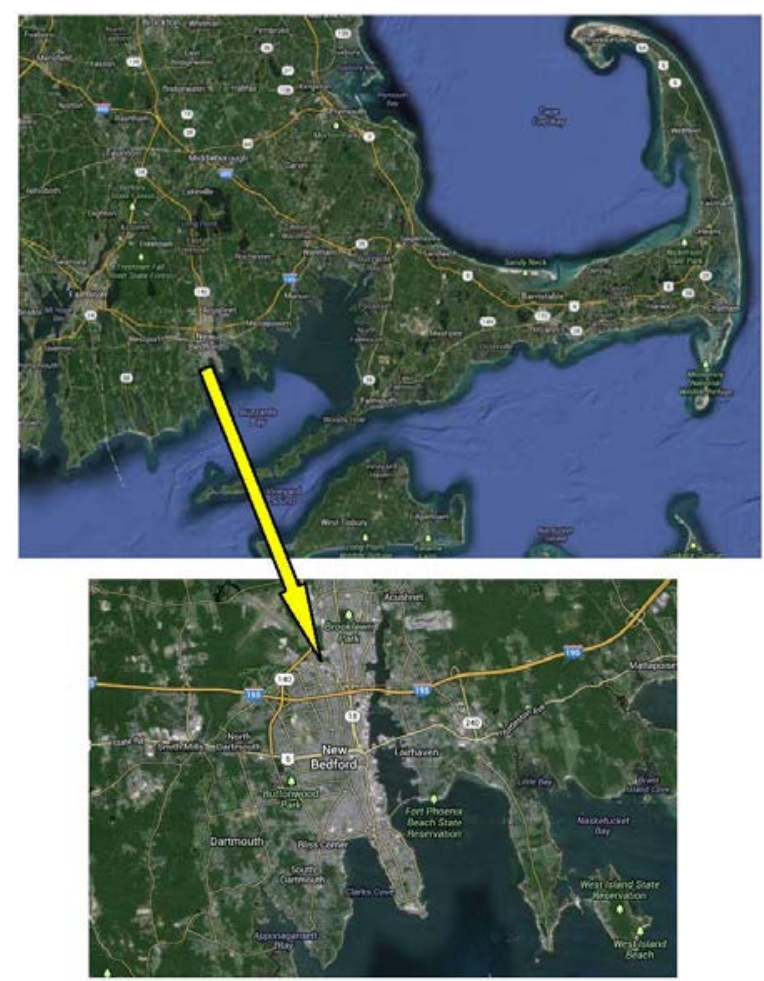

Figure 2. Map showing the location of New Bedford (adapted from maps.google.com)

From the beginning, the economy of the Pilgrim settlement in the area where the city of New Bedford is nowadays located was based on small farming and fishing villages. Soon into its development, the New Bedford Village became a major whaling and foreign trade port and, by the $18^{\text {th }}$ century, the city had become one of the world's leading whaling ports, mainly by virtue of investment by Nantucket entrepreneurs. Over one half of the U.S. whaling fleet, which totaled more than 300 vessels, was registered in New Bedford by the mid 1800s making it one of the richest (per capita) cities in the world at the time (New Bedford Whaling Museum 2013). During the $19^{\text {th }}$ century, the whaling industry attracted many immigrants to New Bedford, especially from Portugal. Mainly Azoreans, the Portuguese established a cohesive colony with considerable cultural importance for the city until the present time.

Despite the significance it had to the city of New Bedford, the whaling industry began to decline in 1859, when the discovery of petroleum greatly reduced the demand 
for sperm oil, bringing economic devastation to New Bedford and all other whaling ports in New England. In addition to the discovery of petroleum, the Whaling Disaster of 1871, during which 22 whalers were lost at sea, also contributed to the end of the whaling days. The last whale ship to leave the port of New Bedford sailed in 1925 (New Bedford Whaling Museum 2013).

After the end of the whaling era the city of New Bedford invested in textile manufacturing, which remained its major economic activity and attracted thousands of people to the city until the end of the textile period in the 1940s. After the decline of the textile industry, New Bedford faced a period of severe unemployment but has greatly diversified its economy since then. One way New Bedford responded to this period of crisis was through reinforcing its connection to the sea. Despite the fact that a commercial fishing fleet had been operating in New Bedford since the mid 1800s, it was in the early $20^{\text {th }}$ century that motors, trucks, and modern refrigeration transformed the industry, and New Bedford soon became a major fresh fish processing center and scallop port on the Northeast Atlantic (Moss and Terkla 1985).

These changes transformed the fishing industry in New Bedford, and fishing vessels no longer had to sail to New York to sell their catch. This allowed for a local competitive market, and the implementation of the fish auction in 1941, which regularized the selling of fish using set rules and time limits. However, as a result of a disagreement between fishermen and boat owners, the auction closed in 1985. Private sales took over until 1994, when the Whaling City Seafood Display Auction was established (Orleans et al. 2010). A display auction allows the buyers to see the catch that is off-loaded into large coolers. Since 1997 the auctions have been performed 
completely electronically (Whaling City Seafood Display Auction nd).

Once New Bedford was well established as a fishing port, many vessel owners and captains began to buy property in the neighboring town of Fairhaven. Today, while most of the fishing activity is located in New Bedford, Fairhaven has a substantial number of marine service establishments. In fact, the ports of New Bedford and Fairhaven are considered to function as a unit (Portman et al. 2011).

Although the range of species landed in New Bedford is very diverse, the primary target species are generally groundfish and scallops. The groundfish fishery experienced enormous growth in the beginning of the $20^{\text {th }}$ century with the advance of technology and thriving markets (NEFSC 2012), but by the 1930s the fish stocks off the coast of New England began showing the first signs of depletion. It was around the same time that the market for scallops in New Bedford began, and by the 1950s the port accounted for 70 percent of all the scallop landings in the U.S. (Hall-Arber et al. 2001). Despite a decline in landings in the 1960s, which caused many vessels to switch their target back to groundfish, New Bedford has consistently been one of the major scallop ports in the country. Since 2000, New Bedford has maintained its position as number one port in terms of value landed due primarily to its scallop fleet. In 2012, landed value for New Bedford represented a total of 411.1 million dollars for 143 million pounds of catch (NOAA 2013a). Table 2 shows volume in pounds and value for significant species landed in New Bedford in 2012. As of May 2013, NMFS databases show a total of 232 vessels homeported in New Bedford. 
Table 2. Volume (lb) and value for significant species landed in New Bedford in 2012 (Data extracted from NMFS databases)

\begin{tabular}{lrr}
\hline Species landed & Volume (lb) & Value (\$) \\
\hline Herring & $34,335,365$ & $2,639,637$ \\
Scallops & $33,461,608$ & $331,937,084^{*}$ \\
Surf clam/ocean quahog & $27,003,499$ & $20,063,482$ \\
Large mesh groundfish ${ }^{\dagger \dagger}$ & $16,240,688$ & $26,590,036$ \\
Small mesh groundfish ${ }^{* *}$ & $6,081,824$ & $3,673,993$ \\
Butterfish/mackerel/squid & $3,460,644$ & $1,506,719$ \\
Skates & $3,192,720$ & $1,691,647$ \\
Red crab & $2,570,412$ & $2,570,412$ \\
Other ${ }^{\dagger}$ & $2,522,961$ & $2,804,294$ \\
Monkfish & $2,185,537$ & $5,856,340$ \\
Summer flounder/scup/black sea bass & $1,732,963$ & $1,970,965$ \\
Lobster & $1,518,344$ & $6,621,099$ \\
Dogfish & 940,233 & 245,841 \\
Bluefish & 34,916 & 29,561 \\
Tilefish & 1,138 & 2,200 \\
Salmon & 0 & \\
\hline Total & & \\
${ }^{*}$ Values in red represent the five most important species in terms of value landed & \\
${ }^{*+*}$ Silver hake (whiting), red hake, and offshore hake & $\mathbf{1 3 5 , 2 8 2 , 8 5 2}$ & $\mathbf{4 0 8 , 2 0 3 , 3 1 0}$ \\
\hline
\end{tabular}

\subsubsection{Cape Cod, Massachusetts}

Cape Cod, located in the far east of the state of Massachusetts is a cape protruding out into the Atlantic Ocean. There are several different fishing ports located in distinct municipalities along Cape Cod. For the purposes of this study four ports will be considered in the characterization of the region's fishing activity: Hyannis (Barnstable), Chatham, Harwich Port, and Provincetown (figure 3). 


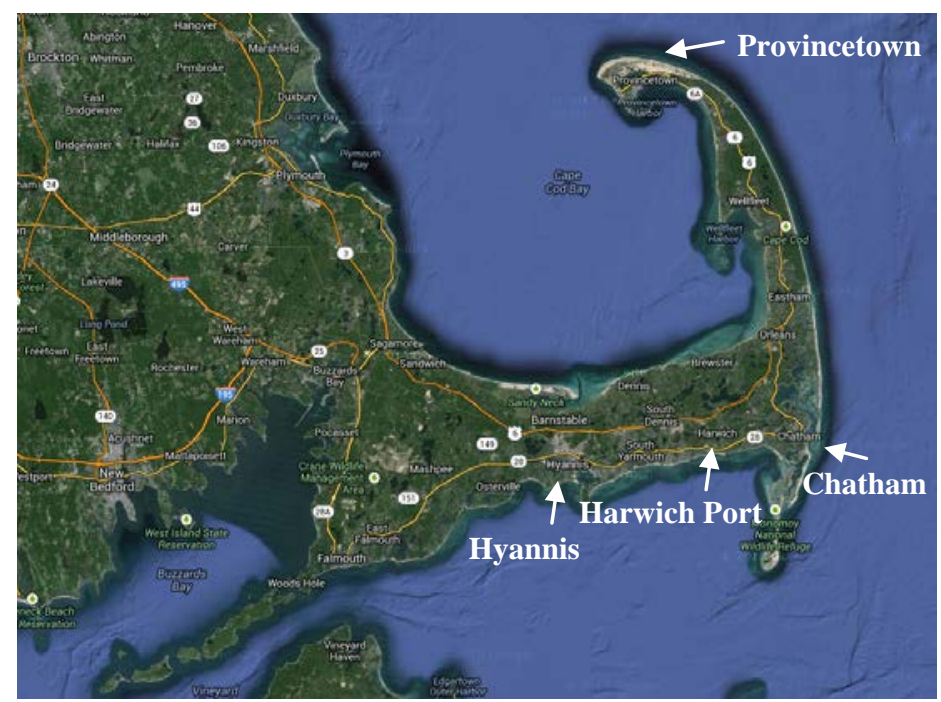

Figure 3. Map showing the location of Cape Cod and the four ports that are the focus of the present study: Hyannis, Harwich Port, Chatham, and Provincetown (adapted from maps.google.com)

The history of Cape Cod is intimately related to the sea and specifically to fishing. The name of the cape was a response to the great amount of cod found in 1602 by the crew of European explorer Bartholomew Gosnold off the coast of what is now Provincetown. During the $19^{\text {th }}$ century, fishing and whaling constituted the main economic activities in most parts of the region. Ports such as Provincetown and Harwich Port experienced great transformations with the expansion of their whaling fleet and consequent economic boost. With the decline of the whaling industry, Cape Cod ports focused on commercial fishing activities especially cod and herring. By the mid 1800s, Provincetown’s economy depended entirely on salt production, fishing, and fish drying (NOAA 2006b).

According to historian Matthew McKenzie as quoted by Weiss (2011) “fish were a critical part of the web of life on the Cape before 1830, providing not only food but also fertilizer for farming.” Herring fishing was of particular importance to Cape Cod fishermen and the decline of this resource had considerable impact on local communities in the late $19^{\text {th }}$ century (Weiss 2011). 
By the late 1800s and throughout the $20^{\text {th }}$ century, Cape Cod grew as an important tourism destination for the entire New England region. Towns and villages such as Hyannis, Chatham, and Provincetown became hubs for summer resorts and tourist attractions creating considerable gentrification pressure on the established fishing ports. Nonetheless, fishing is still an important part of the region's economy and culture and has managed to co-exist with the presence of its summer population and consequent impacts.

The Cape Cod Commercial Fishermen's Alliance, located in the town of Chatham, was founded in 1991 by local fishermen to enhance participation of the region in management decisions and to oversee the interests of local fishermen. Among other projects, the organization was responsible for creating the Cape Cod Fisheries Trust with the objective of keeping fishing permits among local people and providing affordable quota leasing to local fishermen. One of the stated priorities of the Trust is to maintain "diversification of species targeted throughout the season," which is deemed as an important aspect of maintaining a healthy industry (Cape Cod Commercial Fishermen's Alliance 2013). Also located in Chatham is the Cape Cod Commercial Hook Fishermen’s Association, which was implemented in 1993 to oversee the interests of local hook fishermen. The presence of these organizations is an indication that Cape Cod fisheries still have considerable impact on the local economy and culture.

Although cod is still an important resource, the fishing activity in the Cape Cod region is characterized by a diverse fleet targeting a variety of different species of fish and shellfish using many different gear types and methods of fishing. Table 3 
shows volume in pounds and value for significant species landed in 2012 at the ports of Hyannis (Barnstable), Chatham, Harwich Port, and Provincetown combined. As of May 2013, NMFS databases show a total of 22 vessels homeported in Hyannis

(Barnstable), 83 in Chatham, 12 in Harwich Port, and 22 in Provincetown.

Table 3. Volume (lb) and value for significant species landed in the Cape Cod region (Hyannis (Barnstable), Chatham, Harwich Port, and Provincetown in 2012). (Data extracted from NMFS databases)

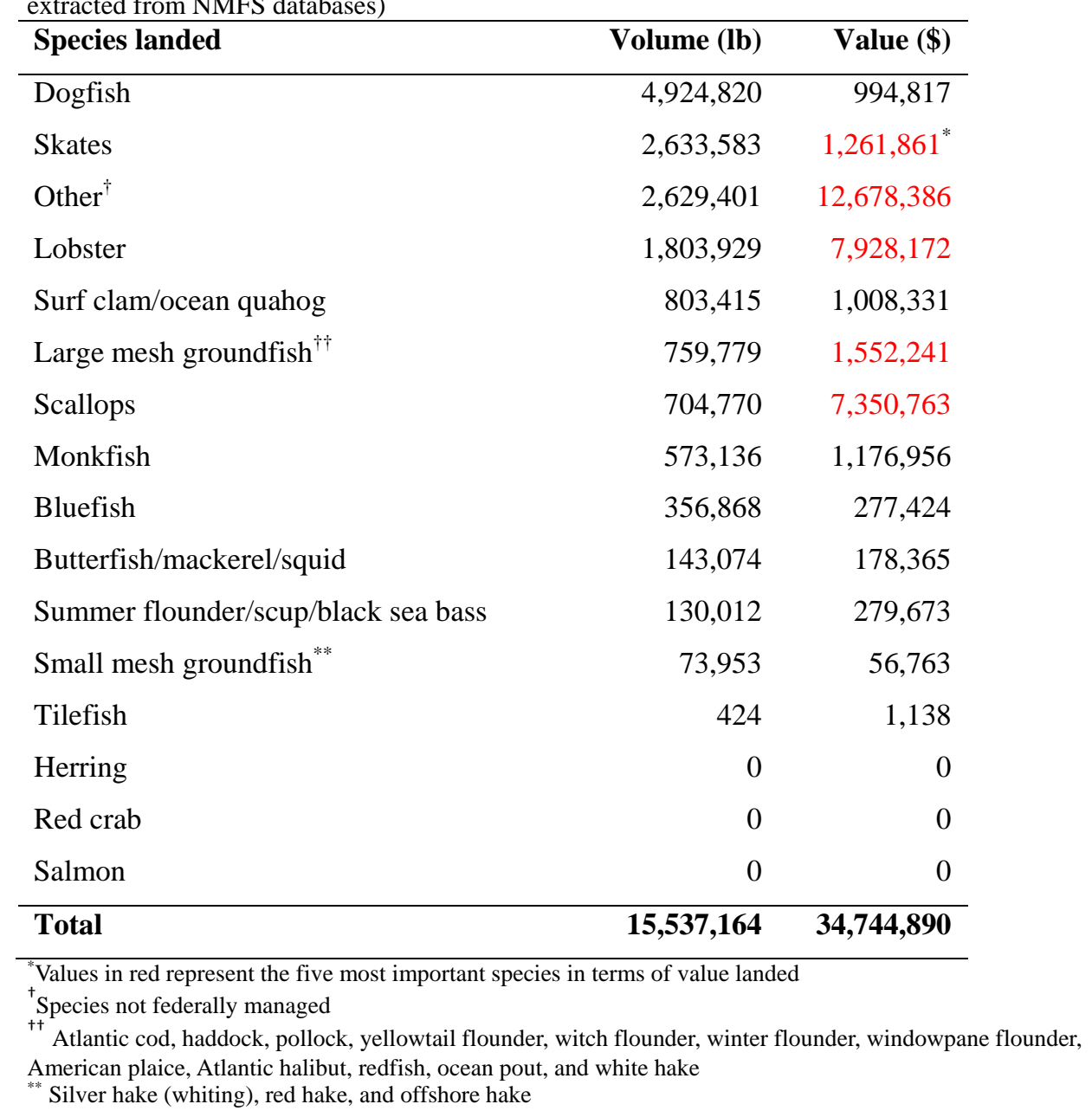

\subsection{Significance of the study}

The present research examines the relationship between fisheries diversity, management, and resilience of fishing communities in the Northeast Region of the United States. One way fishermen are able to adapt to environmental and socio- 
economic changes is through diversification of the catch. A diverse catch composition is also believed to be related to better conservation practices in the fishery. The current study argues that certain management plans, especially those focused on limited entry strategies, have been reducing fishermen’s adaptive flexibility, therefore reducing fishermen's resilience and that of their communities. It is also argued that, a less diversified fishery can have a negative impact on both the ecological resilience of the fish populations and their habitat. Investigating interactions between these phenomena has the potential to make important contributions to a better understanding of relationships between fishermen, their resilience, and the health of the ecosystems they depend upon.

Through an examination of the relationships between changes in catch composition, resilience, and fishery management, this study will contribute to the understanding of adaptability of U.S. fishermen to a changing social and ecological environment. The New England region has been the focus of frequent changes in fishery regulations in response to fluctuations in fish stocks, which strengthens the significance of this research in the studied area. This study will also make a contribution to the pool of knowledge of social resilience in general because it is an attempt to operationalize this variable and show the interactions between resilience, adaptive flexibility, and management - subjects currently of importance to the fisheries scientific community.

Moreover, results from this study have the potential to contribute to the enhancement of knowledge about aspects of adaptability in fishing communities specifically with regard to their impact on future policy strategies. Understanding the 
links between fisheries diversity, resilience, and management has the potential to contribute to the development of regulations that maximize sustainability and resilience in coastal communities through a focus on adaptive flexibility. The theoretical focus of the present study is believed crucial to the incorporation of the findings of this research into future policy plans. 


\section{CHAPTER II}

\section{LITERATURE REVIEW}

Chapter II provides a literature review on the main elements and frameworks related to the present study. The first sections of this chapter cover an overview of resilience theory and its application from ecological sciences onto social sciences and, more specifically, onto studies of fishing communities. The following sections cover the literature on adaptive flexibility and diversification in the context of fisheries. This chapter also provides a historical overview of fisheries management strategies implemented in the New England region for two of the main fishery stocks (groundfish and scallops) that are of particular interest to the ports studied in the present research. This section has the objective of providing examples of the potential complexity and intricacy that fishery management processes involve as well as background information that will help to understand the questions being investigated in this study.

Chapter II has the overall objective of providing the theoretical background that led to the hypotheses presented in Chapter I as well as defining the conceptual framework used as the basis for the present study.

\subsection{Resilience theory ${ }^{1}$}

The past decade was marked by increasing awareness of the importance of management strategies that consider and maximize resilience in coastal communities

\footnotetext{
${ }^{1}$ This section of the chapter benefited from a review of the literature on social resilience and vulnerability developed under the supervision of Dr Lisa Colburn as part of an effort by NOAA/NMFS Social Sciences Branch to develop indices of resilience/vulnerability in fishing communities.
} 
(Adger 2000, Carpenter et al. 2001, Marshall and Marshall 2007, Cinner et al. 2012). The resilience perspective emerged from the ecological sciences and marked a switch from traditional stability theories to the idea of ecosystems as having multiple-stable states, or in other words, presenting multiple possible states of equilibrium (Lewontin 1969, Holling 1973). The first ecological studies on resilience focused mainly on interactions between predators and prey and their responses to habitat stability (Holling 1961, Morris 1963, Rosenzweig 1971, May 1972).

Ecologists adopted the term resilience from mathematical sciences, where it was originally used to describe the behavior of systems with a single domain of attraction, which can be described as the mode a system tends to be in the absence of disturbance. The level of resilience of linear systems is defined by resistance and speed of return to the domain of attraction of a given system after external disturbances. If the system breaks the resilience threshold, the likelihood that it will return to that previous state is decreased (O'Neill et al. 1986, Pimm 1984). This definition of resilience is often called 'engineering resilience' and it is similar to what ecologists call ‘stability’ but differs conceptually from the definition of 'ecological resilience’' (Holling 1996).

In one of the most renowned publications on ecological resilience, Holling (1973) defines the concept as the persistence of ecosystems and their ability to absorb change and disturbance and still persist or maintain the same relationships between populations and state variables. This view of resilience, based on the idea of ecosystems as having multiple domains of attraction, emerged as a consequence of a concern for a more realistic understanding of natural systems highly governed by 
uncertainty, as opposed to artificial and deterministic views and models. According to Holling (1973) the important focus when studying complex systems is not how stable they are but how likely it is for the system to move from one domain to another and still persist. A system can have multiple desirable states, and shifts between such states may be indispensable for the existence of the system as a whole. In this sense, systems can be highly unstable and present enormous resilience (Holling 1973). Under the multi-stable state perspective, adaptation is key to maintaining existence (Folke 2006).

Since first proposed in the 1960s, the idea of alternative stable states and the concept of resilience have deeply influenced studies of population ecology and community response to disturbances. Ecologists have been working on data to increase empirical support for the idea that a community can be found in multiple stable states and that disturbances in state variables and/or parameters (depending on the intellectual context) can force communities to shift from one state to another and still maintain their functional characteristics (Holling 1973, Sutherland 1974, May 1977, Dublin et al. 1990, Laycock 1991, Knowlton 1992, Peterson et al. 1998).

The argument for the existence of alternative stable states and its intrinsic characteristics, such as resilience, has expanded under the ecosystem perspective to incorporate anthropogenic activities (Nystrom et al. 2000, Beisner et al. 2003). In social sciences, the resilience perspective has made important contributions. One of the first and most cited uses of the concept of resilience in the realm of social science is attributed to the work of Vayda and McCay (1975), a methodological piece discussing new directions in ecological anthropology. One of the points made by the authors concerns criticisms of ecological anthropology and its preoccupation with 
static equilibria. Vayda and McCay (1975) focus their argument on human population dynamics and the introduction of the idea of multi-stable systems to understand population fluctuation.

The article by Vayda and McCay (1975) represented an important step for the studies of human populations and the introduction of the idea of multi-stable communities and resilience into human societies (Folke 2006). Since the mid 1970s, trends in social sciences have been shaped primarily by the new ideas introduced by the resilience concept as opposed to an equilibrium-centered view (Klein et al. 2003, Abel et al. 2006, Davidson 2010). The application of resilience theory into social sciences is particularly relevant when addressing societies that are directly dependent on natural resources such as fishing communities. In such societies, social resilience is heavily interconnected with the resilience of the natural system itself, mainly through resource dependency and management actions (Adger 2000). More recently, under a more holistic perspective, resilience has been conceptualized in terms of socialecological systems.

Social-ecological systems (SES) can be defined as complex and dynamic biogeographical units characterized by interactions between human and natural components regulating natural, socio-economic and cultural resources (Redman et al. 2004). The concept of SES is used to emphasize the idea that humans and nature are interrelated and that a separation between human social and non-human ecological units is artificial and arbitrary (Folke 2006). The emergence of the SES perspective was part of extensive paradigm shifts that took place over the past few decades in environmental studies and natural resource management, from the idea of simple and 
linear natural systems where humans are separate agents or 'stressors' to a view of nonlinear complex systems where humans are an integrative component (Kates et al. 2001, Berkes 2004). Over the past one and a half decades, the term SES gained considerable momentum in the literature and a great deal of researchers have focused their work on conceptualizing resilience of SESs (Berkes and Folke 1998, Carpenter et al. 2001, Walker et al. 2002, Adger et al. 2005, Berkes et al. 2006).

Complex SESs with multiple domains of attraction are characterized by unpredictable responses and shifts in the face of disturbances. Gunderson and Holling (2002), in adapting the resilience framework to understand such complex systems, developed a multiscalar system called panarchy that includes adaptive cycles. According to panarchy theory, complex systems feature multiple scales formed by interactions between variables performing at similar speeds. The different levels experience their own change cycles but lower, larger scales set the conditions for faster, smaller ones, while faster, smaller cycles produce variations that can, in turn, generate shifts at larger scales. This dynamic interaction among scales fuels adaptation and therefore evolution of complex systems (Davidson 2010).

The aforementioned multi-scale interactions are represented in figure 4 by the panarchy model. The model depicts two dynamic systems each presenting four different phases of the adaptive cycle: a phase of exponential change (r), that is characterized by growth and exploitation and is the preceding stage for a phase of conservation $(\mathrm{K})$, which is characterized by relative stability; a phase of release $(\Omega)$, characterized by collapse and severe modifications to the system, which is followed by a phase of renewal $(\alpha)$, which in turn precedes another phase of exponential change 
(r). The transition between conservation $(\mathrm{K})$ and release $(\Omega)$ characterizes regime collapse and can happen rapidly at the peak of system intricacy and productivity.

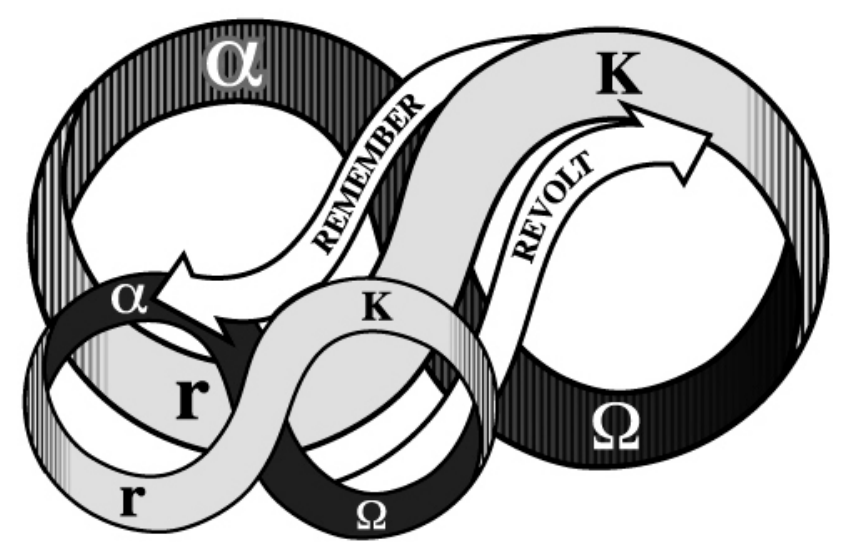

Figure 4. Panarchy model proposed by Gunderson and Holling (2002) (Adapted from www.peopleandplace.net)

The two systems illustrated in the panarchy model are linked by the elements revolt and remember. The element revolt characterizes disturbance $(\Omega)$ of a small and fast cycle on large and slow events, usually breaking a state of conservation (K). The element remember, on the other hand, is related to the learning processes that will help a system in the phase of conservation (K) to cope with the renewal phase $(\alpha)$ in a smaller and faster cycle.

The outcomes of the interaction between different systems will depend on intrinsic characteristics and the size and nature of the perturbations affecting them (Gunderson and Holling 2002). Three possible general outcomes exist: the system can reorganize and maintain the same structural regime without changes to structure or function (persistence); the system can shift to a different state, with different feedback processes but within the same regime (adaptation); or it can switch to a new regime with different processes and functions (transformation). Holling et al. (2002) identified three qualities a system must present to avoid transformation: 1) accumulate rather than deplete resources, 2) contain destabilizing forces to maintain diversity and 
opportunity and stabilizing forces to maintain productivity, and 3) ensure evolutionary processes that generate novelty. In sum, the panarchy theory implies that a complex system must find a balance between dynamism and persistence, diversity and conservation in order to adapt and thrive in the face of disturbances (Davidson 2010).

The adaptive cycle and the panarchy model proposed by Gunderson and Holling (2002) are, by definition, heuristic representations, for the interactions displayed in them are not based on data assessment but on theoretical constructs. The importance of such a representation lies on it being a means of illustrating dynamic systems in which change is an integrative component. In an earlier publication, Holling (1973) emphasizes the intellectual significance of a perspective that steers away from equilibrium centered views and embraces the idea of change: "flowing from [the resilience theory] would not be the presumption of sufficient knowledge, but the recognition of our ignorance; not the assumption that future events are expected but that they will be unexpected” (1973:21).

The application of the resilience concept into SES research has contributed to the expansion of the theory into different disciplines and the incorporation of a vast number of other concepts into the resilience rationale (e.g. social capital, leadership, role of institutions, governance, and climate change). All these contributions to resilience theory have undoubtedly enriched this concept and its potential applications but have also added a great deal of complexity to its conceptualization, often compromising consensus regarding definition and application of the theory (Gallopín 2006). Furthermore, a great deal of debate concerns the relationships between the ideas of resilience and vulnerability. Depending on the conceptual definitions used, 
disciplinary framework, and personal preference, resilience and vulnerability are used interchangeably, as opposite ends of a continuum, or as concepts complexly interrelated (Cutter et al. 2008, Miller et al. 2010, Turner 2010). According to Jacob et al. (2013), although theoretically the concepts of resilience and vulnerability should be considered different concepts, pragmatically they are regarded on a continuum. A wider debate on what constitutes resilience of SESs also contributed to the development of the ideas of specific versus general resilience or, in other words, resilience of 'what to what' versus the resilience of the system as a whole, including unknown disturbances (Carpenter et al. 2001, Resilience Alliance 2009).

It is not among the objectives of the present study to discuss the ramifications of the conceptual framework for resilience theory, but rather to attempt to apply the concept in a practical perspective in the context of U.S. fishing communities. The literature presents a number of different conceptual definitions for resilience (see Walker et al. 2004, Carpenter et al. 2001, Folke 2006, Pollnac et al. 2008, Gibbs 2009, Cutter et al. 2009). The definition adopted in the present study is: the ability of a system to cope with change in the face of specific disturbances that can be of social, political, natural or economical nature. Under the idea of 'coping with change,' a resilient SES undergoing pressure may not necessarily go back to a previous state of equilibrium, but may change to a different desirable state. Based on this idea, managing human-natural systems for resilience involves putting in place mechanisms to maintain diversity and homeostatic functions while steering them away from thresholds of concern and increasing their ability to cope with change (Allen et al. 2011). 


\subsection{Resilience of fishing communities}

Negative changes in fisheries are a global concern (Jackson et al. 2001, Worm et al. 2009). Demands for natural resources and the pressures of a growing population have impacted fish stocks while also causing regulations on the exploitation of natural resources to increase and become stricter (Ostrom et al. 1999). In the face of changing environments, declining fish stocks, and increasing regulations, there has been growing concern for the adaptation and resilience of fishing communities (Allison et al. 2007, Marshall and Marshall 2007, Coulthard 2012, Robards and Greenberg 2007, Healey 2009). Resilience is the ability of a system to cope and adapt to change. Therefore, resilient systems are adaptable, flexible and prepared for change and uncertainty. In fishing communities, resilience outcomes refer generally to long-term sustainability of jobs, identity and culture, together with healthy fish stocks and resilient ecosystems (Marshall et al. 2007, Coulthard 2012).

The resilience concept is often linked to the idea of sustainability (Folke et al. 2004, Maler 2008). The overall idea is that resilient SESs are more capable of achieving sustainable development (Lebel et al. 2006, Perrings 2006). Although the direct relationship between resilience and sustainability in SESs has been contested (see Derissen et al. 2011), in general terms, it can be argued that examining attributes of a system that are more or less resilient to certain disturbances has the potential to favor the adoption of practices of sustainable development that are a better fit for such system as opposed to practices that do not take resilience into account (Turner 2010). This is especially relevant in fishing communities in the current context of fish stock decline and frequent policy changes. 
Increased efforts have been made in the area of coastal hazards to operationalize resilience as well as vulnerability at the community level (Sempier et al. 2010, Cutter et al. 2008), but very little has been done with regard to fishing communities. One of the few efforts made specifically in fishing communities is a study by Jacob et al. (2013), who developed indices of resilience and vulnerability ${ }^{2}$ for fishing communities in the Gulf of Mexico. The indicators used by Jacob et al. (2013) were developed with a secondary data baseline and measure resilience and vulnerability at the community level. The authors explain that developing indicators of resilience and vulnerability in fishing communities can be "very useful in a social impact assessment framework for local governments, regional agencies, and national planning” (Jacob et al. 2013). Ongoing efforts by the National Atmospheric and Oceanic Administration (NOAA) are being made to expand the use of these indicators into other regions of the U.S. (Lisa Colburn, personal communication, 2013).

Marshall and Marshall (2007) provide another example of an effort to measure resilience in fishing communities. Different from the study by Jacob et al. (2013), the authors used survey questions to assess individual subjective resilience among commercial fishermen in northern Australia. Marshall and Marshall (2007) focused specifically on responses of fishermen to changes in fisheries policy. The authors criticize the implementation of management strategies that fail to consider social impacts on fishing communities and argue that this lack of consideration for social aspects such as resilience, i.e. the ability that fishermen have to cope with policy changes, leads to poor compliance with the rules and regulations (Marshall and

\footnotetext{
${ }^{2}$ According to Jacob et al. (2013: 86), even though, theoretically, resilience and vulnerability should be considered different concepts, pragmatically they are measured on a continuum with the assumption that vulnerable communities will be less resilient to impacts.
} 
Marshall 2007). The measures of subjective resilience developed by Marshall and Marshall (2007) are used in the present study and will be examined in Chapter III. The literature describes resilient system responses in terms of absorption of change, reorganization, self-learning, and innovation (Armitage and Plummer 2010, Folke 2006). Coulthard (2012) describes three possible ways that fishermen could cope and reorganize in the face of changes in the fishing industry: exit strategy, livelihood diversification, and remain fishing. The first two possibilities - leave the fisheries and seek alternative occupation - are confronted by aspects of well-being that are very important among fishermen, especially aspects of job satisfaction. According to Pollnac and Poggie (2008) fishermen frequently describe fishing as more than just an occupation, and numerous examples in the literature show that fishermen would resist leaving the occupation of fishing even when income is low (Crawford 2002, Binkley 1995, Pollnac et al. 2001).

Job satisfaction is an important component related to workers' well-being in any occupation, but it is especially significant in fishing jobs. Among fishermen, the structure of job satisfaction includes attributes of 'adventure,' 'challenge' and 'being outdoors’ infrequently found in other occupations (Binkley 1995, Pollnac et al. 2008, Apostle et al. 1985, Pollnac and Poggie 1988). Research in industrialized countries demonstrates that job satisfaction affects individuals’ health and productivity and it is related to mental health, longevity and social illnesses such as family violence and substance abuse (Pollnac et al. 2008).

Levels of job satisfaction have also been associated with personality traits (Bruk-Lee et al. 2009). Pollnac and Poggie (2006, 2008) argue that individuals with a 
personality type characterized as active, adventurous, aggressive, and courageous are attracted by and attached to activities and professions, such as fishing, that enable fulfillment of these needs. Also, for many fishermen, occupation attachment is developed and reinforced by familial traditions and interactions with other fishermen during and outside of working hours (Marshall et al. 2007).

The more attached people are to their occupation, the more difficult it is to either leave it or deal with significant changes to it. According to Marshall et al. (2007):

When people with a strong occupational attachment suddenly face the prospect that they are no longer able to continue in their current occupation, they not only lose a means of earning an income, they lose an important part of their self-identity. (2007: 364)

While examining resilience of fishing communities it is important to consider aspects of cultural resilience, or the capacity to maintain livelihoods that suit both material and moral needs in the face of change and social dynamism to avoid negative cultural transformations (Crane 2010). According to Poggie et al. (1995), “commercial fishing is an occupation that has all the prerequisites for being considered an occupational subculture” (1995: 411). Among the reasons for that, is the fact that fishermen present distinct ideas and behaviors and are subject to factors and pressures that are unique to their life-style (Poggie et al. 1995). The cultural component of the occupation of fishing reinforces the idea that changes to the occupation of fishing have the potential to impact more than just fishermen's source of income.

Considering the attachment that fishermen manifest towards their occupation, it is more likely that they will remain in the fisheries, even after impacts imposed by declining stocks and strict regulations. It has been shown in different parts of the 
world that programs to reduce fishing pressure based on alternative occupations as well as boat buyback programs fail to achieve foreseen goals because many fishermen will not adhere or they will use the money earned to improve their fishing practices (Pollnac et al. 2001, Crawford 2002, Sievanen et al. 2005). For that reason, strategies that aim at maintaining resilience of systems highly dependent on fishing must consider issues of job satisfaction, identity and occupational culture in order to preserve both community and ecosystem resilience.

\subsection{Diversity and 'adaptive flexibility' of fishing communities}

Diversity is associated with flexibility, variability, redundancy, and adaptability: all attributes believed to characterize a resilient system (Ebbin 2009). At the ecosystem level, resilience can be defined in terms of diversity of habitat, species, and trophic levels (Holling 1995). Deriving from the ecological perspective, diversity has also been associated with governance and institutional resilience (Jones et al. 2013, Adger et al. 2005, Ebbin 2009). In social systems, occupational and income diversity have been regarded as key components to adaptability (McCay 2002, Allison and Ellis 2001, Adger 2000, Carpenter et al. 2001, Cinner et al. 2010, Abesamis et al. 2006). Specifically in rural and fishing communities the importance of diversity has been widely discussed in the literature often under the umbrella of the 'livelihood approach’ (Hanazaki et al. 2013, Ha and van Dijk 2013, Marschke and Berkes 2006).

The concept of 'livelihood' encompasses assets and activities (mediated by institutions and social relations) through which people can generate a satisfactory standard of living (Krantz 2001). Assets can be natural, physical, human, financial or 
social capital (Ellis 2000). In the context of fisheries, these assets could be specified respectively as fish stocks and fishing grounds, boats and gear, labor and personal experience, savings and credit, and kinship and social networks (Ha and van Dijk 2013). According to Allison and Ellis (2001), the most favorable livelihood displays “high resilience and low sensitivity” (2001:378). Sensitivity in this context can be described as the degree to which a given system is modified or affected by internal or external disturbances (Gallopín 2006). In the context of fishing communities, the concept of favorable livelihood is closely related to the health and sustainability of the fishing resources. According to Chambers and Conway (1992) a 'sustainable livelihood' can cope and recover from stresses, "maintain or enhance its capabilities, assets and entitlements, while not undermining the resource base” (1992: 6).

Cinner et al. (2010) discuss the importance of diversification to livelihoods in African rural, fishing communities through the principle of 'portfolio' or the spreading of risk. According to the authors "the adoption of a diverse portfolio [is] expected to contribute to the sustainability of rural livelihood because they improve resilience in the face of seasonality, adverse trends, and sudden shocks” (2010: 23). Portfolio theory focuses on the diversification of assets as a means to ensure the most favorable expected outcome (e.g. catch or income), an idea rooted on patterns of statistical averaging and correlations among assets or portfolio options (Sethi 2010). Statistical averaging theory is based on the idea that the sum of given variables (diversification) has lower variance than the individual variables alone (specialization), resulting in greater stability (Doak et al. 1998). Diversification of assets also takes advantage of correlation divergences among variables (Elton and Gruber 1977). In that sense, the 
opportunity for exploiting resources with very different characteristics increases the chance of a favorable outcome in the face of adversities.

The logic behind the idea of diversification of assets is expressed in the concept of 'polymorphic adaptation,' widely employed in biological sciences to describe the process of organisms' adaptation through diversity of forms, physiology, and genetics (Johnson et al. 1996, Majerus 1998). In anthropology, Parkin and Ulijaszek (2007) relate polymorphic adaptation to "the processes that allow human populations to change in response to changing or changed environments” (2007: 24). Following this logic, diversity and flexibility in individual occupations and income sources constitute a mechanism of defense or preparedness in the face of a changing environment - for human societies changes or shocks can be associated with the natural environment (e.g. floods, droughts, and fish stock fluctuations), or be driven by political, economical, social, technical, or other cultural factors. Diversity and flexibility are also associated with increased opportunities for learning and consequently for knowledge-led responses, as well as with facilitated interaction between people (social capital), factors that have been positively associated with human adaptation to changes (Murray et al. 2010).

The idea of livelihood diversification is characterized by an evolutionary approach. A great deal of literature defends the viewpoint that the theory of evolution can be generalized to socioeconomic phenomena (see Dennett 1995, Rammel and van der Bergh 2010). Under this context, alternative occupations, technologies, and sources of income provide the evolutionary potential to adapt to changes, a phenomenon that can be defined as 'adaptive flexibility.' In biology, adaptive or 
behavioral flexibility is seen as an important adaptation to changing environments, which, at the individual level, may arise through innovation or social learning (Wright et al. 2010). Rammel and van der Bergh (2010) argue that the evolutionary thinking behind the idea of adaptive flexibility in human societies is a "fruitful approach to study policies for sustainable development” (2010: 122).

According to Adger (2000) "the promotion of specialization in economic activities has negative consequences in terms of risk for individuals within communities and for communities themselves” (2000: 352). Expressed in this statement is the idea that individual adaptive flexibility not only affects individual resilience, but can also have important impacts on community resilience. Marschke and Berkes (2006) indicate three clusters of strategies for increasing resilience and adaptation in the household and community levels: learning to live with change and uncertainty, nurturing learning and adapting, and creating opportunities for selforganization. Livelihood diversification falls under the first category of strategies that deal with learning to live with change and uncertainty (Marschke and Berkes 2006).

The literature supports the idea that risks associated with a loss of diversity in economic activities are more important in communities that are highly resource and ecosystem dependent (Adger 2000, Kasperski and Holland 2013). Such communities are more likely subject to fluctuations of these resources as well as potentially destructive natural hazards. Fishing, similar to other activities that involve extraction of natural resources, is characterized by the need for effective responsiveness to changes in the external environment (Pitcher 2001). These changes are not only related to the physical environment such as weather and oceanographic features but 
also to biological fluctuations in fish populations, management decisions influencing availability of different species, as well as market variations. Figure 5 illustrates the relationships between human and natural environments and highlights changes in the fisheries that affect fishing community resilience that are pertinent for the current study.

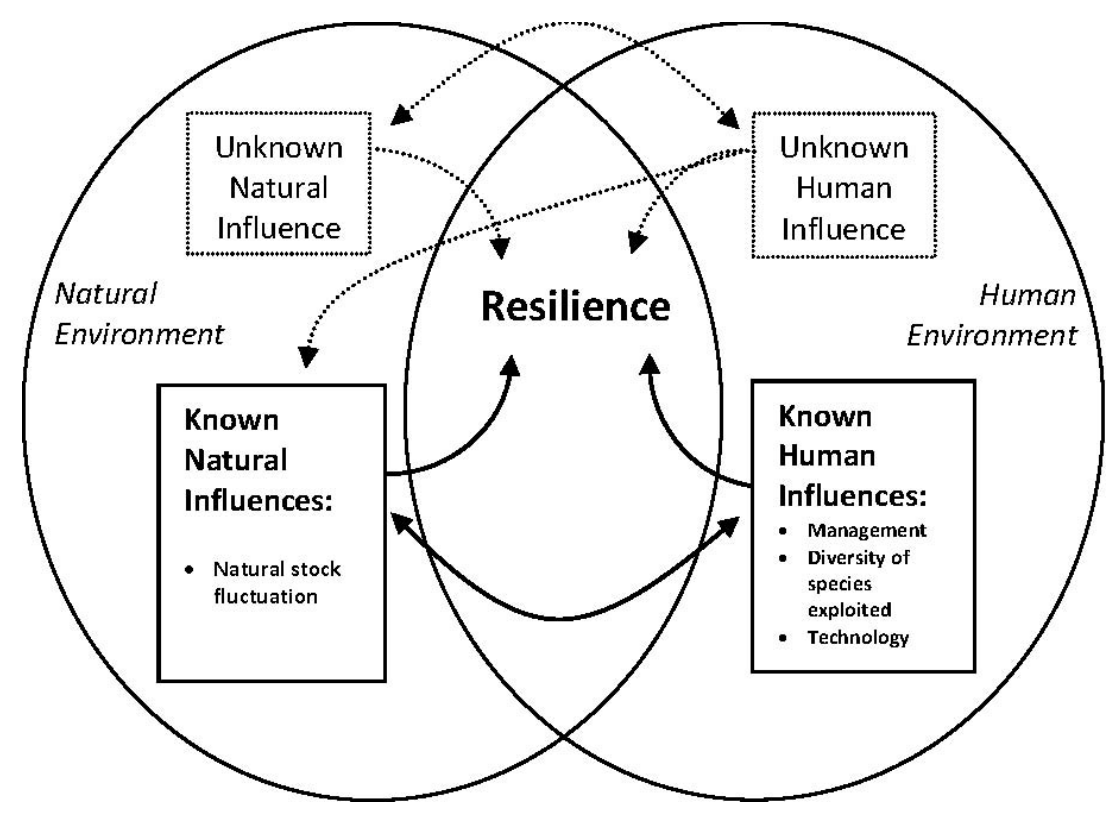

Figure 5. Relationships between the human and natural environments and the resilience of coastal communities for the purposes of this study the relationships between natural stock fluctuation, management, technology, and diversity of species exploited were stressed in the model

Flexibility and adaptability in decision making regarding when to fish and what to fish for are crucial in shaping effective and successful fishermen (Christensen and Raakjaer 2006). According to Ha and van Dijk (2013) diversification of activities and social support capacities is frequently central to achieving sustainability in fisheries. In fishing, diversification can be distinguished between 'outside-' and 'within-fishing,' the first defined by the diversification of employment and sources of income outside the fishing industry and the second by the diversification of characteristics of the fishing itself, such as gear type and target species (Ha and van 
Djik 2013).

As mentioned previously, fishermen are in general highly attached to their occupation, and there is significant evidence in the literature to believe that they are unlikely to search for alternative sources of income outside the fishing industry (Pollnac et al. 2001, 2008, Acheson 1981, 1988, Griffith and Pizzini 2002, Glazier 2007, Ginkel 2007, Smith and Clay 2010). American fishermen have other compelling reasons to persist in their occupation; in developed countries, fishermen are generally more invested in and attain larger incomes from fishing. These factors are likely to increase dependency on fishing (Allison and Ellis 2001), which strengthens the argument for 'within-fishing diversification' as opposed to alternative employment as a strategy to increase fishing community adaptability and ultimately resilience to changes in the fishery.

Different studies conducted in the past couple of decades have shown the importance of 'within-fishing diversification.' While studying small-scale fishermen adaptation to uncertainty, Allison and Ellis (2001) state that one of the strategies implemented by fishermen to deal with fishery resource fluctuations was targeting different species according to availability. Marschke and Berkes (2006) found that in rural Cambodia the ability of fishermen to access and use diverse types of fishing gear, therefore having flexibility to switch gear depending on season and resource abundance, was regarded as an important indicator of well-being among villagers. In a study comparing vulnerability of fishing and farming families in Congo, Bené (2009) found that fishermen who were specialized in one species were more vulnerable than those who targeted a variety of different species. 
Recently, growing efforts in the field of risk management have discussed the stabilizing effects of diversity, especially in the context of natural resources management (see Koellner and Schmitz 2006, Sethi 2010, Tilman et al. 2006). Studies on risk management in the U.S. and in other developed countries have stressed the importance of 'within-fisheries diversification' (portfolio theory) in reducing catch variance and providing a buffering mechanism in the face of change (Hilborn et al. 2003, Baelde 2001, Minnegal and Dwyer 2008, Schindler et al. 2010). Kasperski and Holland (2013) investigated income diversification and risk among U.S. West Coast and Alaska fishermen and concluded that vessels that are able to diversify across multiple resources can reduce income variation and the associated financial risk. According to Sethi (2010), the portfolio theory is applicable as a risk management strategy because it "not only increase[s] efficiency, but also reduce[s] the exposure to both biological and economic variability in fishery systems” (2010: 354).

Policy strategies conventionally used to manage the fisheries in the U.S., however, are generally not aimed at maintaining or inducing fisheries diversity (Whitmarsh 1998, Rammel and van der Bergh 2010, Sethi 2010). In fact, the majority of regulations being implemented to control fishing activities in the U.S. today tend to reduce fishermen’s flexibility to diversify.

Management can influence fishermen’s adaptive flexibility in a variety of different ways. Under rights based limited entry programs, such as catch shares and other quota limitation systems, fishermen harvest species they have quota to catch and avoid those for which they have no quota, thus constraining their options and consequently their adaptive flexibility. As species fluctuate in numbers, holding 
different licenses is one way to guarantee the fishermen flexibility to continue to fish and make a living (Apollonio and Dykstra 2008). Murray et al. (2010) while studying the effects of "enclosure" as a consequence of the implementation of limited entry programs in New Jersey fisheries concluded that this management system led to "loss of flexibility for fishers who depend on moving among fisheries” (2010: 3). The authors used oral histories to discuss the negative consequences of limited entry to adaptability at the individual and community level as well as the potential environmental impacts of specialization due to intensified pressure on fewer resources.

Limited entry programs can also affect fishermen's adaptive flexibility in different ways. The process most often used for determining qualification for limited access programs is "historical landings" for established qualifying years. This means that vessels that historically rotate between resources have a disadvantage when compared to vessels that fished heavily for fewer stocks. In fact, vessels that have diversified their fishing practices to alleviate pressure on certain resources (often in response to NMFS requests) have been denied licenses to stocks they were helping conserve because they did not qualify due to lack of historic landings (Crocker 2008). Consequently, the anticipation of being able to guarantee a license for a certain fishery leads fishermen to focus their effort on fewer resources, inhibiting their natural inclination to diversify and putting even more pressure on specific stocks.

The implementation of closed areas for the conservation of specific stocks can also promote specialization. Large closed areas affect access to all resources within a geographical scope and, according to Apollonio and Dykstra (2008):

[Reduce] the option that fishermen have for responding to natural variations in the numbers of various species [and] limits their ability to shift from one 
species to another, as they have traditionally done for generations, as species naturally fluctuate in numbers or distributions. (2008: 78)

While fishermen are forced out of different fisheries, the possibility of accessing other resources is decreasing. Under an economic focused regimen, prices of licenses and quotas have increased to the extent that they are unaffordable to many fishermen. Furthermore, fishermen who were able to secure multiple licenses are so constrained by bureaucratic processes that it can be virtually impossible to make an unanticipated shift in target species and/or fishing grounds.

All the above mentioned constraints imposed on the fishermen suggest that even though specialization in the fishery has known negative social, economic, and environmental consequences, management practices in the U.S. are in general not designed to promote diversity. Fishing is subject to continuous changes and impacts: variation in catch due to fish stock fluctuation and seasonality, weather, tides and currents, fishing ground attributes, market fluctuations, and management. The means and ability to exploit an array of different resources at different times of the year constitutes part of the adaptive tools fishermen have to overcome change and guarantee a stable flow of income. In other words, diversity of catch functions to maintain adaptive flexibility and to ensure long-term survival in the face of adversities, a concept that can help shape beneficial strategies to safeguard community and cultural resilience. 


\subsection{Fisheries management in New England - an overview of two important stocks}

\subsubsection{Groundfish fishery}

Prior to 1977, the marine fisheries off the coast of the U.S. were primarily overseen by the individual states along with the Interstate Fisheries Commissions ${ }^{3}$, and high seas and continental shelf fisheries were ruled by international treaties and negotiated multilateral agreements controlled by the Department of State with assistance from National Marine Fisheries Service (NMFS) (Hoss et al. 1999). Essentially, the fisheries were characterized by open access. Between 1964 and 1975 the estimated decline in landings in three main states in New England (Maine, Massachusetts, and Rhode Island) was 54\%, mostly due to the presence of foreign fishing vessels in U.S. waters (Jin et al. 2002). As a consequence of the acknowledgment of fish stock decline, the Fishery Conservation and Management Act (FCMA) was implemented in 1976 and marked the end of extensive foreign exploitation off the American coast and the beginning of what came to be a complex body of legislation governing the U.S. fishing resources. The FCMA of 1976 has been amended multiple times over the years and two sets of amendments are of particular significance: the Sustainable Fisheries Act of 1996 and the Magnuson-Stevens Fishery Conservation and Management Reauthorization Act of $2006^{4}$. The FCMA is commonly referred to as the Magnuson-Stevens Act (MSA).

The implementation of the MSA conferred on NMFS (part of the National

\footnotetext{
${ }^{3}$ There are three Interstate Fisheries Commissions in the U.S. responsible for the management and conservation of fishing stocks within the three mile zone: The Atlantic States Marine Fisheries Commission, formed by the 15 Atlantic states in 1942, The Pacific States Marine Fisheries Commission, created by the five Pacific states in 1947, and the Gulf States Marine Fisheries Commission, created by the five Gulf states in 1949 (NOAA Fisheries 2013a). ${ }^{4}$ A new reauthorization is expected in the near future since the legislation expired in September $30^{\text {th }}$ of 2013.
} 
Oceanic and Atmospheric Administration (NOAA), under the Department of Commerce) primary responsibility over the management of the fisheries in the Exclusive Economic Zone (EEZ) of the U.S., between three and 200 nautical miles (nm) offshore. Coastal and inshore waters are managed by the individual states generally out to three $\mathrm{nm}^{5}$. The MSA created eight Regional Fishery Management Councils (RFMCs) that were made responsible for managing waters inside their EEZ adjacent to the constituent states ${ }^{6}$. Each council is in charge of creating Fishery Management Plans (FMPs) and fisheries regulations for the fisheries within their jurisdiction (NOAA 2013b).

The New England Fishery Management Council (NEFMC), like other RFMCs, is comprised of the regional administrator of NMFS, the principal state officials with marine fishery responsibility for constituent states (Maine, Massachusetts, New Hampshire, Rhode Island, and Connecticut), twelve members nominated by the governors of the constituent states and appointed by the Secretary of Commerce for three-year terms, and additional four non-voting members representing the U.S. Coast Guard, U.S. Fish and Wildlife Service, U.S. Department of State, and Atlantic States Marine Fisheries Commission. The council also relies on: 1) Oversight Committees, that review and discuss the individual FMPs and develop measures to create or modify existing plans; 2) Advisory Panels, that are comprised of members of the fishing industry (commercial and recreational), scientists, environmental advocates, and others with fishery expertise, who provide input and assistance in the development of

\footnotetext{
${ }^{5}$ Texas, Puerto Rico, and Florida's Gulf coast have state jurisdiction extended to nine nautical miles (Submerged Lands Act 43 U.S.C. §§ 1301-1315 (2002)).

${ }^{6}$ The eight RFMCs and respective constituent states are: New England FMC (ME, MA, RI, NH, CT), Mid-Atlantic FMC (NY, NJ, DE, PA, MD, VA, NC), South Atlantic FMC (NC, SC, GA, FL), Gulf of Mexico FMC (TX, LA, MS, AL, FL), Caribbean FMC (VI, PR), Pacific FMC (CA, WA, OR, ID), North Pacific FMC (AK, WA, OR), and Western Pacific FMC (HI, AS, GU, MP) (NOAA 2013b).
} 
FMPs; and 3) Plan Development Teams (PDTs), comprised of scientists, managers and others with knowledge on the biology and/or management of particular species. All proposals, suggestions, or amendments to existing plans are presented to the full council for approval (NEFMC 2013a).

When first created, the NEFMC was assigned fisheries in the Gulf of Maine and Georges Bank that, like many other fisheries off the coast of North America, had been depleted under the International Convention for the Northwest Atlantic Fisheries (ICNAF) regulations ${ }^{7}$ (Anthony 1990). Early on in the new management regime, the body of law regulating the fisheries off the coast of New England experienced a considerable increase in complexity. Groundfish ${ }^{8}$ fisheries were initially managed under a quota system, which was the structure inherited from ICNAF. However, this management system motivated a "derby" fishery, i.e. a race for fish, and allocations set for the entire fishing year were taken within a few months (Crocker 2008). To address that problem, new quota allocations were implemented on a quarterly basis, and trip limits by species, weekly landing limits and quotas by vessel class were established (Apollonio and Dykstra 2008). Between 1977 and 1981, one hundred and twenty modifications were made to the fishing regulations (Hennessey and Healey 2000).

Increasing the complexity of rules did little to achieve the goals of the NEFMC of conserving fish stocks. Fishermen were "forced" to throw dead fish overboard to

\footnotetext{
${ }^{7}$ The ICNAF was established in January 1949 during a conference held in Washington DC involving ten other countries. The convention was a consequence of a concern over declining fish stocks throughout the Northwest Atlantic. The ICNAF came into force in July 1950 following ratification by Canada, Iceland, the UK and the USA. The stated purpose of ICNAF was the "investigation, protection, and conservation of the fisheries" (NAFO 2013).

${ }^{8}$ Also called Northeast Multispecies, the groundfish fishery comprises 15 species regulated under one FMP. Twelve species are regulated as large mesh species (based on the size and type of gear used): Atlantic cod, haddock, pollock, yellowtail flounder, witch flounder, winter flounder, windowpane flounder, American plaice, Atlantic halibut, redfish, ocean pout, and white hake. Three species are regulated under a small mesh program: silver hake (whiting), red hake, and offshore hake (NEFMC 2013b).
} 
comply with quota limitations and frequently disrespected the regulations imposed. A fisherman as quoted by Crocker (2008) stated about the new quota systems:

“Fishermen didn’t want to waste fish or break the rules like that, [...] but the system created an untenable situation that undermined a generations-old stewardship ethic and brought out the worst in human nature” (2008: 2).

By the early 1980s, stock assessments indicated that three of the major stocks of groundfish - cod, haddock, and yellowtail flounder - had declined (National Research Council 1998). For that reason, the Council discontinued the quota system in favor of indirect controls for regulating the fisheries off the coast of New England (Jin et al. 2002). Regulations under the indirect controls approach aimed at controlling mesh size, fish size, and area closures. Rules were incorporated into two different groundfish management plans, the Interim Groundfish Plan, implemented in 1982, and the Multispecies Plan, implemented in 1986.

According to Healey and Hennessey (1998), the Interim Groundfish Plan of 1982 "incorporated considerable complexity in an attempt to deal equitably with the diversity of New England fishery” (1998: 111). In order to attend to this diversity, the fishery plan defined areas where cod, haddock, and yellowtail flounder could be caught with mesh sizes larger than the minimum requirement and also offered an “optional settlement program” for specific small mesh species, as to not exclude fishermen who fished for species other than cod, haddock, and yellowtail flounder in the large mesh areas. Fishermen participating in the "optional settlement program" had to land 50 percent of their catch consisting of small mesh species, while only 15 percent could be of cod, haddock, and yellowtail flounder, and they were not required 
to send in logs of their fishing activity. This program allowed fishermen targeting small mesh species to carry nets of different sizes on the boats and change them accordingly to their fishing activity (NEFMC 1981).

Between 1982 and 1984 it was concluded that the Groundfish Interim Plan did little to conserve the fish stocks. Fishermen frequently ignored provisions regarding mesh sizes and complied with fish size rules mainly by discarding and high grading. Closed areas required intensive monitoring by the Coast Guard to be effective. The complexity of the regulations and the difficulty in enforcing them, as well as the perception by the fishermen that the rules lacked fairness, contributed to the overall failure of the plan (Healy and Hennessey 1998).

The Multispecies Plan of 1986 was similar in structure to the Groundfish Interim Plan but regulations were expanded to include minimum size for additional species, larger and new closed areas for spawning, requirements for gillnets, and mesh sizes for catching redfish. Between 1986 and 1988 more provisions were implemented to change closed areas, change by-catch provisions, mesh size requirements, prohibition of scallop fishing in certain closed areas, changes to definition and management of cod ends, and rules for carrying small mesh nets while fishing or traversing large mesh size areas (NEFMC 1985). In 1988 it was concluded that the Multispecies Plan was not effective and very difficult to enforce (Healy and Hennessey 1998). The Technical Monitoring Group of the Council reported in 1988, as quoted by Healey and Hennessey (1998), that "the objective of the Multispecies Plan to retain for the industry its traditional, flexible, open access character, may be incompatible with the goals of maintaining or increasing spawning stock biomasses” 
(1998: 113).

It was concluded that the implementation of both the Groundfish Interim Plan and the Multispecies Plan were not effective in protecting the fish stocks off the coast of New England: by the early 1990s NOAA stock assessments showed record low levels for main groundfish species (National Research Council 1998). Posterior analyses of fish stock trends for the states of Maine, Massachusetts, and Rhode Island show a stock decline of 59 percent between 1982 and 1989 (Jin et al. 2002). In July 1989, NMFS issued the 602 Overfishing Guidelines. These guidelines required that an overfishing definition be specified for each individual stock to direct the council on rebuilding programs for overfished species (Brodziak et al. 2008). As a response to the 602 Overfishing Guidelines as well as the Technical Monitoring Group report, the NEFMC implemented Amendment 4 to the groundfish fishery, which included definitions of overfished stocks but failed to suitably set stock rebuilding programs (Apollonio and Dykstra 2008). According to the council definitions all stocks of cod, haddock, and yellowtail flounder were overfished (Healy and Hennessey 1998).

Following NMFS approval of Amendment 4, the Conservation Law Foundation (CLF) brought suit against the Secretary of Commerce in 1991, arguing that it had failed to meet the conservation requirements of the MSA (Shelley 2001). The CLF was favored by the courts and a "consent decree” was reached between the parties to reduce the groundfish fishing mortality by 50 percent in five years. As a consequence, NOAA implemented Amendment 5 to the Multispecies Plan. The new rules included the creation of additional closed areas for spawning and the implementation of a system of days-at-sea (DAS) to end overfishing in the five- year 
period stipulated (Apollonio and Dykstra 2008). By 1994, NMFS scientists concluded that Amendment 5 alone was insufficient to reverse the downward trends in the major groundfish stocks (Healy and Hennessey 1998).

In May 1996, the NEFMC implemented Amendment 7 with the objective of:

[Reducing] fishing mortality on Georges Bank cod, haddock, and yellowtail flounder and Southern New England yellowtail flounder to as close to zero as practicable, and also to reduce fishing mortality for Gulf of Maine cod to rebuild the spawning stock biomass of the identified stocks. (NEFMC 1996: 13)

Under Amendment 7 the limited access permit covered a larger number of small groundfish otter trawl and gillnet vessels (to thirty, down from forty- five feet) and the DAS plan was reduced from five to a three- year schedule. The new amendment also determined Total Allowable Catch (TAC) values for specific cod, haddock, and yellowtail flounder stocks and aggregated TAC for other stocks and allowed the council to restrict future catch if an individual or aggregated TAC was reached. A bycatch program was implemented to assure that vessels without groundfish DAS quotas were not allowed to fish in groundfish fishing areas unless certified by a NMFS Regional Administrator that the vessels could not achieve a groundfish by-catch of more than 5 percent of the trip catch. Amendment 7 also put in place a Multispecies Monitoring Committee responsible for tracking DAS and TAC utilization and making recommendations to the council regarding FMPs (NEFMC 1996).

Part of the justification for increasing regulations concerning inshore fishing grounds was a consequence of the DAS proposed rules in Amendment 5 (Apollonio and Dykstra 2008). Vessels that fished mainly offshore (e.g. Georges Bank), looking for maximizing their DAS fishing season by reducing steaming time, began fishing in inshore waters. This created further pressure on inshore stocks and increased 
competition among fishermen who traditionally fished in those waters versus

newcomers seeking new grounds and species not included in the DAS program. For that reason, NMFS later implemented Amendment 8 in an attempt to minimize gear conflicts as a result of the regulations previously imposed (Apollonio and Dykstra 2008). The council stated:

Abundance of stocks fluctuate[s] from natural causes and many fisheries resources are harvested well above the level that would maximize yield. As a result, fishermen have learned to make the most efficient use of their capital and labor by targeting other species, possibly with different fishing gear. This pulse fishing may be economically efficient, especially when an underutilized species serve as a substitute for a depleted species in the marketplace. It may not be so beneficial to the fishery resources or the ecosystem. It certainly concentrates fishing effort in areas where the new targeted species occurs and may disturb fishing activities that already occur in that area. (NEFMC 1996)

The concern expressed by the council regarding gear conflicts reflects fishermen's natural inclination to diversify in the face of changes. In the specific case of Amendment 8, changes imposed were in part a consequence of DAS regulations, which caused an imbalance in the distribution of fishermen in the different fishing grounds (Apollonio and Dykstra 2008). In an attempt to resolve conflict, the NEFMC response was to further restrict fishermen's ability to diversify.

The year of 1996 was also marked by the reauthorization and amendment of the MSA with the enactment of the Sustainable Fisheries Act (SFA), which shifted the focus of the MSA from promoting national fisheries to conserving fish stocks. Among other provisions, the SFA required the removal of discretion over the definition of overfishing, (i.e. prevented managers from setting catch limits above sustainable levels to achieve short-term economic gain (PEW 2011)) and the requirement that rebuilding 
of overfished stocks be done within a specific time period (generally ten years). Moreover, the act implemented new requirements to reduce by-catch and waste as well as provisions to protect essential habitat for fish populations. The MSA reauthorization of 1996 also put a moratorium on the implementation on any new Individual Fisheries Quota (IFQ) system in U.S. fisheries for five years (Sustainable Fisheries Act of 1996, U.S. P.L. 104-297, 11 October, 1996). In 1997, NFMS released the first "Status of Fisheries of the United States" report to Congress indicating that eighty- six species of fish were considered overfished (Dell'Apa et al. 2012).

In March 1999, Amendment 9 was implemented and it further revised definitions for overfishing and specifications of optimum yield for 12 groundfish species. Amendment 9 also includes Atlantic halibut in the multispecies plan (64 Federal Register 55 13952-13953, 23 March, 1999). Later in 1999, Amendment $12^{9}$ to the MSA addressed the management of the small-mesh groundfish species (silver hake (whiting), red hake, offshore hake, and ocean pout) including a moratorium on the commercial permits for these species (64 Federal Register 104 29257-29258, 1 June, 1999). In June of the same year NOAA announced Disaster Assistance for Northeast Multispecies Fisheries Failure, which included a plan to disburse funds to those who have incurred losses from declining fish stocks (64 Federal Register 112 31542-31548, 11 June, 1999).

In 2000, the Conservation Law Foundation along with four other organizations once again sued NMFS for failing to address the issue of overfishing of cod, haddock, and yellowtail flounder. The years that followed the lawsuit were marked by the

\footnotetext{
${ }^{9}$ Amendment 10 reflected administrative adjustments to the plan and Amendment 11 set Essential Fish Habitat for all species of groundfish (Apollonio and Dykstra 2008).
} 
development of the NEFMC Groundfish Overfishing Definition Committee (2000), the first Groundfish Assessment Review Meeting (2002), the development of the Working Group on Re-evaluation of Biological Reference Point for New England Groundfish (2002), and the Groundfish Peer Review Panel (2003) (Brodziak et al. 2008). All these efforts culminated in the implementation of Amendment 13 to the New England multispecies FMP in 2004. By the time the amendment was implemented, NMFS was facing five lawsuits on the grounds that it failed to comply with the MSA to protect New England groundfish stocks (Apollonio and Dykstra 2008).

Interestingly, in July 2001, the Stock Assessment Review Committee (SARC) reported to the New England council that the Gulf of Maine cod stock biomass had more than doubled in two years (1999-2001) but could not explain the reason why that happened while fishing mortality was approximately three times the recommended level. The Fmax, or the fishing mortality that ensured the maximum sustainable yield, for the cod stock in question was 0.27 and it was around 0.7 for the period of time assessed in the report. Despite the results presented by the SARC, NMFS advised the NEFMC that rules be set to meet the biological target (Apollonio and Dykstra 2008).

Amendment 13 was implemented with that goal and put in place new rules concerning the DAS program aiming to decrease fishing mortality by approximately 60 percent, and consequently further increase the complexity of the New England groundfish FMP. Among other adjustments to the plan, four new categories of permitted DAS were established (Brodziak et al. 2008). A council member, as quoted by Apollonio and Dykstra (2008), stated: "the current management system needs to be 
simplified. The combination of time, gear, and area restriction is daunting at best and incomprehensible at worst” (2008: 68). Back in 1999, the following quote was published in Commercial Fisheries News as quoted by Apollonio and Dykstra (2008):

The rules have become so complicated and they are changing so often that no one, absolutely no one, can keep track of them all... Even the people at the National Marine Fisheries Service who have to implement the rules admit they can hardly keep up and are having trouble adequately informing fishermen of the latest in the endless stream of changes. (2008: 65)

In addition to all the amendments to the groundfish FMP, between 1994 and 2004, more than forty framework adjustments had been implemented. Framework adjustments are effected without the need for the full administrative review required for amendments.

Besides establishing new rules to the DAS system, Amendment 13 also introduced for the first time the idea of "sectors" and set rules for the creation of the Georges Bank Hook Gear Sector Allocation (NEFMC 2003). The new rules to the groundfish management were also responsible for eliminating a large number of fishermen from the fishery by not allocating them any viable DAS, and for reducing the DAS of remaining vessels causing financial hardship to many fishermen (Holland et al. 2010). By 2006 NEFMC recognized the complexity and consequent problems of the DAS system and considered alternative management options such as a "points" system, “area management,” and an expanded “sector” program (Apollonio and Dykstra 2008). The council considered implementing an IFQ program in the groundfish fishery but was afraid that it might not pass a referendum vote by two- 
thirds majority of permit holders as required in New England ${ }^{10}$ (Holland et al. 2010). Time and bureaucratic constraints prevented work on new provisions, and the council committed itself to revisions of the DAS system. In January 2007, the MagnusonStevens Fishery Conservation and Management Reauthorization Act of 2006 was signed by President George W. Bush. The amendment mandated the use of annual catch limits to end overfishing by 2011, called for "increased international cooperation” (NOAA 2013c), and set guidelines for the implementation of Limited Access Privilege Programs (LAPPs) (Magnuson-Stevens Fishery Conservation and Management Reauthorization Act of 2006 U.S. P.L. 109-479, 27 July 2006).

The primary reason for the implementation of LAPPs, or any catch share system in the fishery, was believed to be to create an incentive for fishermen to fish sustainably (Schikler 2008). Under catch shares fishermen are granted a property right over a portion of the TAC and therefore would feel more compelled to conserve the fish stocks. This reasoning derives from the idea that 'ownership promotes stewardship’ (Costello et al. 2008, Stokstad 2008). Another reason stated for implementing a system of limited access to the groundfish fisheries was to end the race for fish. It is argued that giving fishermen the right to a portion of the catch, therefore eliminating the incentive to race other fishermen for fish, increases safety and lengthens fishing seasons. According to Schikler (2008) “if implemented properly, harvesting rights give fishers an enforceable right to exclude others from the fishery and encourages sustainable behavior that will ensure a long-term flow of benefits from these assets” (2008: 914).

\footnotetext{
${ }^{10}$ The New England Fisheries Management Council (NEFMC) and the Gulf of Mexico Fisheries Management Council (GMFMC) are the only fishery councils prohibited from initiating an IFQ program without the approval by referendum of two-thirds of permit holders and other fishery participants (50 CFR 600.1310).
} 
The idea of introducing limited entry programs into the fisheries was not new in New England. For the first decade after the NEFMC had been implemented, NMFS urged the council frequently to adopt some form of limited entry system in the groundfish fishery. The NEFMC, however, recognized the issue to be controversial and particularly complex, and the lack of practical examples of how it might be implemented and what benefits it posed to the fish stocks drove the council to postpone the debate on limited access programs (Apollonio and Dykstra 2008). According to Apollonio and Dykstra (2008), one main argument for the council to vote against the implementation of limited access plans was that once implemented, it would change aspects of the social and economic characteristics of New England fisheries. Furthermore, it was recognized that because of the complicated and interrelated fishery practices of the New England fisheries, implementing a limited access system in one fishery would deeply affect other fisheries in ways that no one could predict (Apollonio and Dykstra 2008).

Despite the controversial nature of limited access programs, in the early 2000s the council was once again debating the implementation of such management strategy in New England fisheries, convinced that a system of days-at-sea was extremely complicated and no longer effective to control effort of a fleet that had grown more powerful and efficient. In June of 2006, Amendment 14 introduced a limited access program to the small-mesh groundfish fishery to "[reduce] the risk of overcapitalization and [constrain] fishing to a level that minimizes the risks of overfishing or [create] an overfished stock" (Amendment 14 to the Northeast Multispecies Fishery, 71 Federal Register 112 33721-33722, 12 June 2006). In 2009, 
the NEFMC would announce submission of Amendment 16 for review, the amendment that introduced an expanded proposal to implement "fishery sectors" in the New England groundfish fisheries.

Amendment 16 introduced two main changes to the New England Groundfish fisheries: "hard quota" annual limits to the TAC for all species of groundfish and an expansion of "fishing sectors" to allocate groups of vessels (sectors) a portion of the TAC for nine of the forteen species of groundfish in the FMP (Amendment 16 to the Northeast Multispecies Fishery, 74 Federal Register 204 54773-54775, 23 October, 2009). There are fundamental differences between LAPPs and the "sector" concept. While LAPPs grant fishery property rights to an individual fisherman, allocations under "sectors" grant catch shares to individuals only when they participate in a sector, therefore qualifying catch histories are known as "potential sector contributions" (Macinko and Whitmore 2009).

Vessels organized into sectors became exempt of the effort controls previously implemented in the fishery, such as DAS limits. Vessel owners who opt for not participating in a sector formed the "common pool," subject to controls of DAS, trip limits, and all area closures. After Amendment 16 passed, seventeen sectors ${ }^{11}$ were created and each established rules for allocation use of the total quota granted to the sector as a unit. Allocations were granted based on historical catches in the groundfish fishery from a fixed period (1996-2006), resulting in 98 percent of the TAC allocated to sectors, while 2 percent was granted to the "common pool” vessels, which represented 46 percent of all vessels in 2010 (Kitts et al. 2011). Under the new market-

\footnotetext{
${ }^{11}$ As of 2012, there were 16 sectors with active participants and 3 sectors that leased their entire allocation (Labaree 2012).
} 
based approach, sectors and their members can lease or trade allocations from fishermen in other sectors, creating an internal market for fishing privileges (Labaree 2012).

The implementation of sectors in the New England groundfish fisheries under Amendment 16 sealed the transition of the fisheries management scheme in the region from an effort control system to rights based limited access management. From the beginning, fishery participants were split with regard to their support over the implementation of sectors and some of the main criticisms concerned the fear of consolidation, increased difficulty of entry for new participants, and decreased fleet diversity (Macinko and Whitmore 2009). It is true that these issues would exist in the groundfish fishery regardless of the implementation of sectors, but the nature of limited access programs is known to facilitate and even motivate them. In Alaska, for example, the implementation of catch-shares to the red king crab fishery contributed to a decrease of approximately 65 percent in the total number of vessels (Knapp 2008).

Specifically with regard to sectors, permit holders are allowed and even encouraged to pool allocations into fewer vessels (Macinko and Whitmore 2009). It is also argued that the method used for the initial allocations to sector members favored larger vessels, therefore further compromising fleet diversity. A number of other impacts to fishermen and fishing communities have also been considered (Olson 2011, Olson et al. Forthcoming 2013). One example, a survey conducted by the Gulf of Maine Research Institute in 2011, showed that a significant number of groundfish permit holders had dropped out either permanently (selling out) or temporarily (leasing out) because they believed their "potential sector contribution" was not 
enough to stay profitable (Labaree 2012).

It is undeniable that the implementation of Amendment 16 posed substantial changes to the groundfish fishery in New England and possibly to entire communities. According to Macinko and Whitmore (2009: 38) "sectors will not provide protection to communities unless such protection is built in.” In 2012, the NEFMC considered Amendment 18 to the groundfish FMP, which, if passed, would put in place "measures that will impose limits on the amount of allocations that individuals or groups of individuals may control” and could "create other incentives for maintaining diversity and fishery infrastructure” (NEFMC nd). Amendment 18 is the council's recognition that current management practices have threatened the flexible and diverse characteristics of the New England groundfish fisheries.

\subsubsection{Scallop fishery}

The Atlantic sea scallop fishery ranges from the Gulf of Maine to the MidAtlantic and it represents one of the most valuable fishing resources to the region today and the most valuable wild scallop fishery in the world (NOAA 2010). Although five stock components ${ }^{12}$ are recognized by science, they are managed as one single unit by NMFS, with the exception of the Gulf of Maine stock (Repetto 2001). The Atlantic Sea Scallop FMP was first implemented by the NEFMC in 1982. The stated objective of the plan was to "maximize overtime the joint social and economic benefits from the harvesting and use of the sea scallop resource” (NEFMC 1982). Until 1993, the scallop resources were managed almost exclusively by a "meat count,"

\footnotetext{
12 The 5 recognized stocks are: Eastern Georges Bank, the Great South Channel, the Gulf of Maine, the New York Bight, and the waters adjacent to Delaware, Maryland, and Virginia (Hartley 2010).
} 
or the maximum number of scallop "meats"13 that was contained in one pound of shucked scallops. Entry into the fishery was open until 1994, when the stocks were declared overfished and a moratorium on the issuance of new permits was put in place.

Amendment 4 of 1994 established the rules to the new limited access scallop management system. Approximately 350 fishermen qualified for licenses, representing basically all fishermen who could prove significant harvest history in the previous years (Repetto 2001). Licenses were broken down into full-time, part-time, and occasional, with the majority of granted licenses (264) representing full-time vessels (Edwards 2002). To prevent permit “stacking,” licenses could not be disengaged from vessels, and therefore could only be transferred upon sale or transfer of the vessel itself. This type of program is referred to as non-transferable Individual Vessel Effort Quotas (IVEQs). Fishermen who did not qualify for limited access had the option of applying for a "general category” permit, also effected with Amendment 4, and were allowed to land up to 400 pounds of scallops a day (Hartley 2010). Other measures to address overfishing were also adopted. Days at sea were scheduled to decrease from 200 to 120 over the years, crew size was limited to a maximum of seven men to constrain the amount of scallops that could be shucked on a trip, and minimum diameters were established for the rings on dredges to allow small scallops to escape (Repetto 2001).

In December 1994, due to the collapse of the groundfish fishery, three areas of Georges Bank were closed to all vessels that could potentially catch groundfish, including scallop boats. This measure culminated with a shift in effort to other areas in

\footnotetext{
13 "Meat" is the term used to describe the adductor muscle attached to both shells, which is the edible part of the scallop.
} 
the Mid-Atlantic and small open areas, which caused these areas to be subsequently closed to protect juveniles. The groundfish and scallop closed areas represented about one-third of the scallop resource area and approximately 85 percent of harvestable biomass (Edwards 2002). After the reauthorization of the MSA in 1996, more drastic measures were proposed to further decrease effort in the scallop fishery. In 1998 it was proposed that the allowable days at sea would fall from 120 to only fifty- one (Repetto 2001). These measures generated a response from permit holders, who in 1999 created the Fisheries Survival Fund, a group dedicated to lobby for access to closed areas. Research funded by the industry revealed that stocks had increased eight to sixteenfold in closed areas after four years of their establishment. This evidence led the government to allow closed area trips, and the discovery of large scallops in such areas, ensured limited harvest in three closed areas in Georges Bank in a rotating system and prevented the proposed reduction of DAS (Amendment 10). Between 1998 and 2001 it was estimated that scallop landings increased 264 percent, from 5,879 to 21,404 metric tons (Baskaran and Anderson 2005).

In the early 2000s it was determined that effort in the "general category" fishery should be reduced. In 1994 the total number of licenses was 1,992 and 181 vessels landed scallops. By 2005 the number of licenses had increased to 2,950 and the number of vessels landing scallops had surpassed 600 (NOAA 2010). Vessels carrying "general category” licenses were part of a very diverse fleet. Some harvested scallops seasonally, others as by-catch, and others as a year round resource. In 2008, Amendment 11 established a limited access program to the "general category.” The program was implemented in the form of an IFQ granted to qualifying vessels with 
significant catch history. The new rules established three categories of Limited Access General Category (LAGC) permits: the IFQ, the Northern Gulf of Maine (NGOM), and the incidental catch permit. Fishermen granted LAGC permits were allocated 5 percent of the established scallop TAC (NOAA 2010).

The Final Decision Document for Amendment 11 stated:

The overall intent of this action is to stabilize capacity and prevent overfishing from the general category fishery, to maintain the diverse nature and flexibility within this component of the scallop fleet, and preserve the ability for vessels to participate in the general category fishery at different levels (NEFMC 2007: 1).

Although maintaining diversity and flexibility was a stated objective of Amendment 11, there was growing concern by many fishermen and researchers at the time that the implementation of limited entry programs (in this case an IFQ) in the scallop fishery could have negative social and economic consequences for many fishing communities (see Olson 2006).

The fishing ports that constitute the focus of the present research are characterized by diverse fishing activity and are subject to impacts from regulations governing an array of different species of fish and shellfish. The groundfish and the scallop fishery were used as examples of the complexity of processes involving the management of fish stocks off the coast of New England and the potential consequent social and economic effects that such practices can have on fishermen and fishing communities. Moreover, the examples used provide an illustration of the processes that can lead to specialization as a result of management pressure, which represent the focal point of the present research. 


\section{CHAPTER III}

\section{METHODS}

Chapter three presents the methods used in the present study to investigate the research problem and address the hypotheses presented in Chapter I. Two research methods were used in the development of this study: structured surveys and analyses of secondary data of fishery landings for the ports studied. This chapter will provide an explanation for the employment of these research methods and present sampling techniques and measurements used in the course of the research.

\subsection{Surveys}

Structured surveys conducted with fishermen from the ports studied were employed as a means of assessing and measuring their perception of changes in flexibility and diversity, as well as the processes behind these changes. Surveys were also deemed as the most appropriate method for obtaining data on the potential effects that a decrease in diversity can have on fishermen resilience. Moreover, surveys were also used to investigate correlational patterns between fishing related variables and subjective perceptions of resilience and job satisfaction among fishermen.

\subsubsection{Participants and sampling design}

A total of 117 fishermen were interviewed from the ports of Point Judith, Rhode Island, New Bedford and Fairhaven, Massachusetts, and the Cape Cod region of Massachusetts, more specifically the ports of Chatham, Harwich Port, Hyannis, and 
Provincetown. For the purposes of this study the studied communities will be referred to as the ports of Point Judith, New Bedford, and Cape Cod.

The method used for sampling individuals was a direct approach at the docks, characterizing an opportunistic sampling technique (Bernard 2006, Rudestam and Newton 2007). The reason for choosing this sampling design was due to the challenges involved in drawing a truly random sample from the universe studied. There is currently no registry of active fishermen available for the studied area, making a random approach at the docks the most effective way to contact them, which is especially true when attempting to reach crew members. Moreover, fishermen often live far from the ports they sail from, and their schedules are difficult to predict. Fishing is at the mercy of weather conditions, seasonal fluctuations in fish stocks, and regulations, which will determine when they can sail and for how long they will be away on a trip. It has been determined by previous research (Pollnac and Poggie 1978: 365) that the most successful way to obtain information from fishermen is to approach them at the docks when they are working gear, preparing to leave on a trip, coming back from a trip, or simply socializing with other fishermen. All these activities are difficult to predict, making it further challenging to draw a truly random sample from the universe of fishermen. In an attempt to avoid biases, fishermen were approached at random days of the week and times of the day. A sample obtained in this manner can be conceptualized as a sample from the universe of all hypothetically possible data sets collected under similar conditions (Chein 1976, Freund 1960, Thomas 1976). Interviews lasted an average of fifteen to twenty minutes. 


\subsubsection{Measures}

The questionnaire (Appendix I) was designed to 1) obtain information about demographics and aspects of respondent's fishing activity; 2) obtain information on fishermen's perceptions of changes in catch composition through open ended questions; 3) assess individual subjective resilience; and 4) assess individual subjective levels of job satisfaction.

\subsubsection{Subjective resilience}

Levels of subjective resilience were measured at the individual level using a scale developed by Marshall and Marshall (2007). The scale consists of twelve statements designed to assess levels of well-being among fishermen concerning their flexibility, opportunities, and acceptability with regard to changes in the fisheries. The scale replicated in this study was the result of a reliability analysis involving seventeen initial statements developed by Marshal and Marshal (2007). The twelve statements selected (table 4) represented those with a Cronbach's $\alpha$ of 0.7 or greater ${ }^{14}$.

\footnotetext{
${ }^{14}$ Cronbach's $\alpha$ is a type of reliability test used in statistics to calculate reliable generalization to a universe of variables from a sample of variables (Rummel 1970). The test is based on correlations between statements (variables) and it has a maximum value of one.
} 
Table 4. Statements developed by Marshal and Marshal (2007) to measure levels of subjective resilience

1. I have many options available if I decide to no longer be a fisher

2. I am confident that I could get work elsewhere if I needed to

3. I am too young to retire and too old to find work elsewhere*

4. I would be nervous trying something else*

5. I can cope with small changes in the industry

6. I have planned for my financial security

7. Every time there is a change I plan a way to make it work for me

8. I am more likely to adapt to change compared to other fishers

9. I do not think I am competitive enough to survive much longer ${ }^{*}$

10. I am confident things will turn out well for me

11. If there are any more changes I will not survive much longer*

12. I am interested in learning new skills outside of the industry

* Negatively worded statements were coded on a reversed scale

Respondents were asked to indicate their levels of agreement with the statements above and responses were coded on a five-point Likert scale (1 = strongly disagree; 2 = disagree; 3 = neutral; 4 = agree; 5 = strongly agree). Four statements (indicated with an asterisk in table 4) were negatively worded and were therefore coded on a reversed scale $(1=$ strongly agree; 2 = agree; $3=$ neutral; 4 = disagree; $5=$ strongly disagree). The original scale developed by Marshal and Marshal (2007) was coded on a four-point Likert scale ( 1 = strongly agree; 2 = agree; 3 = disagree; $4=$ strongly disagree - reversed for negatively worded statements). In the current study it was considered important to include a neutral point in the scale, therefore offering respondents the option to neither agree nor disagree with the statements.

\subsubsection{Job satisfaction}

Job satisfaction among fishermen was first assessed by Pollnac and Poggie in 1977 (Acheson et al. 1980, Pollnac and Poggie 1988) and then by them and many 
others in the U.S. and Canadian fisheries (e.g., Gatewood and McCay 1990, Pollnac et al. 2008, Pollnac and Poggie 2008, 2006, 1988, Binkley 1995, Apostle et al. 1985). This variable was originally measured using a twenty-two-item scale including topics that were shown by previous research to be associated with job satisfaction among fishermen. Factor analysis involving the original scale was used to develop the three components of job satisfaction: Basic Needs, Social and Psychological Needs, and Self-Actualization. Since the structure of job satisfaction had remained relatively similar across numerous analyses (e.g. Binkley 1995), Pollnac $(2010,2011)$ reduced the number of indicators for each component to the three that manifested the highest loadings on each component (table 5), thus reducing the length of interviews while still obtaining valid data.

Table 5. Items derived from the twenty-two item scale developed by Pollnac and Poggie (1988) to measure levels of job satisfaction
1. Your actual earnings (from fishing)
2. Predictability of your earnings
3. Job safety
4. Time spent away from home
5. Physical fatigue of the job
6. Healthfulness of the job
7. Adventure of the job
8. Challenge of the job
9. Opportunity to be your own boss

Fishermen were asked about their levels of satisfaction with each one of the nine items listed above. Responses were coded on a scale of one to five $(1=$ very dissatisfied, 2 = dissatisfied, $3=$ neutral, $4=$ satisfied, $5=$ very satisfied). Traditionally, the variables 'actual earnings,' 'predictability of earnings,' and 'safety' represent the Basic Needs component; 'adventure of the job,' 'challenge of the job,' 
and 'opportunity to be own boss' the Self-Actualization component; and 'time away from home,' 'physical fatigue of the job,' and 'healthfulness of the job' the Social and Psychological Needs component (Pollnac and Poggie 2006). Two other job satisfaction questions (“Would you advise a young person to go into fishing?” and “Would you still fish if you had your life to live over?”), previously used by Pollnac and others, were also used as job satisfaction indicators. Responses to these two questions were coded as yes, maybe, or no.

\subsection{Post-survey supplementary questions}

After obtaining results for the interviews conducted using the questionnaire described above, it was regarded appropriate to conduct additional fieldwork to query fishermen more directly concerning perceptions of their flexibility to exploit an array of different species or to use multiple gear types and about potential changes in flexibility through time. Due to the fact that surveys were administered in Cape Cod ports after the decision of obtaining further data, fishermen in these ports were asked the additional questions concurrently with the questionnaire described above.

\subsubsection{Participants and sampling design for supplementary questions}

A total of forty fishermen were interviewed between the ports of Point Judith and New Bedford using the supplementary questionnaire and twenty-five fishermen in Cape Cod were asked the supplementary questions along with the main questionnaire. The sampling method used was the same described for the main surveys and fishermen were approached at the docks to comply with the same methods and 
considerations described previously. In Point Judith and New Bedford, where supplementary questions were asked alone, interviews lasted on average five to ten minutes.

\subsubsection{Measures}

Post-survey supplemental questionnaires (Appendix II) consisted of 1) a brief demographic section and questions on fishing attributes; 2) questions regarding the level of flexibility to exploit different species and switch gear types both at the time of the interview and when respondent first began fishing; and 3) follow-up questions regarding reasons and times of changes reported.

\subsubsection{Flexibility questions}

Questions regarding flexibility to exploit different species and to switch gear types were intended to capture potential changes that fishermen may have perceived during their fishing experience with regard to their flexibility. Responses were coded on a Likert scale to allow quantitative analysis of reported changes. The scale used ranged from one to fifteen, with one being the lowest possible level of flexibility - or no flexibility - and fifteen being the highest possible level of flexibility - or absolute flexibility. For both themes regarding flexibility to exploit different species and to use different gear types, a question was asked for the current time of the interview and for when the respondent first began fishing, both coded on the same Likert scale ranging from one to fifteen. 


\subsubsection{Follow-up questions}

Fishermen who reported any changes with regard to their flexibility to either exploit different species or use multiple gears or both were asked follow-up questions regarding perceived reasons and time of the change mentioned. These questions were open-ended questions that were later coded according to categories of responses.

\subsection{Landings data}

\subsubsection{Sample}

In order to investigate potential changes in diversity of species caught through time, catch composition of vessels homeported in the studied areas for the period between 1994 and 2012 were analyzed. The landings data was obtained from the National Oceanic and Atmospheric Administration (NOAA) commercial fisheries databases with permission granted. Information on gear type and pounds of species caught by vessel were obtained for New Bedford and Fairhaven (referred to as New Bedford), Narragansett (referred to as Point Judith), Chatham and Provincetown ${ }^{15}$ (referred to as Cape Cod) for the eighty-eight different species listed in Appendix III.

\subsubsection{Diversity measure}

The landings data was used to calculate a measure of diversity that could be assigned to each landing by vessel to represent the level of contribution of different species to the overall catch composition of a particular vessel in a given year. The measurement chosen was the Shannon Index, which has been extensively used in the

\footnotetext{
${ }^{15}$ Due to characteristics of the data obtained through the databases and necessary data transformations it was decided that the two largest ports in the Cape Cod region and those with the most significant number of fishermen surveyed in this study, Chatham and Provincetown, would be used.
} 
ecological literature to quantify ecosystem diversity. The Shannon Index is based on the idea that a higher number of species signifies a more proportional abundance, therefore higher diversity. The closer the Shannon value is to zero the less diversity exists in the system. The Shannon Index is calculated by the equation:

$$
\mathrm{H}=\sum_{i=1}^{R} \mathrm{P} i * \ln \mathrm{P} i
$$

where:

$\mathrm{H}=$ Shannon diversity index

$\mathrm{P} i=$ proportion of the entire population belonging to species $i$

$\mathrm{R}=$ the number of species categories encountered

$\sum=$ the sum of all species

The Shannon Index was deemed appropriate for the purposes of this study because values of diversity obtained for each vessel landing can be used to investigate changes in diversity, or proportions of contribution by different species to overall catch composition, through time for the ports studied, using analysis of variance.

Landings data was also used to examine co-occurrence of species landed in order to investigate potential fluctuations in landings by combinations of species through time using principal component analysis and analysis of variance.

\subsection{Analyses}

Results obtained from survey questions as well as from the landings data were analyzed using statistical tests for the appropriate measurement levels on Systat ${ }^{\circledR}$ software. 


\section{CHAPTER IV}

\section{ANALYSES AND RESULTS}

This chapter presents analyses conducted with data obtained through the use of surveys presented in the previous chapter as well as analyses conducted using landings data obtained through assessment of NOAA Fisheries databases. This chapter will provide information necessary for discussing the research hypotheses.

\subsection{Survey data}

\subsubsection{Description of the sample}

\subsubsection{Age and education}

The total sample of fishermen $(n=117)$ from the ports of New Bedford $(n=$ 41), Point Judith $(n=51)$, and Cape Cod $(n=25)$ had an average age of 46.8 years $(S D=11.740)$ and 12.6 years of formal education $(S D=2.202)$. Table 6 presents results of basic statistics for age and education for each port separately and all ports combined.

Table 6. Results of basic statistics regarding years of age and education for each port studied and for all three ports combined

\begin{tabular}{lll|ll|lll|ll}
\hline & \multicolumn{2}{l}{ New Bedford $(\mathrm{n}=41)$} & \multicolumn{2}{l}{ Point Judith $(=51)$} & \multicolumn{2}{c}{ Cape Cod $(\mathrm{n}=25)$} & \multicolumn{2}{c}{ All ports $(\mathrm{n}=117)$} \\
\cline { 2 - 9 } Min & Age & Education & Age & Education & Age & Education & Age & Education \\
\cline { 2 - 9 } Max & 20 & 4 & 18 & 9 & 20 & 10 & 18 & 4 \\
Median & 47 & 16 & 65 & 19 & 74 & 17 & 74 & 19 \\
Mean & 46.073 & 11.768 & 45.157 & 12.902 & 51.360 & 13.380 & 46.803 & 12.607 \\
SD & 9.076 & 2.225 & 10.959 & 2.052 & 15.824 & 2.98 & 11.740 & 2.202 \\
\hline
\end{tabular}


While average age did not differ significantly between the three ports, $F(2$, $114)=2.53, p>0.05$, a comparison with regard to average years of formal education showed statistically significant results, $F(2,114)=5.34, p<0.05$. Post hoc t test analyses revealed significant variations between New Bedford and Point Judith (t(90) $=2.54, p<0.05$, pooled variance) and between New Bedford and Cape Cod $(t(64)=$ 2.92, $p<0.05$, pooled variance), both with New Bedford scoring lower than the other two ports.

\subsubsection{Marital status}

Overall, more than half of the sample was married (61\%) and only one person chose not to answer the question. In New Bedford and Point Judith the percentages of married fishermen were just above half (58 and 57\%, respectively) and in Cape Cod married fishermen represented 72\%. Differences observed were, however, not statistically significant $\left(\chi^{2}(2)=1.73, p>0.05\right)$. The overall rate of divorced fishermen was relatively low (11\%), and differences between ports did not show statistically significant results $\left(\chi^{2}(2)=2.92, p>0.05\right)$. The majority of married fishermen $(76 \%)$ stated that their spouses also had an occupation. The lowest incidence of spouses with an occupation was observed in New Bedford (60\%). Point Judith and Cape Cod presented similar results (83 and 87\% respectively). Differences between ports with regard to the frequency of spouses with an occupation were statistically significant $\left(\chi^{2}\right.$ $(2)=6.24, p<0.05)$. 


\subsubsection{Residency}

The majority of fishermen in the total sample (65\%) lived in the same state where their boats were homeported but in a different town. The frequency of fishermen living out of the state was relatively low (8\%). The port with the highest incidence of out of state fishermen was New Bedford (17\%) and the port with the highest incidence of fishermen living in their homeport town was Cape Cod (42\%). Point Judith presented the highest incidence of fishermen who lived in their homeport state but in a different town (82\%). The differences observed were statistically significant $\left(\chi^{2}(4)=16.65, p<0.01\right)$. Tables and figures with frequencies with regard to fishermen’s residency can be seen in Appendix IV.

\subsubsection{Occupations besides fishing}

The majority of fishermen in the sample (79\%) did not have any additional occupations besides fishing. New Bedford and Point Judith presented a higher percentage of fishermen without additional occupations (80\% and $84 \%$ respectively) when compared to Cape Cod (68\%). These differences, however, were not statistically significant $\left(\chi^{2}(2)=2.77, p>0.05\right)$. A list of all occupations mentioned by fishermen interviewed and their respective frequencies can be seen in Appendix V.

\subsubsection{Fishery variables}

\subsubsection{Fishing experience}

Fishermen interviewed presented an overall average of 27 years of fishing experience (SD = 11.258), 22.7 years of experience in their respective homeports (SD 
$=11.910)$, and 8.6 years of experience on their current boats $(\mathrm{SD}=8.471)$. Average values for these variables were similar across all three ports $(F(2,114)=0.1, p>0.05$ for fishing experience; $F(2,103)=0.38, p>0.05$ for experience in port; and $F(2,102)$ $=1.3, p>0.05$ for experience on current boat). Table 7 shows the results for years of fishing experience overall, on respective homeports, and on current boats for each port studied and all ports combined.

Table 7. Results of basic statistics regarding years of experience fishing, years of experience in current port, and years of experience on current boat for each port studied and all three ports combined

\begin{tabular}{llll|lll|lll|lll}
\hline & \multicolumn{3}{c}{ New Bedford } & \multicolumn{4}{c}{ Point Judith } & \multicolumn{3}{c}{ Cape Cod } & \multicolumn{3}{c}{ All ports } \\
\cline { 2 - 12 } Min & Fishing & Port & Boat & Fishing & Port & Boat & Fishing & Port & Boat & Fishing & Port & Boat \\
Max & 45 & 2 & 0.5 & 2 & 2 & 0.15 & 3.5 & 0.1 & 0.1 & 2 & 0.1 & 0.1 \\
Median & 30 & 24 & 30 & 50 & 50 & 33 & 52 & 50 & 35 & 52 & 50 & 35 \\
Mean & 27.29 & 22.05 & 7.18 & 26 & 26.5 & 7 & 30 & 22 & 8 & 30 & 24.5 & 6 \\
SD & 9.98 & 11.20 & 8.02 & 11.30 & 10.96 & 8.55 & 13.40 & 14.56 & 8.96 & 11.26 & 11.91 & 8.47 \\
N & $\mathbf{4 1}$ & $\mathbf{4 1}$ & $\mathbf{4 1}$ & $\mathbf{5 1}$ & $\mathbf{4 0}^{*}$ & $\mathbf{3 9}^{*}$ & $\mathbf{2 5}$ & $\mathbf{2 5}$ & $\mathbf{2 5}$ & $\mathbf{1 1 7}$ & $\mathbf{1 0 6}$ & $\mathbf{1 0 5}$ \\
\hline
\end{tabular}

${ }^{*}$ Total sample size for these questions varies because they were not included in the first ten surveys administered in Point Judith and because of one missing case for 'experience on current boat.'

The average number of boats fishermen in the sample had fished on since they began fishing was 13.5 (SD = 14.064). The port with the highest average number of boats mentioned by fishermen was New Bedford $(\mathrm{M}=18.6, \mathrm{SD}=20.25)$. Both Point Judith and Cape Cod presented similar results $(\mathrm{M}=10.7, \mathrm{SD}=7.959$ and $\mathrm{M}=11.12$, $\mathrm{SD}=8.885$, respectively). Differences observed between ports with regard to the number of boats fishermen fished on throughout their fishing experience were statistically significant $(F(2,112)=4.18, p<0.05)$. Post hoc $t$ test analyses show that statistically significant differences exist between New Bedford and Point Judith $(t(48.64)=-2.31, p<0.05$, separate variance $)$ and between New Bedford and Cape Cod $(t(57.81)=2.04, p<0.05$, separate variance $)$. 


\subsubsection{Familial involvement in fishing}

The overall average of generations involved in fishing was $2.1(\mathrm{SD}=1.343)$.

The lowest mean value for number of fishing generations was observed in Point Judith $(\mathrm{M}=1.7, \mathrm{SD}=1.002)$. Averages for New Bedford and Cape Cod yielded similar results $(M=2.4, S D=1.245$ and $M=2.48, S D=1.851$, respectively $)$. The difference observed between Point Judith and the other two ports was statistically significant, $F(2,114)=4.3, p<0.05$. Table 8 presents the results of basic statistics for number of generations involved in fishing for each port and all ports combined.

\begin{tabular}{lllll}
\multicolumn{5}{l}{$\begin{array}{l}\text { Table 8. Results of basic statistics involving the number of generations involved in fishing for each port } \\
\text { and all three ports combined }\end{array}$} \\
\hline & New Bedford & Point Judith & Cape Cod & All ports \\
\hline Minimum & 1 & 1 & 1 & 1 \\
Maximum & 5 & 4 & 8 & 8 \\
Median & 2 & 1 & 2 & 2 \\
Mean & 2.415 & 1.725 & 2.48 & 2.128 \\
SD & 1.245 & 1.002 & 1.851 & 1.343 \\
$\mathbf{N}$ & $\mathbf{4 1}$ & $\mathbf{5 1}$ & $\mathbf{2 5}$ & $\mathbf{1 1 7}$ \\
\hline
\end{tabular}

Out of the total sample of fishermen interviewed, about half (55\%) reported the presence of relatives who are also involved in fishing and just below half of them (45\%) reported the presence of relatives fishing on the same boat as them. A comparison between ports did not show statistically significant results $\left(\chi^{2}(2)=1.99\right.$, $p>0.05)$. Table 9 presents results of basic statistics for the number of relatives involved in fishing for each port studied and all ports combined. 
Table 9. Results of basic statistics regarding number of relatives involved in fishing and number of relatives fishing on the same boat for each port studied and all three ports combined

\begin{tabular}{|c|c|c|c|c|c|c|c|c|}
\hline & \multicolumn{2}{|c|}{ New Bedford } & \multicolumn{2}{|c|}{ Point Judith } & \multicolumn{2}{|c|}{ Cape Cod } & \multicolumn{2}{|c|}{ All ports } \\
\hline & Rel. & Rel. boat & Rel. & Rel. boat & Rel. & Rel. boat & Rel. & Rel. boat \\
\hline Minimum & 1 & 1 & 1 & 1 & 1 & 1 & 1 & 1 \\
\hline Maximum & 12 & 3 & 8 & 1 & 15 & 2 & 15 & 3 \\
\hline Median & 2 & 1 & 2 & 1 & 2 & 1 & 2 & 1 \\
\hline Mean & 3 & 1.692 & 2.64 & 1 & 3.615 & 1.167 & 2.984 & 1.345 \\
\hline SD & 2.592 & 0.855 & 1.912 & 0 & 4.214 & 0.408 & 2.752 & 0.67 \\
\hline $\mathbf{N}$ & 26 & 13 & 25 & 10 & 13 & 6 & 64 & 29 \\
\hline
\end{tabular}

\subsubsection{Fishery position}

Overall the position with the highest incidence in the sample $(n=45)$ was ‘captain/owner’ (also known as ‘owner/operator’), followed by ‘captain’ ( $\mathrm{n}=30)$, 'crew' (n = 29), 'mate' ( $\mathrm{n}=10)$, and finally 'owner' $(\mathrm{n}=3)$. In New Bedford the fishery position most frequently found was ‘captain' $(\mathrm{n}=18)$, followed by 'crew' (n = 10). In Point Judith and Cape Cod the most frequently observed fishery position was 'captain/owner' ( $\mathrm{n}=21$ and $\mathrm{n}=18$, respectively), followed by crew ( $\mathrm{n}=15$ and $\mathrm{n}=4$, respectively). Table 10 shows the distributions of the different positions across the three ports studied and figure 6 provides a visual representation of the distribution found.

Table 10. Distribution of the different fishery positions in the sample across the three ports studied and all ports combined

\begin{tabular}{lllll}
\hline & New Bedford & Point Judith & Cape Cod & All ports \\
\hline Captain/owner & 6 & 21 & 18 & 45 \\
Captain & 18 & 9 & 3 & 30 \\
Crew & 10 & 15 & 4 & 29 \\
Mate & 7 & 3 & 0 & 10 \\
Owner & 0 & 3 & 0 & 3 \\
$\mathbf{N}$ & $\mathbf{4 1}$ & $\mathbf{5 1}$ & $\mathbf{2 5}$ & $\mathbf{1 1 7}$ \\
\hline
\end{tabular}




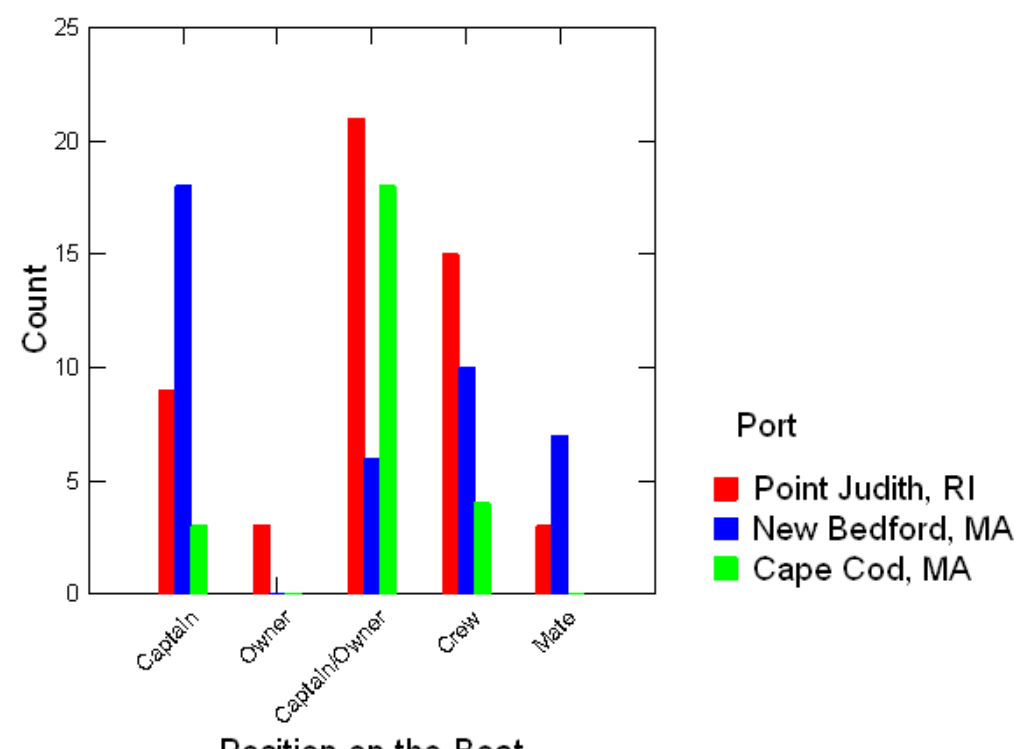

Figure 6. Chart showing the distribution of fishery positions across the three ports studied

\subsubsection{Characteristics of current fishing activity}

\subsubsection{Crew size}

The average crew size in the overall sample was 3.7 (SD =1.9). New Bedford presented a significantly higher average crew size $(M=5.3, S D=1.657)$ when compared to Point Judith and Cape Cod $(\mathrm{M}=2.8, \mathrm{SD}=1.194$ and $\mathrm{M}=2.4, \mathrm{SD}=$ 1.044 , respectively), $F(2,101)=48.9, p<0.001$. Table 11 shows results of basic statistics for crew size for each port studied and all ports combined.

Table 11. Results of basic statistics for crew size for each port and all three ports combined

\begin{tabular}{lllll}
\hline & New Bedford & Point Judith & Cape Cod & All ports \\
\hline Minimum & 2 & 1 & 1 & 1 \\
Maximum & 7 & 6 & 5 & 7 \\
Median & 5 & 3 & 2.5 & 3 \\
Mean & 5.329 & 2.803 & 2.38 & 3.697 \\
SD & 1.657 & 1.194 & 1.044 & 1.9 \\
$\mathbf{N}$ & $\mathbf{4 1}$ & $\mathbf{3 8}^{*}$ & $\mathbf{2 5}$ & $\mathbf{1 0 4}^{*}$
\end{tabular}

"Total sample size for this question is different from expected because the first ten surveys administered in Point Judith did not include crew size and because of missing data for the same port. 


\subsubsection{Trip length}

Average trip length for the overall sample was 4.3 days $(\mathrm{SD}=4.057)$. All three ports presented significantly distinct mean values for this variable, $F(2,113)=47.6$, $p<0.001$. Post hoc t test analyses showed statistically significant results for comparisons between New Bedford and Point Judith $(t(89)=-6.48, p<0.001$, pooled variance), New Bedford and Cape Cod $(t(41.49)=11.3, p<0.001$, separate variance), and Point Judith and Cape Cod $(t(56.75)=5.61, p<0.001$, separate variance). Cape Cod and New Bedford were the ports with the shortest $(\mathrm{M}=.86, \mathrm{SD}=.55)$ and longest $(\mathrm{M}=7.9, \mathrm{SD}=3.87)$ trips respectively. Table 12 shows basic statistics for trip length for each port studied and all ports combined.

\begin{tabular}{lllll}
\multicolumn{5}{l}{ Table 12. Results of basic statistics for trip length in days for each port and all three ports combined } \\
\hline & New Bedford & Point Judith & Cape Cod & All ports \\
\hline Minimum & 0.5 & 0.15 & 0.5 & 0.15 \\
Maximum & 12 & 15 & 3 & 15 \\
Median & 9.75 & 3 & 0.5 & 2.75 \\
Mean & 7.887 & 3.258 & 0.86 & 4.338 \\
SD & 3.87 & 2.95 & 0.55 & 4.057 \\
$\mathbf{N}$ & $\mathbf{4 0}^{*}$ & $\mathbf{5 1}$ & $\mathbf{2 5}$ & $\mathbf{1 1 6}^{*}$ \\
\hline
\end{tabular}

"Total sample size for this question is different from expected because of one missing case for New Bedford

Figure 7 shows a visual representation of the differences between ports with regard to frequencies of trip length reported by fishermen interviewed. While Cape Cod shows a concentration of responses that characterize a majority of short trips, Point Judith shows a more diversified range of trip lengths with the majority lying between short and medium trips, and New Bedford shows a bimodal distribution of trip lengths with some short trips and a majority of long trips. 


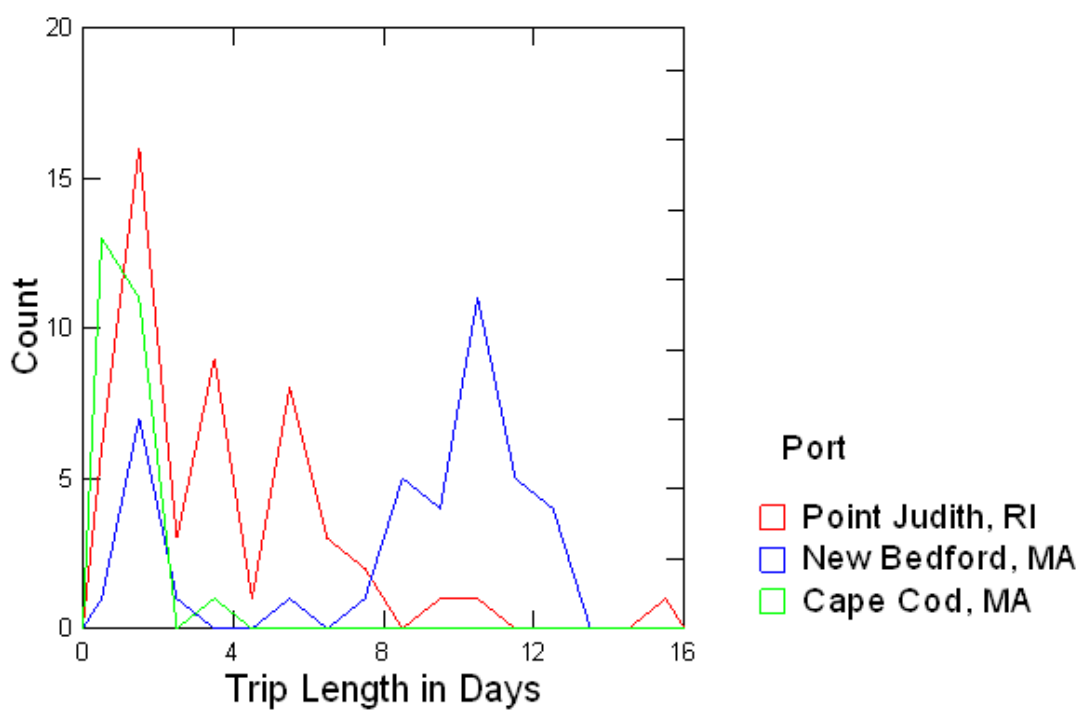

Figure 7. Histogram of the frequencies of trip length in days reported by the fishermen interviewed comparing the three ports studied

\subsubsection{Permit type}

The majority of fishermen interviewed (91\%) fished on boats with federal

permits. The frequency of boats with federal permits was similar across all ports $\left(\chi^{2}\right.$ $(2)=0.25, p>0.05)$. Table 13 shows frequencies for presence of federal permits on boats in the overall sample and in each port studied.

Table 13. Frequencies for presence of federal permits on boats in the overall sample and in each port studied

\begin{tabular}{lllll}
\hline & New Bedford & Point Judith & Cape Cod & All ports \\
\hline Federal permit & $38(93 \%)$ & $44(90 \%)$ & $23(92 \%)$ & $105(91 \%)$ \\
State permit only & $3(7 \%)$ & $5(10 \%)$ & $2(8 \%)$ & $10(9 \%)$ \\
Total & $41(100 \%)$ & $49^{*}(100 \%)$ & $25(100 \%)$ & $115^{*}(100 \%)$ \\
\hline
\end{tabular}

${ }^{*}$ Total sample size for this question is different from expected because of missing cases for Point Judith

\subsubsection{Annual income from fishing}

Annual income from fishing was assessed using the latest census categories.

Categories were coded on a scale from one to sixteen. The average income among the total sample was $10.9(\mathrm{SD}=3.496)$, which falls between the categories [50,000- 
59,999] and [60,000-74,999] U.S. dollars a year. New Bedford presented the highest levels of income with an average of $12.8(\mathrm{SD}=3.137)$, which falls between the categories [75,000-99,999] and [100,000-124,999] U.S. dollars a year. An analysis of variance revealed that fishermen from New Bedford have a significant higher annual income when compared to the other ports studied, $F(2,111)=11.9, p<0.001$. Post hoc t tests showed statistically significant differences between New Bedford and both Point Judith and Cape Cod $(t(89)=-4.9, p<0.001$, pooled variance, and $t(61)=2.7$, $p<0.001$, pooled variance, respectively). Table 14 shows the categories used for measuring annual income and their respective codes and table 15 shows the results of basic statistical analyses for each port and all ports combined with regard to levels of annual income from fishing (in categories). Figure 8 shows a visual representation of the distribution of income categories by port.

\begin{tabular}{ll}
\multicolumn{2}{l}{$\begin{array}{l}\text { Table 14 Categories for annual income } \\
\text { (based on Census 2010) and respective } \\
\text { codes }\end{array}$} \\
\hline Code & Category \\
\hline 1 & Under 10,000 \\
2 & $10,000-14,999$ \\
3 & $15,000-19,999$ \\
4 & $20,000-24,999$ \\
5 & $25,000-29,999$ \\
6 & $30,000-34,999$ \\
7 & $35,000-39,999$ \\
8 & $40,000-44,999$ \\
9 & $45,000-49,999$ \\
10 & $50,000-59,999$ \\
11 & $60,000-74,999$ \\
12 & $75,000-99,999$ \\
13 & $100,000-124,999$ \\
14 & $125,000-149,999$ \\
15 & $150,000-199,999$ \\
16 & Over 200,000 \\
\hline
\end{tabular}


Table 15. Results of basic statistics for annual income (in categories) for each port and all three ports combined

\begin{tabular}{lllll}
\hline & New Bedford & Point Judith & Cape Cod & All ports \\
\hline Minimum & 5 & 2 & 4 & 2 \\
Maximum & 16 & 16 & 16 & 16 \\
Median & 14 & 10 & 10 & 11.5 \\
Mean & 12.825 & 9.549 & 10.522 & 10.895 \\
SD & 3.137 & 3.12 & 3.475 & 3.496 \\
$\mathbf{N}$ & $\mathbf{4 0}^{*}$ & $\mathbf{5 1}$ & $\mathbf{2 3}^{*}$ & $\mathbf{1 1 4}^{*}$ \\
\hline
\end{tabular}

${ }^{*}$ Total sample size for this question is different from expected because three interviewees chose not to answer this question

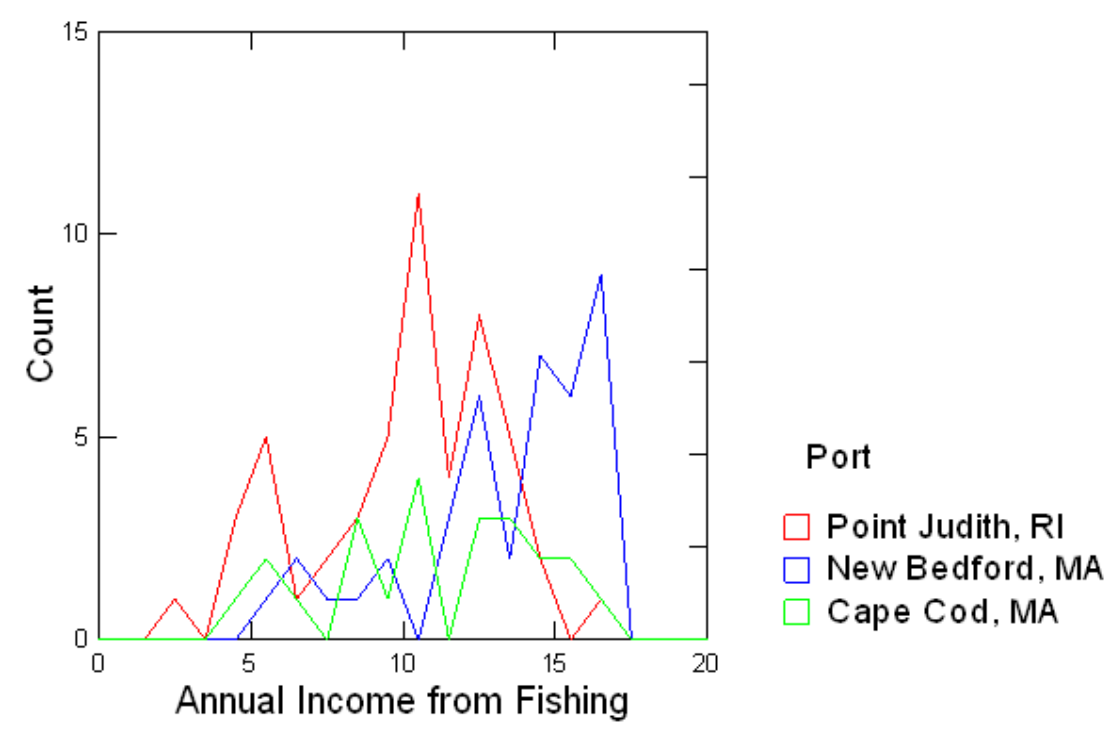

Figure 8. Histogram comparing the distribution of income categories across the three ports studied

\subsubsection{Gear types}

Overall, the most common primary gear type in the sample was trawl (dragger) (42\%) followed by dredges (21\%). Other primary gear types found in the overall sample can be seen in table 16 . 


\begin{tabular}{ll}
$\begin{array}{l}\text { Table 16. Frequencies for primary gear type found in } \\
\text { the overall sample }\end{array}$ & Frequency $^{*}$ \\
\hline Primary gear type & $49(42 \%)$ \\
\hline Trawl (dragger) & $25(21 \%)$ \\
Dredge & $17(14 \%)$ \\
Lobster traps & $13(11 \%)$ \\
Gillnet & $6(5 \%)$ \\
Rod \& Reel & $6(5 \%)$ \\
Hydraulic dredge & $1(1 \%)$ \\
Lobster and fish traps & $117(100 \%)$ \\
Total &
\end{tabular}

"Percentages are approximated

In New Bedford, the most common primary gear type found was dredge (46\%) followed by trawl (34\%). In Point Judith the most common primary gear type found was trawl (67\%) followed by lobster traps (25\%). In Cape Cod the most common primary gear type was gillnet (32\%) followed by rod \& reel (24\%). All primary gear types and their frequencies for New Bedford, Point Judith, and Cape Cod can be seen in tables 17,18 , and 19 respectively.

Table 17. Frequencies for primary gear type found in New Bedford

\begin{tabular}{ll}
\hline Primary gear type & Frequency $^{*}$ \\
\hline Dredge & $19(46 \%)$ \\
Trawl (dragger) & $14(34 \%)$ \\
Hydraulic dredge & $3(7 \%)$ \\
Gillnet & $2(5 \%)$ \\
Lobster traps & $2(5 \%)$ \\
Lobster and fish traps & $1(3 \%)$ \\
Total & $41(100 \%)$ \\
\hline
\end{tabular}

${ }^{*}$ Percentages are approximated 


\begin{tabular}{ll}
$\begin{array}{l}\text { Table 18. Frequencies for primary gear type found in } \\
\text { Point Judith }\end{array}$ & Frequency \\
\hline Primary gear type & $34(67 \%)$ \\
\hline Trawl (dragger) & $13(25 \%)$ \\
Lobster traps & $3(6 \%)$ \\
Gillnet & $1(2 \%)$ \\
Dredge & $51(100 \%)$ \\
Total & \\
\hline${ }^{*}$ Percentages are approximated & \\
Table 19. Frequencies for primary gear type found in \\
Cape Cod
\end{tabular}

${ }^{*}$ Percentages are approximated

The majority of fishermen in the overall sample (64\%) did not make use of any secondary gear types. The same pattern was observed for New Bedford (71\%) and for Point Judith (69\%). In Cape Cod the majority (56\%) of fishermen interviewed made use of secondary gear type(s). Results of comparisons across ports, however, did not show statistically significant differences $\left(\chi^{2}(2)=5.63, p>0.05\right)$. Tables $20,21,22$, and 23 show the secondary gear types and their frequencies found in the overall sample, in New Bedford, Point Judith, and in Cape Cod respectively. 
Table 20. Frequencies of secondary gear types

found in the overall sample of fishermen who used more than one gear type

\begin{tabular}{ll}
\hline Secondary gear type & Frequency \\
\hline Dredge & $10(24 \%)$ \\
Trawl (dragger) & $9(21 \%)$ \\
Rod \& Reel & $9(21 \%)$ \\
Lobster traps & $5(12 \%)$ \\
Long line & $4(9 \%)$ \\
Fish pots & $2(4 \%)$ \\
Gillnet & $2(4 \%)$ \\
Other nets (trawl) & $2(4 \%)$ \\
Harpoon & $2(4 \%)$ \\
Hand line & $1(2 \%)$ \\
Hydraulic dredge & $1(2 \%)$ \\
Total & $47^{*}$ \\
\hline${ }^{*}$ Total amount does not equal total amount of fishermen \\
with secondary gear types (n=42) and percentages do not \\
sum one hundred percent because five interviewees \\
listed more than one secondary gear type. Percentages \\
are approximated
\end{tabular}

Table 21. Frequencies for secondary gear type used by fishermen who used more than one gear type in New Bedford

\begin{tabular}{ll}
\hline Secondary gear type & Frequency \\
\hline Dredge & $7(58 \%)$ \\
Trawl (dragger) & $4(33 \%)$ \\
Lobster traps & $1(8 \%)$ \\
Total & $12(100 \%)^{*}$ \\
\hline
\end{tabular}

"None of the fishermen who used secondary gears in New Bedford listed more than one gear type. Percentages are approximated 
Table 22. Frequencies of secondary gear types

used by fishermen who used more than one gear type in Point Judith

\begin{tabular}{ll}
\hline Secondary gear type & Frequency \\
\hline Rod \& Reel & $4(25 \%)$ \\
Dredge & $3(19 \%)$ \\
Trawl (dragger) & $2(12 \%)$ \\
Lobster traps & $2(12 \%)$ \\
Gillnet & $2(12 \%)$ \\
Fish pots & $2(12 \%)$ \\
Other nets (trawl) & $2(12 \%)$ \\
Total & $17^{*}$ \\
\hline $\begin{array}{l}\text { *Total amount does not equal total amount of fishermen } \\
\text { with secondary gear types (n=16) and percentages do not } \\
\text { sum one hundred percent because one interviewee listed } \\
\text { more than one secondary gear type. Percentages are } \\
\text { approximated }\end{array}$
\end{tabular}

Table 23. Frequencies of secondary gear types used by fishermen who used more than one gear type in Cape Cod

\begin{tabular}{ll}
\hline Secondary gear type & Frequency \\
\hline Rod \& Reel & $5(25 \%)$ \\
Long line & $4(19 \%)$ \\
Trawl (dragger) & $3(12 \%)$ \\
Lobster traps & $2(12 \%)$ \\
Harpoon & $2(12 \%)$ \\
Hydraulic dredge & $1(12 \%)$ \\
Hand line & $1(12 \%)$ \\
Total & $18 *$ \\
\hline * Total amount does not equal total amount of fishermen \\
$\begin{array}{l}\text { with secondary gear types (n=14) and percentages do not } \\
\text { sum one hundred percent because four interviewees } \\
\text { listed more than one secondary gear type. Percentages } \\
\text { are approximated }\end{array}$
\end{tabular}

The most common combination of primary and secondary gear in the overall sample was trawl (draggers) and dredges (38\%). All combinations found for the overall sample can be found in Appendix VI. Tables 24 through 26 show the combinations of primary and secondary gear for New Bedford, Point Judith, and Cape Cod respectively. 
Table 24. All combinations of primary (rows) and secondary (columns) gear types and respective frequencies of occurrence found for fishermen who used multiple gear types in New Bedford

\begin{tabular}{l|lcll}
\hline \multicolumn{5}{c}{ Secondary gear types } \\
Primary gear & Trawl & Traps & Dredge & Total \\
\hline Trawl & - & - & 7 & 7 \\
Dredge & 4 & 1 & - & 5 \\
Total & $\mathbf{4}$ & $\mathbf{1}$ & $\mathbf{7}$ & $\mathbf{1 2}$ \\
\hline
\end{tabular}

Table 25. All combinations of primary (rows) and secondary (columns) gear types and respective frequencies of occurrence found for fishermen who used multiple gear types in Point Judith

\begin{tabular}{|c|c|c|c|c|c|c|c|c|c|}
\hline \multicolumn{10}{|c|}{ Secondary gear types } \\
\hline $\begin{array}{l}\text { Primary } \\
\text { gear } \\
\text { types }\end{array}$ & Trawl & $\begin{array}{l}\text { Lobster } \\
\text { traps }\end{array}$ & Dredge & Gillnet & $\begin{array}{l}\text { Fish } \\
\text { pots }\end{array}$ & $\begin{array}{l}\text { Rod } \\
\& \\
\text { Reel }\end{array}$ & $\begin{array}{l}\text { Traps } \\
\text { and } \\
\text { Rod \& } \\
\text { Reel }\end{array}$ & $\begin{array}{l}\text { Other } \\
\text { nets } \\
\text { (trawl) }\end{array}$ & Total \\
\hline Trawl & - & - & 3 & - & - & 1 & - & 2 & 6 \\
\hline Traps & - & - & - & 2 & 2 & 2 & - & - & 6 \\
\hline Dredge & 1 & - & - & - & - & - & - & - & 1 \\
\hline Gillnet & 1 & 1 & - & - & - & - & 1 & - & 3 \\
\hline Total & 2 & 1 & 3 & 2 & 2 & 3 & 1 & 2 & 16 \\
\hline
\end{tabular}

Table 26. All combinations of primary (rows) and secondary (columns) gear types and respective frequencies of occurrence found for fishermen who used multiple gear types in Cape Cod

\begin{tabular}{|c|c|c|c|c|c|c|c|c|c|c|c|c|}
\hline \multicolumn{13}{|c|}{ Secondary gear types } \\
\hline $\begin{array}{l}\text { Primary } \\
\text { gear } \\
\text { types }\end{array}$ & Trawl & $\begin{array}{l}\text { Lobster } \\
\text { traps }\end{array}$ & $\begin{array}{l}\text { Long } \\
\text { line }\end{array}$ & $\begin{array}{l}\text { Rod } \\
\& \\
\text { Reel }\end{array}$ & $\begin{array}{l}\text { Hyd. } \\
\text { dredge }\end{array}$ & $\begin{array}{l}\text { Long } \\
\text { line and } \\
\text { trawl }\end{array}$ & $\begin{array}{l}\text { Long } \\
\text { line } \\
\text { and } \\
\text { R\&R }\end{array}$ & $\begin{array}{l}\text { Lobster } \\
\text { traps and } \\
\text { harpoon }\end{array}$ & Harpoon & $\begin{array}{l}\text { Hand } \\
\text { line }\end{array}$ & $\begin{array}{l}\text { R\&R } \\
\text { and } \\
\text { trawl }\end{array}$ & Total \\
\hline $\begin{array}{l}\text { Lobster } \\
\text { traps }\end{array}$ & - & - & - & - & - & - & - & - & - & - & 1 & 1 \\
\hline Dredge & 1 & 1 & - & - & 1 & - & - & - & - & - & - & 3 \\
\hline Gillnet & - & - & 2 & 3 & - & 1 & 1 & - & - & - & - & 7 \\
\hline $\begin{array}{l}\text { Rod \& } \\
\text { Reel }\end{array}$ & - & - & - & - & - & - & - & 1 & 1 & 1 & - & 3 \\
\hline Total & 1 & 1 & 2 & 3 & 1 & 1 & 1 & 1 & 1 & 1 & 1 & 14 \\
\hline
\end{tabular}

\subsubsection{Sector affiliation}

Out of the total fishermen asked if their boats belonged to a sector $\left(n=98^{16}\right)$ about half of them (47\%) had an affiliation with a fishery sector, and half (50\%) did

\footnotetext{
${ }^{16}$ Total sample size is different because this question was not asked during the first ten interviews in Point Judith and there are seven missing cases for that port and one missing case for Cape Cod regarding this specific question.
} 
not have an affiliation with a fishery sector (3\% did not know). In New Bedford and Cape Cod the majority of fishermen interviewed did not belong to a sector (66 and 58\% respectively). In Point Judith the majority of fishermen who responded to this question (67\%) belonged to a sector. The differences observed were statistically significant $\left(\chi^{2}(2)=11.24, p<0.01\right)$.

\subsubsection{Species targeted}

The overall average number of primary species targeted mentioned by the fishermen in the sample was 2.8 ( $\mathrm{SD}=1.928)$. The highest average observed for total amount of target species was in Point Judith $(\mathrm{M}=3.4, \mathrm{SD}=2.148)$. Average number of target species for New Bedford and Cape Cod were $2.1(\mathrm{SD}=1.584)$ and $2.6(\mathrm{SD}=$ 1.557), respectively. Results of an analysis of variance among ports comparing total number of target species mentioned by fishermen were statistically significant, $F(2$, $114)=6.137, p<0.01$. Post hoc $t$ test analyses show that the only statistically significant relationship existed between Point Judith and New Bedford $(t(90)=3.304$, $p<0.01$, pooled variance).

The species most frequently mentioned overall as primary targets, in terms of volume, were scallops (23\%) and squid (17\%). Although the response with the highest frequency with regard to the existence of secondary principal target species was 'none' (17\%), the two species most frequently mentioned as secondary targets, in terms of volume, were fluke and monkfish (both with 10\%). In New Bedford, the most frequently targeted primary species was scallops (44\%). The second most important primary target species in New Bedford was flounder (10\%). The most frequent answer 
regarding secondary species targeted in New Bedford was “none” (24\%). Monkfish was the species with the highest frequency of response (22\%) among the fishermen who targeted a secondary species. In Point Judith the most frequently mentioned primary target species was squid (37\%) followed by scup (15\%). Fluke (24\%) and scup (18\%) were the species most frequently mentioned as secondary target species in terms of volume. Only one fisherman in Point Judith did not have a secondary target species. In Cape Cod the primary target species most frequently mentioned were scallops (20\%) and dogfish (16\%). The most frequent response among Cape Cod fishermen with regard to the existence of a secondary target species was 'none' (28\%) and the most common secondary target species mentioned was tuna (24\%). Tables with all species targeted and their frequencies by ports can be seen in Appendix VII.

\subsubsection{Job satisfaction variables}

A factor analysis with varimax rotation using the nine job satisfaction questions derived from the scales developed by Pollnac and Poggie (1988) and presented in Chapter III was used to reduce the data into three components. Careful examination of the scree plot and a cut-off Eigenvalue of one were used as criteria for selecting the number of components. The results reflect groupings of variables that are similar to those found by Pollnac and Poggie $(1988,2006)$. The components Basic Needs, Social and Psychological Needs, and Self-Actualization can be identified using the highest factor scores for each variable, with the exception of the variable “opportunity to be your own boss,” which was found along with variables characterized by the component Social and Psychological Needs as opposed to the 
component Self-Actualization where it had been previously grouped. Table 27 presents the results for the factor analysis of job satisfaction variables. Factor loadings above 0.40 were considered significant.

\begin{tabular}{llll}
$\begin{array}{l}\text { Table 27. Results of a factor analysis involving the nine job satisfaction variables (Varimax } \\
\text { rotation) }\end{array}$ & $\begin{array}{l}\text { Social \& } \\
\text { Psychological } \\
\text { Needs }\end{array}$ & $\begin{array}{l}\text { Self- } \\
\text { Actualization }\end{array}$ & Basic Needs \\
\hline Actual earnings & -0.057 & -0.076 & $\mathbf{0 . 8 5 9}$ \\
Predictability of earnings & 0.199 & 0.14 & $\mathbf{0 . 7 5 9}$ \\
Job safety & 0.277 & -0.024 & $\mathbf{0 . 4 9 9}$ \\
Time away from home & $\mathbf{0 . 6 7 9}$ & 0.055 & 0.167 \\
Physical fatigue & $\mathbf{0 . 7 3 6}$ & 0.01 & -0.024 \\
Healthfulness of job & $\mathbf{0 . 7 5 6}$ & 0.042 & 0.125 \\
Adventure of the job & 0.101 & $\mathbf{0 . 9 2 0}$ & 0.012 \\
Challenge of the job & 0.06 & $\mathbf{0 . 9 0 7}$ & 0.01 \\
Opportunity to be own boss & $\mathbf{0 . 5 0 4}$ & 0.205 & 0.266 \\
\hline Eigenvalues & 2.555 & 1.624 & 1.201 \\
Total variance explained (\%) & 21.8 & 19.4 & 18.6 \\
\hline
\end{tabular}

\subsubsection{Job satisfaction and ports}

The three ports studied were compared on their levels of job satisfaction for each of the three components. The result of an analysis of variance with regard to Social and Psychological Needs was statistically significant when New Bedford, Point Judith, and Cape Cod were compared, $F(2,114)=3.553, p<0.05$. Post hoc t test analyses revealed that the only significant difference existed between New Bedford $(\mathrm{M}=-.299)$ and Cape Cod $(\mathrm{M}=0.338)(t(64)=-2.6, p<0.05$, pooled variance $)$. The job satisfaction components Self-Actualization and Basic Needs did not show statistically significant results when compared across the three ports $(F(2,114)=.63$, $p>0.05$, and $F(2,114)=1.32, p>0.05)$. 


\subsubsection{Job satisfaction and gear types}

Levels of job satisfaction were also compared among different primary gear types. In order to accommodate the diversity of gears found in the sample and to avoid small sample sizes by gear type, gears were grouped into the three categories multispecies, traps, and shellfish gear. The multispecies category encompasses the gear types: trawl, gillnet, and rod \& reel; the category traps includes lobster and fish traps; and the category shellfish groups the gear types dredges and hydraulic dredges.

Table 28 shows the distribution of the transformed gear categories for each port.

Table 28. Distribution of gear types by transformed category by port

\begin{tabular}{lllll}
\hline & Multispecies gear & Traps & Shellfish gear & Total \\
\hline New Bedford & $16(39 \%)$ & $3(7 \%)$ & $22(54 \%)$ & $\mathbf{4 1}(\mathbf{1 0 0} \%)$ \\
Point Judith & $37(73 \%)$ & $13(25 \%)$ & $1(2 \%)$ & $\mathbf{5 1}(\mathbf{1 0 0} \%)$ \\
Cape Cod & $15(60 \%)$ & $2(8 \%)$ & $8(32 \%)$ & $\mathbf{2 5 ( 1 0 0 \% )}$ \\
Total & $\mathbf{6 8}(\mathbf{5 8 \% )}$ & $\mathbf{1 8}(\mathbf{1 5 \% )}$ & $\mathbf{3 1}(\mathbf{2 7 \% )}$ & $\mathbf{1 1 7}(\mathbf{1 0 0 \% )}$ \\
\hline
\end{tabular}

Analyses comparing the different gear categories above with regard to levels of job satisfaction showed statistically significant results only for the component Basic Needs, $F(2,114)=15.8, p<0.001$. Post hoc $t$ test analyses for the component Basic Needs showed statistically significant differences between the categories multispecies $(\mathrm{M}=-.24)$ and shellfish gear $(\mathrm{M}=.77)$, and between the categories traps $(\mathrm{M}=-.41)$ and shellfish gear $(t(87.9)=-6.02, p<0.001$, separate variance, and $t(47)=-5.8$, $p<0.001$, pooled variance, respectively).

\subsubsection{Additional job satisfaction questions}

As part of the job satisfaction measure, fishermen were asked about their willingness to become a fisherman if they had their lives to live over and whether they 
would advise a young person to become a fisherman. Overall, the majority of responses (60\%) with regard to advising a young person to enter the occupation of fishing was negative (30\% positive and $10 \%$ 'maybe' or 'depends') $\left(\chi^{2}(2)=43.74\right.$, $p<0.001)$. When asked about their willingness to become a fisherman if they had their lives to live over the majority of responses (69\%) was positive (25\% negative and 6\% 'maybe' or 'depends') $\left(\chi^{2}(2)=74.05, p<0.001\right)$. Chi square analyses comparing the three ports studied with regard to negative versus positive responses were not statistically significant for either one of the job satisfaction questions. The same was found when primary gear type categories were compared. Tables showing frequencies of responses for each port and primary gear type can be seen in Appendix VIII.

\subsubsection{Resilience variables}

The twelve resilience variables developed by Marshall and Marshall (2007) and presented in the previous chapter were reduced into three distinct components using factor analysis with varimax rotation. Careful examination of the scree plot and a cut-off Eigenvalue of one were used as criteria for selecting the number of components. These results differ from the findings by Marshall and Marshall (2007), in which the variables were reduced into four components. The three components were named Ability to Cope, Perception of Risk, and Adaptation to Change according to the characteristics of the variables with the highest factor loadings for each component. Factor loadings above 0.40 were considered significant. Table 29 shows the factor loadings for all resilience variables and highlights the highest loadings for each variable that contribute significantly to the three components listed. 
Table 29. Results of a factor analysis involving the twelve resilience variables (Varimax rotation)

\begin{tabular}{llll}
\hline & $\begin{array}{l}\text { Ability to } \\
\text { Cope }\end{array}$ & $\begin{array}{l}\text { Perception } \\
\text { of Risk }\end{array}$ & $\begin{array}{l}\text { Adaptation } \\
\text { to Change }\end{array}$ \\
\hline I have many options available if I decide to no longer be a fisherman & 0.108 & $\mathbf{0 . 7 1 2}$ & 0.005 \\
I am confident I could get work elsewhere if I needed to & 0.199 & $\mathbf{0 . 7 2 3}$ & 0.151 \\
I am too young to retire and too old to find work elsewhere & 0.199 & $\mathbf{0 . 7 4 8}$ & -0.129 \\
I would be nervous trying something else & -0.253 & $\mathbf{0 . 5 6 9}$ & 0.404 \\
I can cope with small changes in the industry & 0.075 & -0.167 & $\mathbf{0 . 7 5 7}$ \\
I have planned for my financial security & $\mathbf{0 . 6 9 3}$ & 0.039 & -0.084 \\
Every time there is a change I plan a way to make it work for me & 0.428 & 0.097 & $\mathbf{0 . 4 7 3}$ \\
I am more likely to adapt to change compared to other fishermen & 0.314 & 0.347 & $\mathbf{0 . 4 1 5}$ \\
I do not think I am competitive enough to survive much longer & $\mathbf{0 . 6 2 2}$ & -0.005 & 0.316 \\
I am confident things will turn out well for me & $\mathbf{0 . 7 8 9}$ & 0.280 & -0.036 \\
If there are any more changes I will not survive much longer & $\mathbf{0 . 5 3 3}$ & 0.121 & 0.269 \\
I am interested in learning new skills outside of the industry & 0.041 & $\mathbf{0 . 4 7 2}$ & -0.317 \\
\hline Eigenvalues & 3.144 & 1.762 & 1.151 \\
Total variance explained (\%) & 18.5 & 20.0 & 12.1 \\
\hline
\end{tabular}

Although the number of components differs, the groupings of the resilience variables found in the present study are similar to the results found by Marshall and Marshall (2007). The only differences are with regard to the variables "I can cope with small changes in the industry,” which in Marshall and Marshall (2007) was grouped along with the variables included in the component Perception of Risk; "I have planned for my financial security," which was then grouped with the variables belonging to the component Adaptation to Change; and the variable "I am interested in learning new skills outside the industry,” which formed a single variable component in the study by Marshall and Marshall (2007).

\subsubsection{Resilience and ports}

The three ports studied were compared on their levels of resilience for each of the three components developed. All ports presented similar mean values with regard to their levels of resilience for each of the components and none of the results for 
analyses of variance were statistically significant. Table 30 shows mean standardized values for the resilience components across the three ports.

Table 30. Mean standardized values for the three resilience components for each port studied

\begin{tabular}{llll}
\hline & Ability to Cope & Perception of Risk & $\begin{array}{l}\text { Adaptation to } \\
\text { Change }\end{array}$ \\
\hline New Bedford & 0.01 & 0.08 & 0.05 \\
Point Judith & -0.02 & 0.01 & -0.08 \\
Cape Cod & 0.03 & -0.14 & 0.07 \\
\hline
\end{tabular}

\subsubsection{Resilience and gear types}

Levels of resilience for each of the three components were compared across the three categories of primary gear type. Results of an analysis of variance shows that for the component Ability to Cope differences between gear types were statistically significant, $F(2,113)=5.91, p<0.01$. Post hoc t test analyses showed statistically significant differences between multispecies and shellfish gear $(t(96)=-3.4, p=0.001$, pooled variance) and between traps and shellfish gear $(t(47)=-2.7, p=0.01$, pooled variance).

Analyses of variance comparing the three gear categories with regard to their levels of resilience for the component Perception of Risk showed a statistically significant result, $F(2,113)=2.84, p<0.05$ (one tail) ${ }^{17}$. Post hoc $t$ test analyses showed that multispecies gear fishermen scored lower than shellfish gear $(t(96)=-1.88$, $p<0.05$ (one tail), pooled variance) and trap gear $(t(83)=-1.9, p<0.05$ (one tail), pooled variance). Analyses for the component Adaptation to Change were not statistically significant. Table 31 shows mean standardized values for the components Ability to Cope and Perception of Risk for each gear type.

\footnotetext{
${ }^{17}$ One-tail statistics were used because it has been hypothesized in the present study that multispecies fishermen are expected to be the most affected by impacts of management on the diversity of species exploited, which consequently affects their levels of resilience. Therefore, the analyses conducted tested the statistical significance in the direction of interest.
} 
Table 31. Mean standardized values for the components Ability to Cope and Perception of Risk for each transformed gear type

\begin{tabular}{llll}
\hline & Shellfish & Multispecies & Traps \\
\hline Ability to Cope & 0.50 & -0.17 & -0.23 \\
Perception of Risk & 0.21 & -0.18 & 0.32 \\
\hline
\end{tabular}

Comparisons between fishermen who used multiple gear types and single gear users with regard to their levels of resilience showed statistically significant results for the component Ability to Cope $(t(114)=2.2, p<0.05$, pooled variance). Fishermen who reported the use of more than one type of gear presented a lower mean standardized value $(M=-0.27)$ when compared to single gear users $(M=0.15)$ for this component. Comparisons involving the other resilience components and multiple gear type users were not statistically significant.

\subsubsection{Correlations between variables}

Pearson Correlation analyses were used to understand relationships between the various independent and dependent variables. A Principal Components analysis with varimax rotation including demographic and fishing related variables was conducted previously in order to reduce these variables into components that were then correlated with the job satisfaction and resilience components. Although, based on a cut-off point of one for the Eigenvalues, six components would have been accepted, a thorough examination of the resulting groups of variables suggested that five components yielded a more appropriate aggregation. The scree plot supported the choice of five components. The first component was named Fishing Occupation Attributes and it includes the variables average crew size, presence of federal license 
on the boat, trip length in days, lack of presence of occupations besides fishing, and annual income from fishing. The second component was named Age and Experience and it includes the variables fishing experience, fishing experience in port, experience on current boat, and age. The third component was named Familial Involvement in Fishing and it includes the variables number of relatives fishing, number of relatives fishing on the same boat, and number of generations involved in fishing. The fourth component named Number of Boats is composed of a single variable number of boats fished on since began fishing. The variable experience on current boat scored relatively high (and negatively) with this component as well, but it presented a stronger correlation with the component Age and Experience. The fifth and last component was named Gear Use and Education and it includes the variables multiple gear use and education. Table 32 shows the results for the principal component analysis for demographic and fishing related variables and their respective factor loadings. Factor loadings above 0.40 were considered significant and are highlighted in the table showing the groupings for the five different components. 
Table 32. Results of a factor analysis involving demographic and fishing related variables (Varimax rotation)

\begin{tabular}{llllll} 
& $\begin{array}{l}\text { Fishing } \\
\text { Occupation } \\
\text { Attributes }\end{array}$ & $\begin{array}{l}\text { Age and } \\
\text { Experience }\end{array}$ & $\begin{array}{l}\text { Familial } \\
\text { Involvement } \\
\text { in Fishing }\end{array}$ & $\begin{array}{l}\text { Number } \\
\text { of Boats }\end{array}$ & $\begin{array}{l}\text { Gear Use } \\
\text { and } \\
\text { Education }\end{array}$ \\
\hline Average crew size & $\mathbf{0 . 8 6 9}$ & 0.161 & 0.111 & 0.170 & -0.043 \\
Federal license & $\mathbf{0 . 4 9 8}$ & 0.144 & 0.174 & -0.142 & -0.119 \\
Multiple gear use & -0.080 & -0.068 & -0.191 & 0.318 & $\mathbf{0 . 7 2 4}$ \\
Trip length in days & $\mathbf{0 . 8 0 5}$ & 0.165 & 0.093 & 0.167 & -0.236 \\
Fishing experience in years & -0.093 & $\mathbf{- 0 . 9 1 2}$ & 0.024 & 0.198 & -0.021 \\
Fishing experience in port in years & -0.138 & $\mathbf{- 0 . 7 9 6}$ & 0.033 & -0.041 & -0.238 \\
Experience on current boat in years & 0.020 & $\mathbf{- 0 . 6 2 5}$ & 0.058 & -0.568 & 0.181 \\
Age in years & -0.111 & $\mathbf{- 0 . 8 3 9}$ & -0.142 & 0.063 & 0.089 \\
Education in years & -0.302 & 0.208 & 0.162 & -0.319 & $\mathbf{0 . 6 4 3}$ \\
N of boats fished since began fishing & 0.108 & -0.151 & 0.113 & $\mathbf{0 . 8 3 1}$ & 0.128 \\
N of relatives currently fishing & -0.068 & 0.058 & $\mathbf{0 . 8 1 5}$ & 0.096 & -0.058 \\
N of relatives fishing on the same boat & 0.124 & 0.086 & $\mathbf{0 . 6 5 4}$ & -0.098 & 0.185 \\
N of generations that fished & 0.200 & -0.123 & $\mathbf{0 . 7 4 6}$ & 0.083 & -0.222 \\
Current occupation besides fishing & $\mathbf{- 0 . 4 5 7}$ & 0.047 & 0.136 & 0.027 & 0.144 \\
Annual income from fishing & $\mathbf{0 . 7 7 0}$ & 0.016 & 0.145 & 0.038 & 0.256 \\
\hline Eigenvalues & 3.406 & 2.407 & 1.661 & 1.312 & 1.115 \\
Variance explained \% & $\mathbf{1 7 . 8}$ & 18.1 & 12.3 & 9.1 & 8.6 \\
\hline
\end{tabular}

* Although score exceeds the cut-off point for significance (0.4), this variable presented a higher score in the component Age and Experience

In order to investigate the relationships between the components created above and variables of job satisfaction and resilience in the studied sample, a Pearson Correlation analysis was used. Statistically significant correlations were found between the job satisfaction component Social and Psychological Needs and the components Fishing Occupation Attributes, Gear Use and Education, and the job satisfaction variables willingness to advise a young person to enter fishing and willingness to be a fisherman if had life to live over. The component Basic Needs was statistically significantly correlated with the resilience components Ability to Cope and Perception of Risk, as well as with the job satisfaction variable willingness to advise a young person to enter fishing. The resilience components Ability to Cope and Adaptation to Change were statistically significantly correlated with the job 
satisfaction variables willingness to advise a young person to enter fishing and willingness to be a fisherman if had life to live over respectively. A correlation between the two job satisfaction variables willingness to advise a young person to enter fishing and willingness to be a fisherman if had life to live over was also observed. Table 33 shows the correlation matrix between all the different components and highlights the statistically significant relationships. Figure 9 shows a heuristic model based on the statistically significant correlations between the different components. 
Table 33. Matrix of correlations between components of demographic and fishing related variables and components of job satisfaction and resilience

\begin{tabular}{|c|c|c|c|c|c|c|c|c|c|c|c|c|c|}
\hline & $\begin{array}{l}\text { Soc. \& } \\
\text { Psychol. } \\
\text { Needs }\end{array}$ & Self-Act. & $\begin{array}{l}\text { Basic } \\
\text { Needs }\end{array}$ & $\begin{array}{l}\text { Ability to } \\
\text { Cope }\end{array}$ & $\begin{array}{l}\text { Perception } \\
\text { of Risk }\end{array}$ & $\begin{array}{l}\text { Adaptation } \\
\text { to change }\end{array}$ & $\begin{array}{l}\text { Fishing } \\
\text { Attributes }\end{array}$ & Age \& Exp. & $\begin{array}{l}\text { Familial } \\
\text { Involvement }\end{array}$ & $\begin{array}{l}\mathrm{N} \text { of } \\
\text { Boats }\end{array}$ & $\begin{array}{l}\text { Gear \& } \\
\text { Education }\end{array}$ & $\begin{array}{l}\text { Advise } \\
\text { young }\end{array}$ & $\begin{array}{l}\text { Fish if } \\
\text { live life } \\
\text { over }\end{array}$ \\
\hline $\begin{array}{l}\text { Social \& } \\
\text { Psychological } \\
\text { Needs }\end{array}$ & 1.000 & & & & & & & & & & & & \\
\hline Self-Actualization & -0.061 & 1.000 & & & & & & & & & & & \\
\hline Basic Needs & -0.006 & -0.046 & 1.000 & & & & & & & & & & \\
\hline Ability to Cope & -0.008 & 0.118 & $0.524^{* * *}$ & 1.000 & & & & & & & & & \\
\hline Perception of Risk & -0.009 & 0.114 & $0.209^{*}$ & 0.047 & 1.000 & & & & & & & & \\
\hline $\begin{array}{l}\text { Adaptation to } \\
\text { Change }\end{array}$ & 0.179 & 0.120 & 0.057 & -0.018 & 0.034 & 1.000 & & & & & & & \\
\hline Fishing Attributes & $-0.254^{*}$ & 0.187 & 0.166 & 0.085 & -0.137 & -0.003 & 1.000 & & & & & & \\
\hline Age \& Experience & 0.003 & 0.022 & 0.102 & -0.048 & 0.179 & -0.116 & 0.000 & 1.000 & & & & & \\
\hline $\begin{array}{l}\text { Familial } \\
\text { Involvement }\end{array}$ & -0.079 & 0.002 & 0.071 & -0.053 & 0.063 & 0.067 & 0.000 & 0.000 & 1.000 & & & & \\
\hline $\mathrm{N}$ of boats & -0.108 & -0.065 & -0.190 & -0.139 & -0.017 & -0.109 & 0.000 & 0.000 & 0.000 & 1.000 & & & \\
\hline Gear \& Education & $0.296^{* *}$ & 0.126 & 0.086 & 0.119 & -0.031 & 0.061 & 0.000 & 0.000 & 0.000 & 0.000 & 1.000 & & \\
\hline Advise young & $0.231^{*}$ & 0.087 & $0.330^{* *}$ & $0.244^{*}$ & 0.137 & 0.172 & 0.092 & 0.054 & -0.036 & -0.082 & 0.070 & 1.000 & \\
\hline Fish if live life over & $0.256^{*}$ & 0.129 & 0.125 & 0.167 & -0.013 & $0.249^{*}$ & -0.033 & -0.174 & -0.072 & -0.028 & 0.118 & $0.422^{* * *}$ & 1.000 \\
\hline
\end{tabular}




\section{Fishing Occupation Attributes}

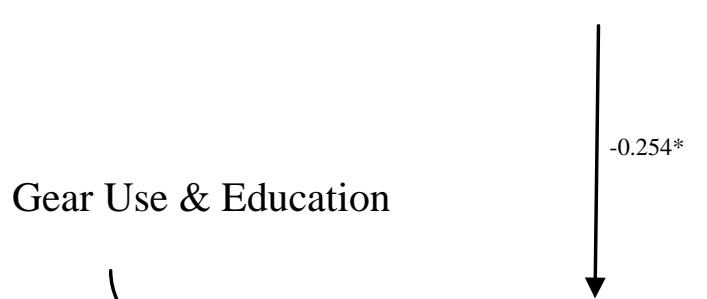

Social \& Psychological Needs
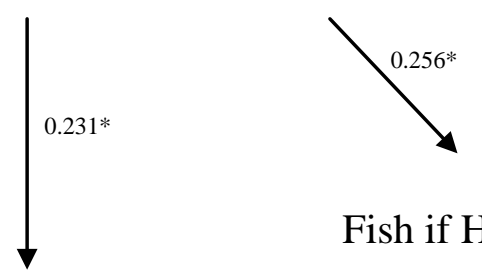

Fish if Had Life to Live Over

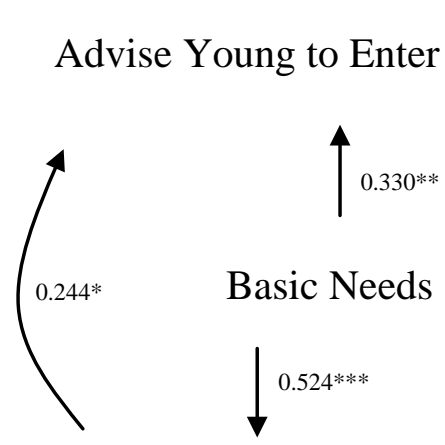

Ability to Cope

Perception of Risk

Figure 9. Heurist model reflecting the statistically significant correlations found between the components of demographic and fishing related variables and components of job satisfaction and resilience $\left(^{*} p<0.05\right.$, $\left.{ }^{* * *}<<0.01, \quad{ }^{* * *} p<0.001\right)$

\subsubsection{Changes in catch composition}

Fishermen in New Bedford and Point Judith ${ }^{18}$ were asked open-ended questions to assess their opinion with regard to potential changes in catch composition throughout their fishing experience. Overall, the majority of respondents (77.5\%) believed the composition of the catch to have changed throughout their experience $\left(\chi^{2}\right.$

\footnotetext{
${ }^{18}$ At the time the surveys were administered in Cape Cod, the supplemental questions concerning changes in flexibility coded on a Likert scale had been regarded as a best substitute for the open-ended questions described in this section.
} 
$(1)=24.2, p<0.001)$. Analyses of the two ports separately showed the same patterns observed for the overall sample. In New Bedford $(n=41), 76 \%$ of respondents believed catch composition to have changed $\left(\chi^{2}(1)=10.76, p=0.001\right)$ and in Point Judith $\left(n=39^{19}\right)$ fishermen with the same opinion accounted for $79 \%\left(\chi^{2}(1)=13.56\right.$, $p<0.001)$. Chi square analyses comparing the two ports did not show statistically significant results.

Fishermen were queried on the time they believed changes in catch composition to have begun to occur as well as reasons for changes mentioned. Overall, fishermen believed changes to have begun around 1998 (SD = 15.02). In order to investigate potential patterns of response by different age groups with regard to the time changes were believed to have begun to occur, the sample was dichotomized using the mean age for New Bedford and Point Judith combined as a cut-off point (M $=46, \mathrm{SD}=10.12)$. Fishermen younger than 46 years believed changes to have occurred around $1999(\mathrm{SD}=21.4)$ and fishermen older than 46 years believed changes to have occurred around 1998 (SD = 9.33). A comparison between the two age groups with regard to the average year changes have occurred was not statistically significant $(t(23)=-.39, p>0.05$, separate variance $)$.

Overall, the majority of fishermen interviewed (73\%) believed regulations to be the main reason for changes in catch composition. Other answers involved stock depletion or overfishing (11\%), market fluctuations (10\%), and climate change (2\%) ${ }^{20}$.

\footnotetext{
${ }^{19}$ Sample size in Point Judith is smaller than expected due to the fact that the first ten surveys administered in the port did not include this question and due to two cases for which data is missing.

${ }^{20}$ A portion of the answers given was idiosyncratic and failed to address the question asked.
} 


\subsection{Supplementary questions}

\subsubsection{Description of the sample}

A total of sixty-four fishermen from Point Judith $(n=30)$, New Bedford ( $n=10)$, and Cape Cod $\left(n=24^{21}\right)$ were asked supplementary questions aimed at investigating their opinion with regard to changes to their level of flexibility, in other words, changes to the ability of diversifying their fishing activity in terms of target species and gear type. The average age of the sample was 50 years $(\mathrm{SD}=11.5)$ and the average years of education was $12.5(\mathrm{SD}=2.02)$. The average fishing experience was 29.9 years $(\mathrm{SD}=10.32)$ with 24.6 years of experience in the current port $(\mathrm{SD}=$ 12.0). Table 34 shows results of basic statistics for age, education, and fishing experience for the overall sample.

Table 34. Results of basic statistics for age, education, and fishing experience for the supplementary questionnaire sample

\begin{tabular}{lllll}
\hline & Age & Education & $\begin{array}{l}\text { Fishing } \\
\text { Experience }\end{array}$ & $\begin{array}{l}\text { Experience in } \\
\text { Current Port }\end{array}$ \\
\hline Minimum & 20 & 6 & 3 & 0.5 \\
Maximum & 73 & 17 & 52 & 50 \\
Median & 51 & 12 & 31.5 & 25 \\
Mean & 50.078 & 12.547 & 29.875 & 24.602 \\
SD & 11.494 & 2.023 & 10.319 & 12.0 \\
N & $\mathbf{6 4}$ & $\mathbf{6 4}$ & $\mathbf{6 4}$ & $\mathbf{6 4}$ \\
\hline
\end{tabular}

The fishery position with the highest frequency in the sample was ‘captain/owner' ( $\mathrm{n}=28(44 \%))$, followed by 'captain’ $(\mathrm{n}=16(25 \%))$. Table 35 shows the frequencies for all fishery positions and figure 10 shows a visual representation of the distribution.

\footnotetext{
${ }^{21}$ One missing case
} 
Table 35. Frequencies for fishery positions in the supplementary questionnaire sample

\begin{tabular}{ll}
\hline Fishery Position & Frequency \\
\hline Captain/owner & $28(44 \%)$ \\
Captain & $16(25 \%)$ \\
Crew & $15(23 \%)$ \\
Owner & $3(5 \%)$ \\
Mate & $2(3 \%)$ \\
Total & $\mathbf{6 4}(\mathbf{1 0 0} \%)$ \\
\hline
\end{tabular}

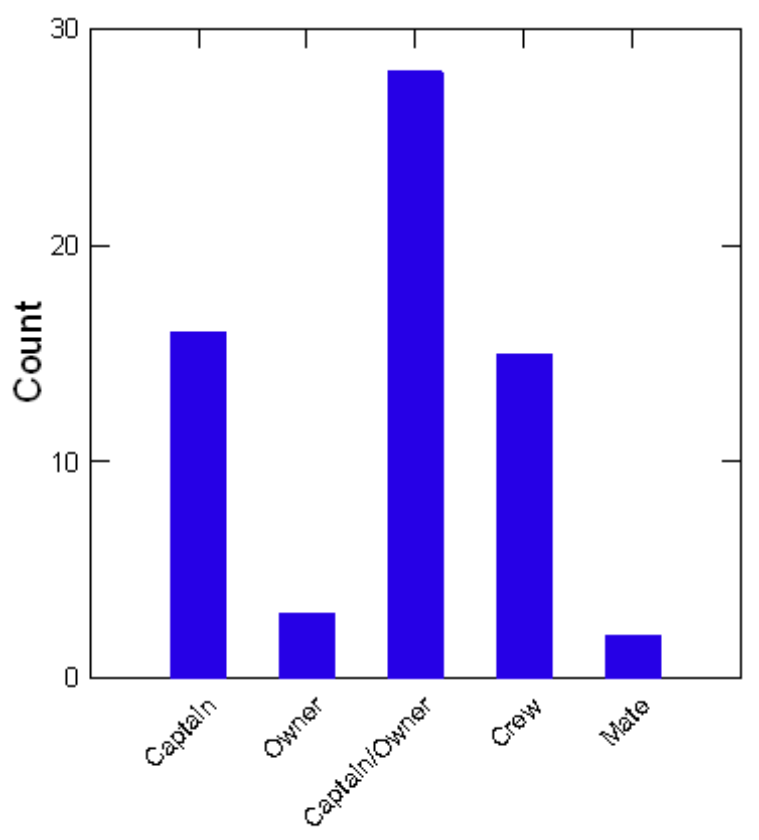

\section{Position on Boat}

Figure 10. Chart of the distribution of fishery positions found among fishermen in the supplementary questionnaire sample

Multispecies fishermen were the focus of the supplementary questionnaires especially in Point Judith and New Bedford and therefore constitute the majority of the gear types in the sample. Table 36 shows the distributions of all gear types found in the overall sample. 


\begin{tabular}{ll}
$\begin{array}{l}\text { Table 36. Frequencies of gear types used by the } \\
\text { overall sample of fishermen interviewed using } \\
\text { the supplementary questionnaire }\end{array}$ \\
\hline Gear type & Frequency \\
\hline Trawl (dragger) & $38(42 \%)$ \\
Gillnet & $13(14 \%)$ \\
Rod \& Reel & $12(13 \%)$ \\
Dredge & $9(10 \%)$ \\
Lobster traps & $5(5 \%)$ \\
Fish pots & $4(4 \%)$ \\
Hydraulic dredge & $3(3 \%)$ \\
Long line & $3(3 \%)$ \\
Harpoon & $2(2 \%)$ \\
Hand line & $1(1 \%)$ \\
Total & $90 *$ \\
\hline Total amount does not equal total amount of fishermen \\
in the sample (n=64) and percentages do not sum one \\
hundred percent because interviewees listed more than \\
one gear type. Percentages are approximated
\end{tabular}

Out of the sixty-one fishermen who were queried about their affiliation with a fishery sector, a statistically significant majority of $66 \%$ responded affirmatively $\left(\chi^{2}\right.$ (1) $=5.92, p<0.05)$.

The fishermen interviewed using the supplementary questionnaire listed a total of twenty-nine target species. The species with the highest frequency among responses was squid $(n=28)$, followed by fluke $(n=19)$, scup $(n=16)$ and groundfish in general $(n=14)$. A list of all species listed and their respective frequencies can be seen in Appendix IX.

\subsubsection{Flexibility questions}

Responses given by fishermen interviewed using the supplementary questionnaire with regard to their levels of flexibility today and when they first began fishing concerning the diversity of species they can exploit and the types of gear they 
can use were coded on a Likert scale ranging from one to fifteen. The two time periods were paralleled using paired sample t tests to compare the point in the scale where fishermen consider themselves to be today and where they were when they first began fishing. Results for differences between the two time periods were statistically significant both with regard to diversity of species and gear types, and in both cases mean levels of flexibility were perceived to be considerably higher when fishermen began to fish in comparison to the present time. Results of the paired sample tests comparing levels of perceived flexibility to exploit different species and to use different gear types are shown in tables 37 and 38, respectively.

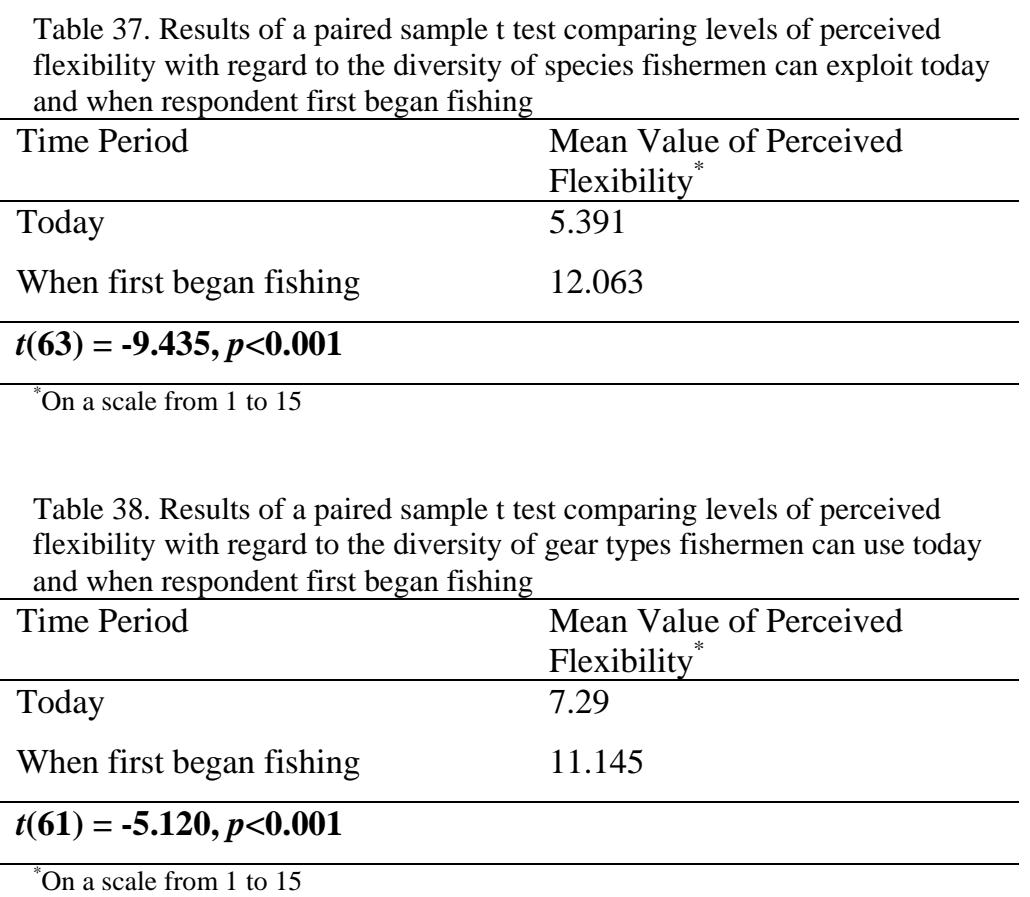

Fishermen were asked about the time period in which the perceived changes mentioned, if any, began to occur. The overall mean time period was 1993 (SD = 10.83). In order to test differences between generations with regard to the perceived mean time period of changes, the sample was dichotomized using the mean age ( $\mathrm{M}=$ 
$50)$ as the cut-off point. Fishermen who were younger than 50 years $(n=19)$ perceived changes to have occurred in the year 2000 on average (SD $=8.5)$ and fishermen who were older than 50 years old $(n=27)$ perceived changes to have occurred in 1988 on average ( $\mathrm{SD}=9.93$ ). Changes with regard to the flexibility to exploit different species and use multiple gear types maintained the same statistically significant patterns observed for the entire sample when tested for the two age groups separately (results can be seen in Appendix X).

Fishermen who mentioned changes with regard to their flexibility to exploit different species or use multiple gear types were also asked their opinion about the reasons behind the changes mentioned. A total of fifty-two fishermen in the sample responded to this question and $90 \%$ of them believed regulations to be the main reason for changes in flexibility. Other reasons mentioned more than once were overfishing or too many fishermen $(\mathrm{n}=5(9.6 \%))$, pressure from environmental groups $(\mathrm{n}=3(5.8 \%))$, and flawed science $(\mathrm{n}=3(5.8 \%))$. Table 39 shows all the different reasons believed by fishermen interviewed to have affected their flexibility to exploit different species and/or use multiple gear types. 
Table 39. Reasons believed by fishermen interviewed using the supplementary questionnaire to have influenced their flexibility to exploit different species and/or use multiple gear types

\begin{tabular}{ll}
\hline Reason & Frequency Mentioned \\
\hline Regulations & $47(90 \%)$ \\
Overfishing/too many fishermen & $5(9.6 \%)$ \\
Pressure from environmental groups & $3(5.8 \%)$ \\
Flawed science & $3(5.8 \%)$ \\
Too much paperwork & $1(1.9 \%)$ \\
Technology & $1(1.9 \%)$ \\
Outside investment (large corporations) & $1(1.9 \%)$ \\
Market changes & $1(1.9 \%)$ \\
Environmental changes & $1(1.9 \%)$ \\
Gear is more selective (positive change) & $1(1.9 \%)$ \\
Total & $\mathbf{6 4}{ }^{*}$ \\
\hline${ }^{*}$ Total amount of responses does not equal total amount of fishermen who responded to the question \\
(n = 52) and total percentage does not equal one hundred percent because some respondents stated \\
multiple reasons. The maximum amount of reasons per respondent was three and only one person \\
stated three different reasons.
\end{tabular}

\subsection{Landings data}

\subsubsection{Overall characteristics of the fleet}

A total number of 6,420 cases of landings by vessel were analyzed for the time period between 1994 and 2012 for vessels homeported in the ports of New Bedford (New Bedford $(n=2,983)$ and Fairhaven $(n=318)$ ), Point Judith $(n=1,670)$, and Cape Cod (Chatham $(n=1,138)$ and Provincetown $(n=311))$.

New Bedford was the port with the largest boats $(\mathrm{M}=75.8$ feet, $\mathrm{SD}=18.3)$, Point Judith was the port with the second largest fleet in terms of vessel size ( $\mathrm{M}=53.7$ feet, SD = 18.4), and Cape Cod was the port with the highest incidence of small vessels $(\mathrm{M}=35.4$ feet, $\mathrm{SD}=11.6), F(2,6,417)=3,031.6, p<0.001$.

The gear types most commonly found in New Bedford were trawl, dredge (scallops), dredge (other), and pots/traps (other). In Point Judith the gear types with the highest incidence were trawl, pots/traps (other), pots/traps (lobster inshore), and 
handline. In Cape Cod the most common gear types found were longline, gillnet, handline, and trawl. Table 40 shows the total number of landings reported for each of the main gear types for all three ports.

Table 40. Incidence of landings between 1994 and 2012 using the most common gear types in the three ports studied

\begin{tabular}{lllllllll}
\hline & Trawl & $\begin{array}{l}\text { Pots/traps } \\
\text { (other) }\end{array}$ & Handline & $\begin{array}{l}\text { Dredge } \\
\text { (scallops) }\end{array}$ & $\begin{array}{l}\text { Dredge } \\
\text { (other) }\end{array}$ & $\begin{array}{l}\text { Pots/traps } \\
\text { (lobster inshore) }\end{array}$ & Longline & Gillnet \\
\hline New Bedford & 1,337 & 196 & 96 & 1,427 & 916 & 15 & 51 & 144 \\
Point Judith & 856 & 342 & 268 & 24 & 92 & 245 & 16 & 138 \\
Cape Cod & 284 & 195 & 835 & 84 & 143 & 17 & 331 & 330 \\
Total & $\mathbf{2 , 4 7 7}$ & $\mathbf{7 3 3}$ & $\mathbf{1 , 1 9 9}$ & $\mathbf{1 , 5 3 5}$ & $\mathbf{1 , 1 5 1}$ & $\mathbf{2 7 7}$ & $\mathbf{3 9 8}$ & $\mathbf{6 1 2}$ \\
\hline
\end{tabular}

The number of gear types reported by vessel increased overall from 1994 to 2012, $F(18,6,401)=31.8, p<0.001$. A large increase was observed around 2004 followed by a general decrease and then maintaining low fluctuation patterns for the last four or five years. The same trend was observed in a by port basis. Figure 11 shows the chart resulting from the analysis of variance involving all three ports for number of gear types reported by vessel across time.

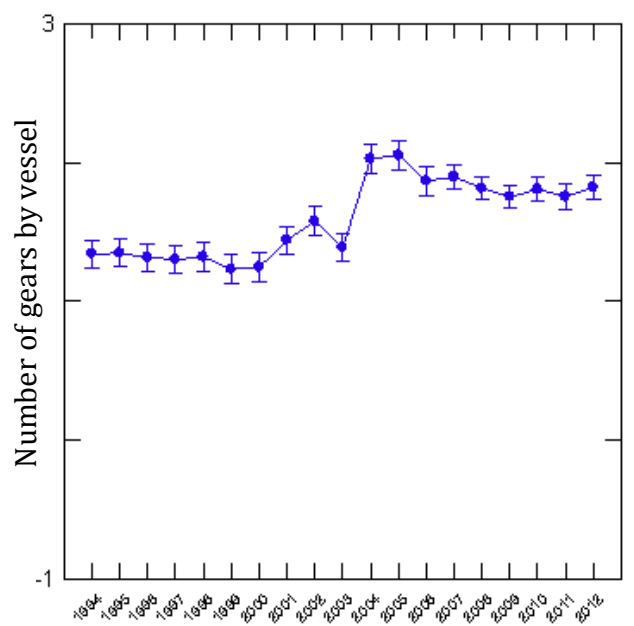

Figure 11. Results of an analysis of variance involving the three ports analyzed comparing the average number of gear types reported by vessels across the time period studied 


\subsubsection{Diversity analyses}

The landings data was analyzed to investigate changes in diversity of species landed at the vessel level using the Shannon Index. Landings for a total of eighty-eight species were analyzed between 1994 and 2012 (a list of all species can be seen in Appendix III). Overall, results show a decrease in the Shannon value, indicating a decrease in diversity in the landings between 1994 and 2012 in terms of the contribution of species to the total weight landed by each vessel/landing $(F(18,6,401)$ $=10.2, p<0.001)$ (figure 12).

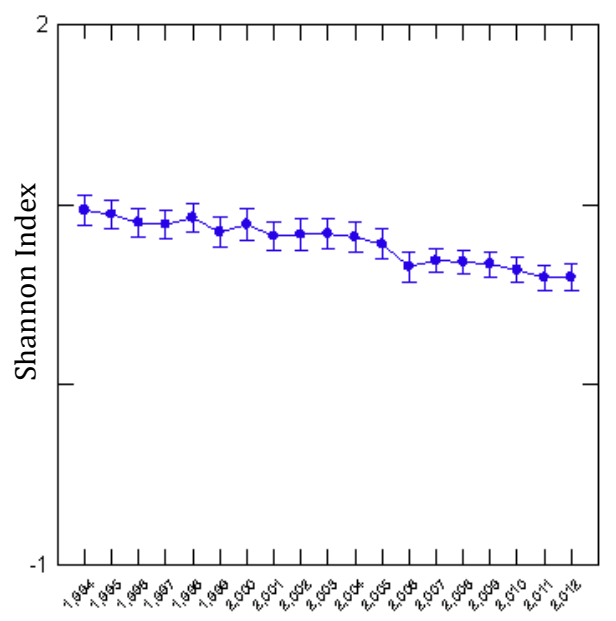

Figure 12. Results of an analysis of variance involving the three ports analyzed comparing average Shannon Index score across the time period studied

The data was also analyzed for each port separately, and significant results indicating a decrease in diversity in the landings through time was found only for New Bedford $(F(18,3,282)=22.13, p<0.001)$, suggesting that the port contributed considerably to the significant results observed in the overall dataset. Although both of the other ports presented stable levels of diversity through time measured by the Shannon Index, Point Judith $(M=0.935, S D=0.733)$ presented a higher level of diversity overall when compared to Cape $\operatorname{Cod}(\mathrm{M}=0.619, \mathrm{SD}=0.629)$. An analysis 
of variance comparing the three ports on their overall levels of diversity was statistically significant, $F(2,6,417)=75.34, p<0.001$. Post hoc $\mathrm{t}$ test analyses showed statistically significant results $(\mathrm{p}<0.001)$ for all comparisons between New Bedford $(\mathrm{M}=0.763, \mathrm{SD}=0.753)$, Point Judith $(\mathrm{M}=0.935, \mathrm{SD}=0.733)$, and Cape Cod $(\mathrm{M}=$ $0.619, \mathrm{SD}=0.629$ ). Figures showing the charts resulting from the analyses of variance involving the Shannon index for each port and between ports can be seen in Appendix XI.

Analysis comparing diversity levels through time for trawl gear users only showed statistically significant results for New Bedford $(F(18,1,318)=1.73, p<0.05)$ and Cape $\operatorname{Cod}(F(18,265)=2.17, p<0.01)$, both cases showing fluctuations and a general decrease in diversity in the last five years, despite the small increase in the last year (figure 13).
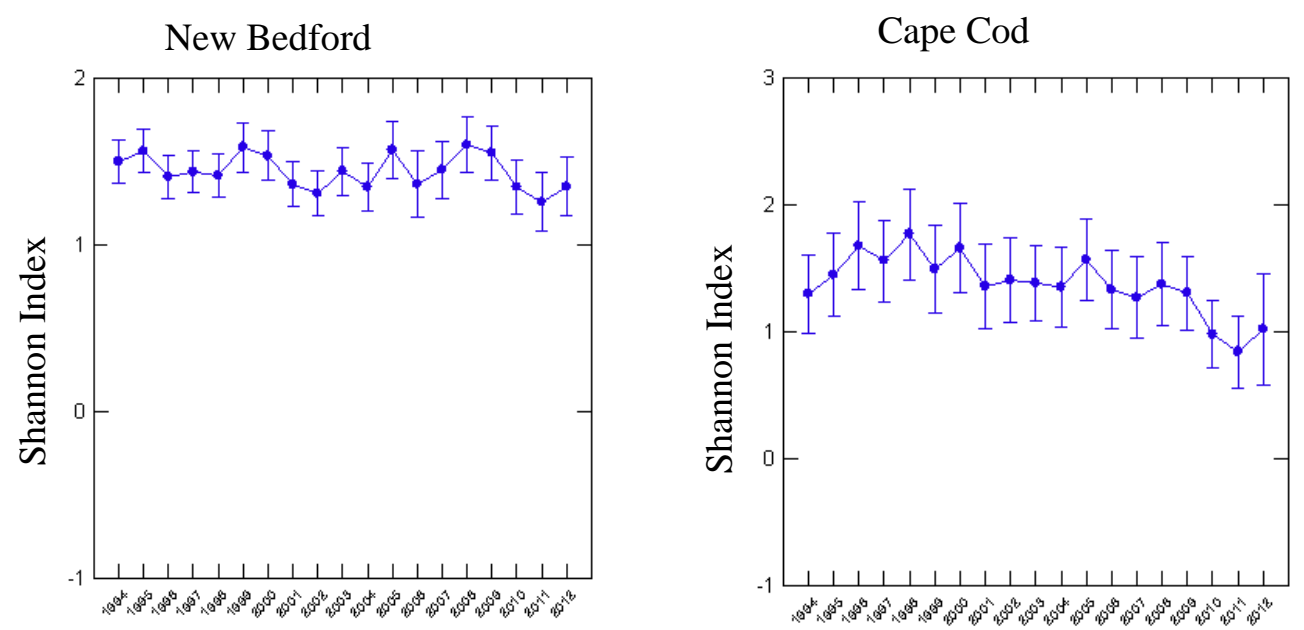

Figure 13. Results of an analysis of variance for New Bedford and Cape Cod comparing average Shannon scores through time for multispecies (trawl) gear users only

\subsubsection{Species landings fluctuation}

The species included in the diversity analyses above were analyzed for fluctuations in landings through time. The total number of species was reduced by first 
grouping different types of similar species together (e.g. silver hake and red hake) and then using principal component analysis to group species based on the co-occurrence of landings by vessel. The data was reduced to eighteen components using an Eigenvalue of one. The scree test was not used in this case because its interpretation was unclear after the fourth component (Appendix XII). Groupings of species were deemed appropriate based on field knowledge and previous research. Variable transformations and results for the principal component analysis (varimax rotation) can also be seen in Appendix XII.

Groups of species with total landings that did not exceed one million pounds for the period from 1994 to 2012 in the three ports combined were not included in the final analyses. These groups were dolphin/swordfish/wahoo/tunas, menhaden/mackerel, quahog/conch, sea bass/bay scallops, ocean pout/tautog, king whiting/octopus, and oyster. The remaining eleven groups were analyzed for fluctuations in landings through time using analyses of variance to compare factor scores for each group through the period from 1994 to 2012.

The most remarkable results involved the groups of groundfish and other bottom and pelagic species that constitute some of the most important resources for the area studied. These groups were cod/winter flounder/yellowtail flounder/haddock, summer flounder/scup/black sea bass/loligo squid/tilefish/hakes, red fish/pollock/Atlantic halibut, butterfish/ilex squid, monkfish/witch flounder/American plaice flounder, and wolf fish/dogfish. When the landings were analyzed through time for each port the results showed generally similar trends for the groups of species mentioned above. The group composed by cod, flounders, and haddock showed an 
increase up until the late 1990s and early 2000s for all three ports. In New Bedford and Point Judith, a significant decrease was observed around 2004 and then a more stable pattern after that, with a general tendency to decrease, especially in the last couple of years. In Cape Cod a decrease was observed in the early 2000s and then a stable trend was observed until around 2009, when landings began to decrease again (figure 14). These fluctuations were shown to be statistically significant for New Bedford $(F(18,3,282)=4.92, p<0.001)$, Point Judith $(F(18,1,651)=9.48, p<0.001)$, and Cape $\operatorname{Cod}(F(18,1,43)=3.14, p<0.001)$.

New Bedford

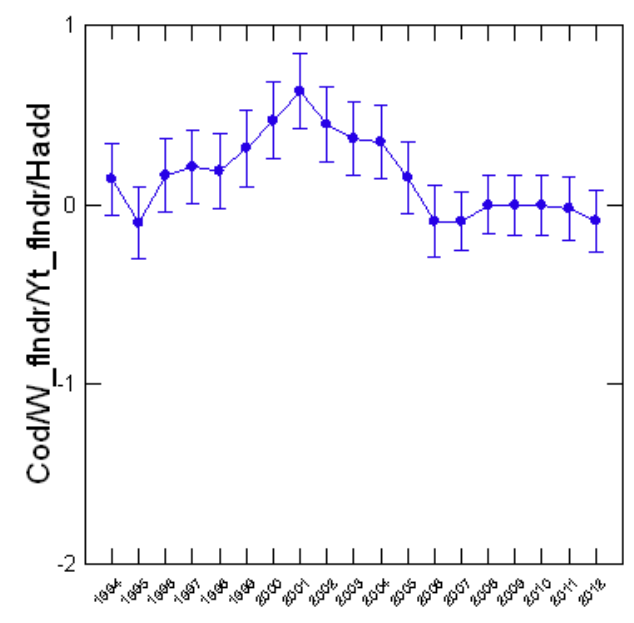

Cape Cod

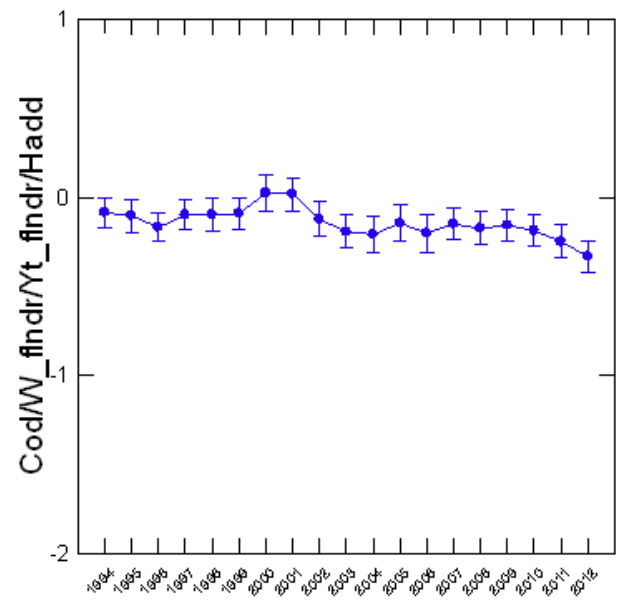

Figure 14. Charts showing results for analyses of variance for landings of the group including the species cod, winter flounder, yellowtail flounder, and haddock between 1994 and 2012 for the three ports studied 
The group composed by the species red fish, pollock, and Atlantic halibut showed some fluctuations throughout the years but landings presented a general tendency to increase between 2004 and 2008 for all three ports (figure 15), more noticeably so in New Bedford $(F(18,3,282)=5.95, p<0.001)$. Cape Cod appears to have increased in 2007 and then decreased over the last several years. Landings in Point Judith presented a great deal of fluctuation in the 1990s and early 2000s but a general increasing trend was observed starting in 2005. Results for Point Judith and Cape Cod were also statistically significant $(F(18,1,651)=3.42, p<0.001$ and $F(18$, $1,43)=3.49, p<0.001$, respectively) 
New Bedford

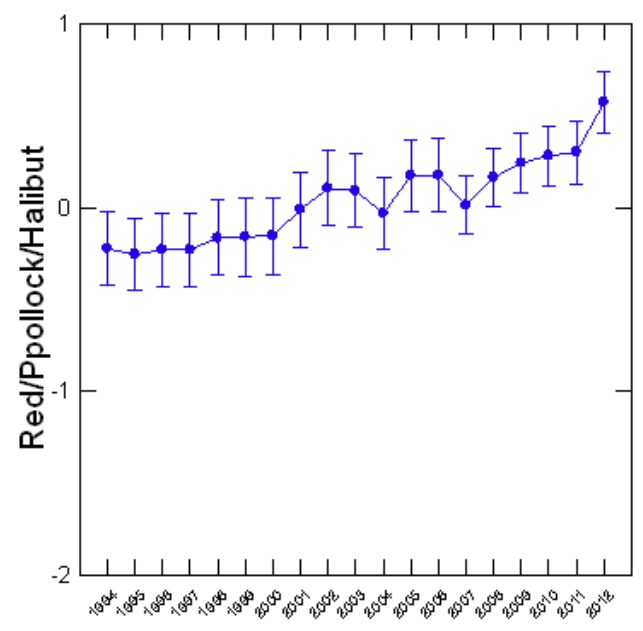

Cape Cod

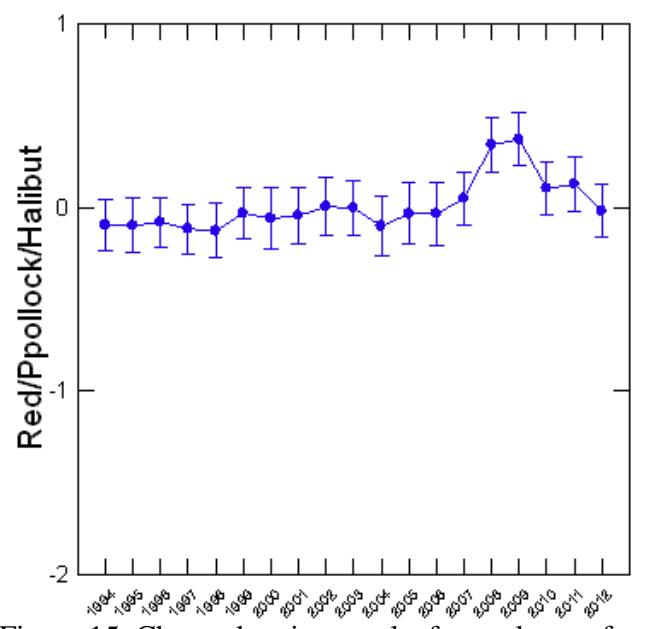

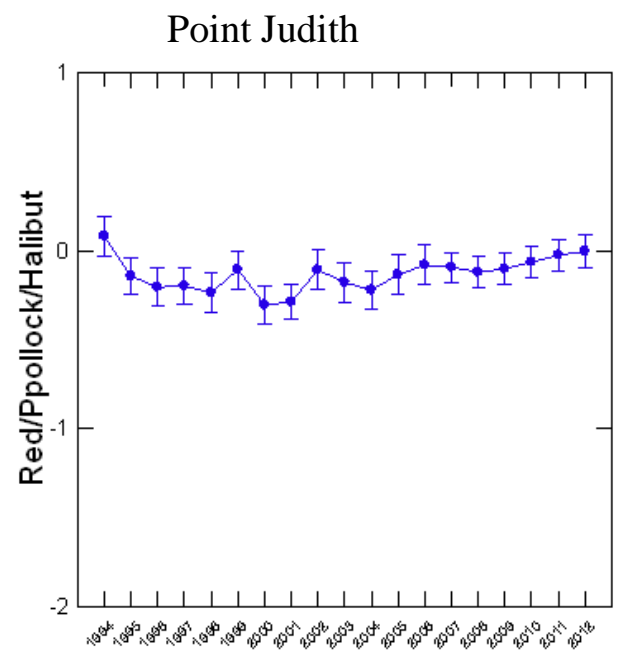

Figure 15. Charts showing results for analyses of variance for landings of the group including the species red fish, pollock, and Atlantic halibut between 1994 and 2012 for the three ports studied

The group composed by monkfish, witch flounder, and American plaice flounder also showed a general increase in landings starting around 2006 despite fluctuations in the 1990s and a significant decrease in 2004 for all three ports (figure 16). Cape Cod shows a general decrease until around 2005 and, after that, landings increased and became more stable throughout the last couple of years. Results were statistically significant for all three ports $($ New Bedford $(F(18,3,282)=11.64$, 
$p<0.001)$, Point Judith $(F(18,1,651)=4.93, p<0.001)$, and Cape $\operatorname{Cod}(F(18,1,43)=$ 1.64, $p<0.001))$.
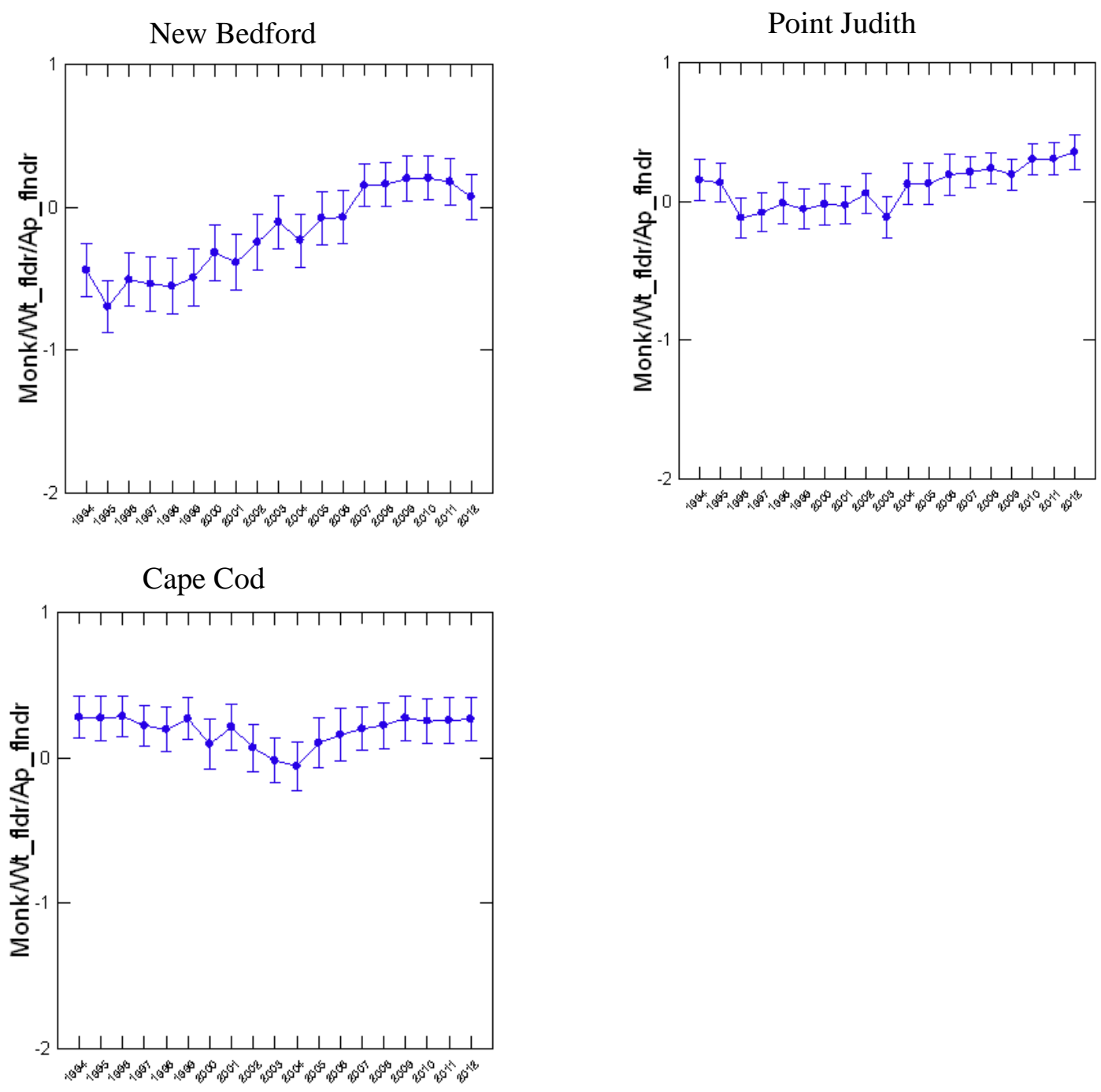

Figure 16. Charts showing results for analyses of variance for landings of the group including the species monkfish, witch founder, and American plaice flounder between 1994 and 2012 for the three ports studied

The group including the species summer flounder, scup, black sea bass, loligo squid, tilefish, and hakes showed statistically significant fluctuations for Point Judith $(F(18,1,651)=1.97, p<0.01)$ and Cape $\operatorname{Cod}(F(18,1,43)=1.9, p<0.05)$ only. In both cases, a significant increase can be observed in the early 2000s followed by a general decrease. For Point Judith, after 2006 a considerable increase in landings is observed. 
For Cape Cod, there is a slight increase up to 2002 and then an overall decreasing trend until 2006, when a slight increase occurred, and then another decreasing trend for the last three years. Although results were not statistically significant for New Bedford $(F(18,3,282)=1.25, p>0.05)$, there was a slight increase in the early 2000s followed by a decrease around 2006 and then a slight increasing trend until 2011 (figure 17).
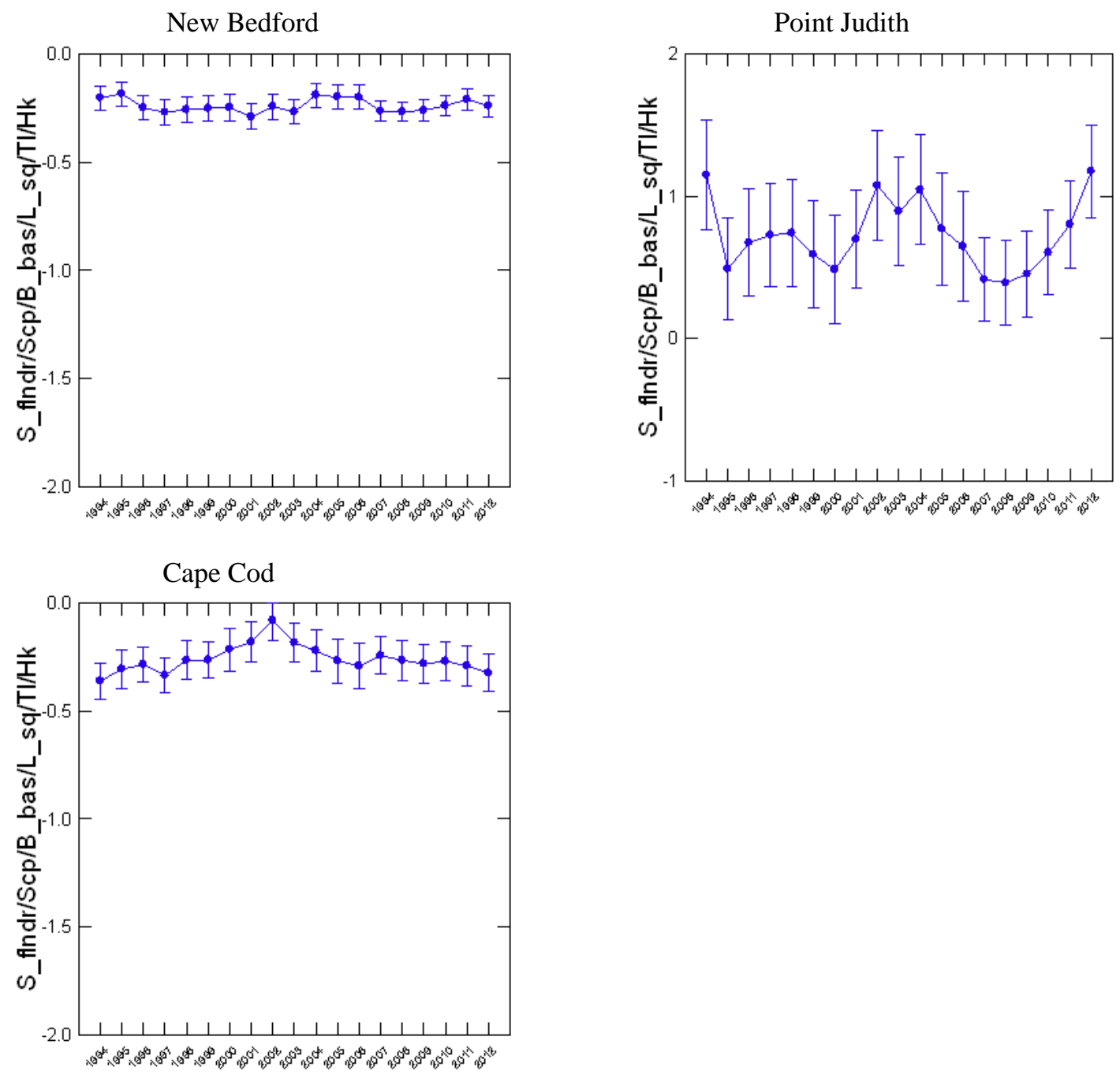

Figure 17. Charts showing results for analyses of variance for landings of the group including the species summer flounder, scup, black sea bass, loligo squid, tilefish, and hakes between 1994 and 2012 for the three ports studied 
The group including the species butterfish and ilex squid showed statistically significant results for Point Judith $(F(18,1,651)=3.06, p<0.01)$ and Cape Cod $(F(18$, $1,43)=2.82, p<0.05)$. Cape Cod landings showed a slight increase in the early 2000s and a general decreasing trend around 2006. In Point Judith, although landings also showed an increase in the early 2000s, with the exception of a considerable decline in 2004, the general trend was an increase in landings throughout the 2000s (figure 18).
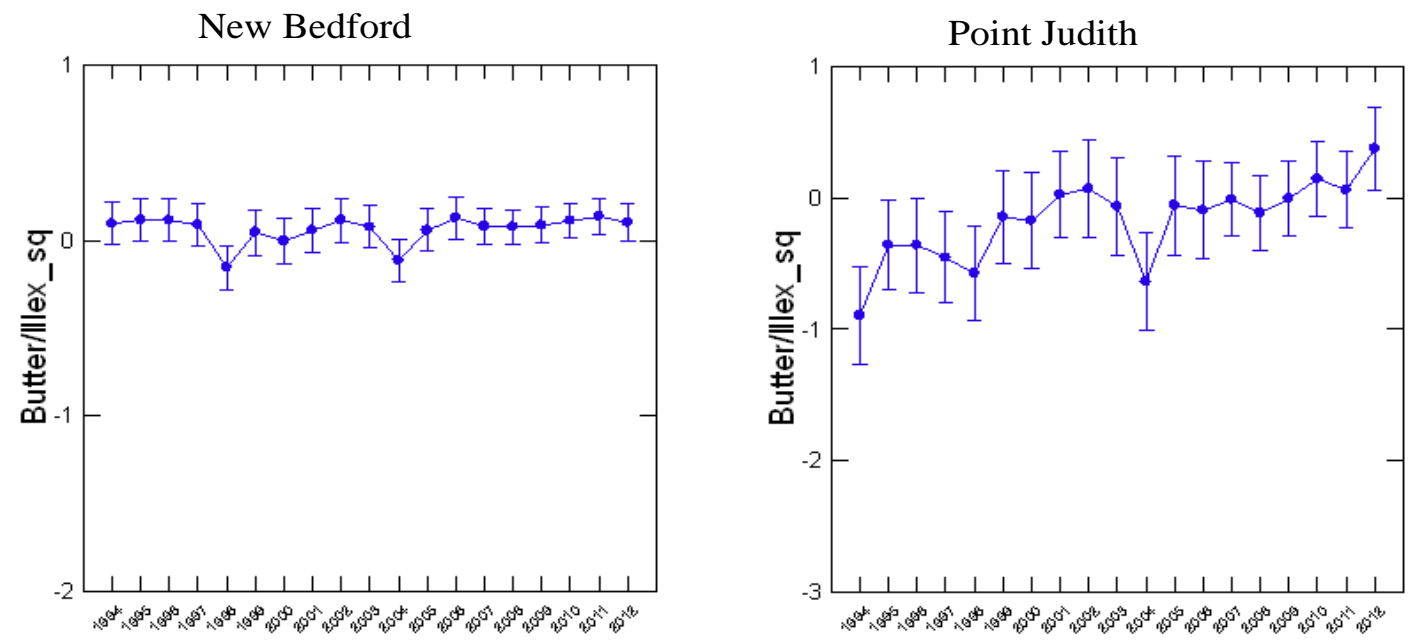

Cape Cod

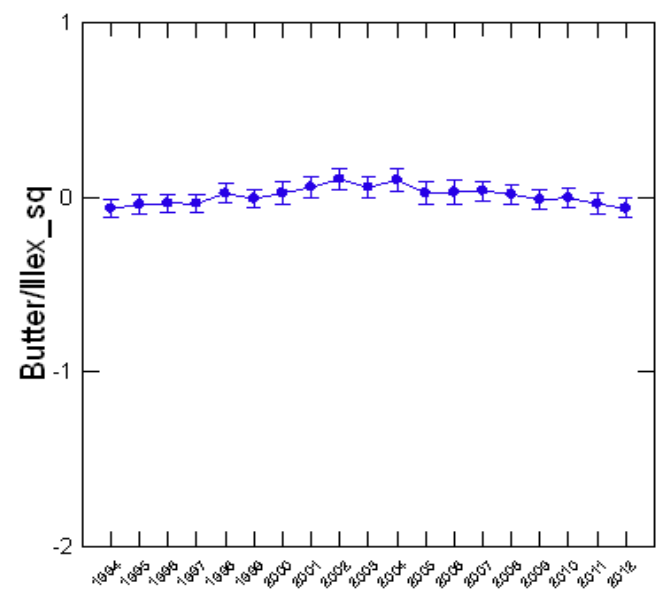

Figure 18. Charts showing results for analyses of variance for landings of the group including the species butterfish and ilex squid between 1994 and 2012 for the three ports studied

Finally, the group including the species wolf fish and dogfish showed statistically significant results for all three ports (New Bedford $(F(18,3,282)=25.04$, 
$p<0.05)$, Point Judith $(F(18,1,651)=2.39, p<0.01)$ and Cape $\operatorname{Cod}(F(18,1,43)=1.94$, $p<0.05)$. In all cases, landings showed a general tendency to increase in the second half of the period of time analyzed. In Point Judith, landings dropped considerably around 2001 and then increased until 2004, when a decreasing trend lasted for about three years, and then stabilized again. Generally, in Point Judith, landings were slightly higher in the 2000s when compared to the 1990s. In Cape Cod a significant increase occurred during the first 10 years analyzed and then landings began to show a more stable pattern, with a distinct decrease in the past three years. In New Bedford, the overall tendency was clearly an increase, despite some fluctuations and a distinct peak in 2004, followed by a decrease and then another increase (figure 19). 
New Bedford

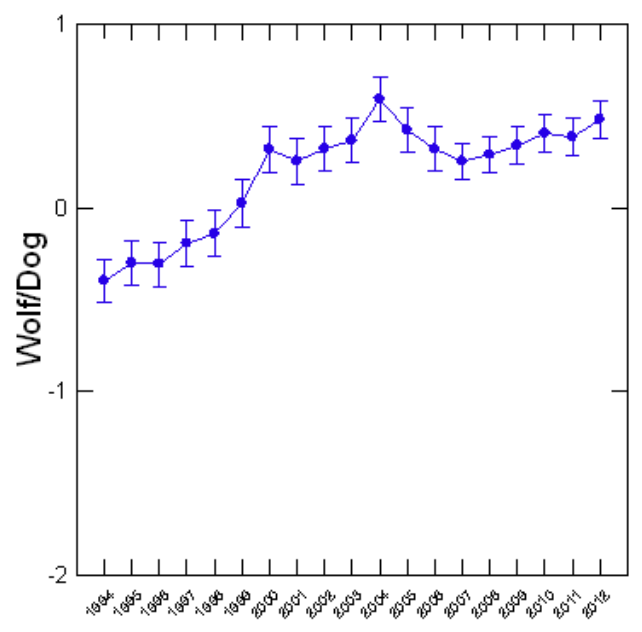

Cape Cod

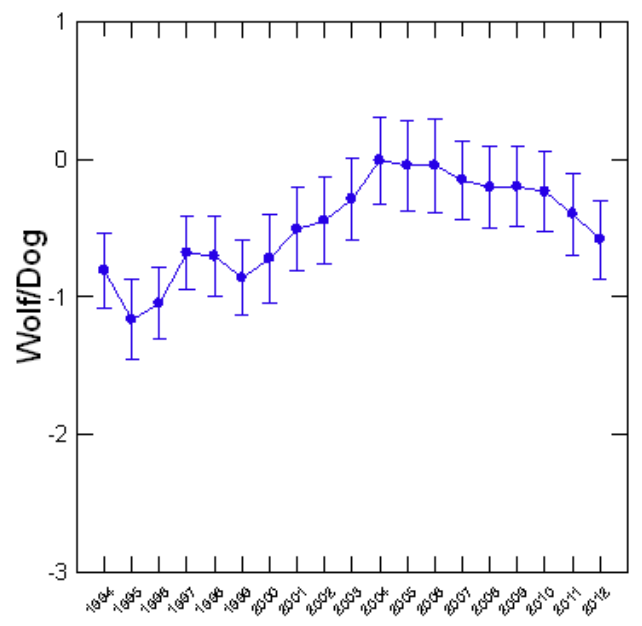

Point Judith

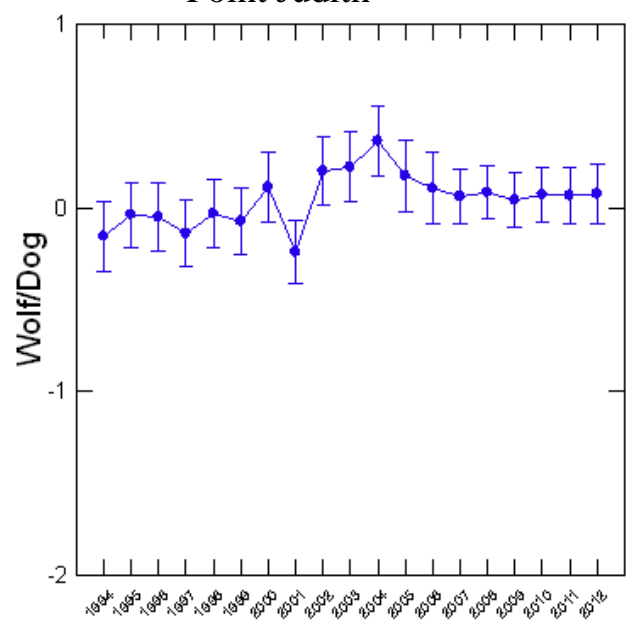

Figure 19. Charts showing results for analyses of variance for landings of the group including the species wolf fish and dogfish between 1994 and 2012 for the three ports studied

Results of the analyses of variance involving the remaining groups with species that presented landings that exceeded one million pounds for the period from 1994 to 2012 can be seen in Appendix XIII. 


\section{CHAPTER V \\ DISCUSSION AND CONCLUSIONS}

This final chapter provides an explanation of the results presented in Chapter IV in the context of the research question and hypotheses that were the basis for the present study, as well as other important findings. Chapter V also presents the conclusions drawn from the findings of this study, which includes a description of the limitations of the research, and how they were understood to have affected the general outcomes, as well as opportunities for future research.

\subsection{Primary findings}

The principal findings of this study will be discussed in this section. Overall, the findings provide interesting new insights on issues involving the impacts of fisheries management on catch composition and fisheries diversity in the New England region. The results also provide meaningful information about the social structure of fishing communities and how this structure may have or can be affected by change. An additional, brief characterization of the ports studied will be provided based on the results obtained with the analyses of fishing related variables, and major findings of this research will be discussed in the context of the two hypotheses developed and presented in Chapter I. 


\subsubsection{Additional characterization of the ports}

Results of analyses involving fishing attribute variables showed that New Bedford, Point Judith, and Cape Cod are considerably distinct from each other with regard to characteristics of their fishing activities, a fact that is believed to enrich the findings of the present research. New Bedford is mainly characterized by the presence of larger vessels, generally sailing on long offshore trips of about a week with large crews of generally five and up to seven people. The involvement of large corporations in the port, due primarily to the lucrative scallop business, is evidenced by the lower occurrence of captain/owners in the sample and a larger number of captains, most likely working on vessels belonging to "shore owners." The prevalence of scallop fishing also makes New Bedford the port with the highest average annual income among the ports studied. This is likely to attract fishermen from farther areas, and, combined with the large scale of the New Bedford fisheries, possibly explains why the port has the highest incidence of out-of-state fishermen when compared to the other ports studied. The predominance of scallop fishing in New Bedford also makes it the most specialized port, with the least number of different species being targeted by vessels.

Point Judith, although a relatively large port, was characterized by a majority of medium sized trawler vessels, making relatively short trips lasting approximately three days on average, and crew sizes rarely exceeding five people. Point Judith presented a relatively diverse fishery, with a primary focus on pelagic species such as squid and scup. The relatively high incidence of captain/owners in the sample likely 
indicates lower corporative influence in the port, especially in contrast with New Bedford.

The Cape Cod region was characterized by a majority of smaller boats, in general day-trippers, and with small crews typically not exceeding three people. Although the most common primary gear type found in the sample was gillnet, the most frequently mentioned target species was scallop. Other important resources were dogfish and tuna. These results emphasize the relative diversity of the Cape Cod fishery regarding both target species and gear types. The high incidence of captain/owners and relatively small crews in Cape Cod are indicative of small business operations. The high incidence of fishermen living in the same town as their homeports likely indicates that these businesses are mainly controlled by local people.

\subsubsection{Hypothesis $I$}

The first hypothesis developed in this study states that diversity in New England fisheries, specifically in the ports and regions studied, has decreased as a consequence of fisheries management practices, more so for fishermen using multispecies gear types. This hypothesis can be confirmed in part with results from surveys showing that, in general, fishermen feel very strongly that they have lost flexibility throughout their fishing experience, and indubitably believe regulations to have been the main cause for this loss. The general sentiment expressed by fishermen interviewed is that, about ten or fifteen years ago, they had more flexibility to choose what species to target and what gear types to use and that rules and regulations have negatively affected that flexibility through restrictions introduced by permits and 
quota systems, and also due to constraints imposed to their decision making process

by paperwork requirements. The results based on the survey data very clearly confirms the first hypothesis and quotes by some of the fishermen interviewed can be used as illustration:

Today there are so many permits it's become hard. We used to jump between species to make a living. (Captain/owner, personal communication, Provincetown, August 2013)

Before we would switch around according to what was paying more. (Captain, personal communication, New Bedford, November 2012)

We used to go fishing with different gear and switch them out there. Now you can't because it is illegal to have dredges and nets on the boat (Crew, personal communication, New Bedford, August 2013)

Less and less choices... I used to go groundfishing. With regulations you have to fish for what you can. (Captain, personal communication, New Bedford, November 2012)

It is hard to get permits to fish different species. Very difficult to do different things. (Captain, personal communication, Harwich, August 2013)

On the other hand, results of analyses involving the landings data show that, although diversity in catch composition has decreased to a certain degree, they are not nearly as alarming as the survey data suggests. The analyses of variance comparing Shannon Index scores throughout nearly two decades show that diversity in catch composition has decreased significantly only in New Bedford and in Cape Cod, the latter only when trawl gear landings were analyzed separately.

The higher levels of specialization observed in New Bedford can be in part explained by the success of scallop fishing in the port. It is possible that fishermen consciously became more specialized as the market value for scallops increased considerably in the past decades. However, New Bedford is also one of the ports in the New England region with the highest incidence of groundfish permits, and when 
landings by trawl gear were analyzed exclusively, levels of diversity also showed a slight overall decrease in New Bedford, which supports the first hypothesis that diversity has declined in the fishery for reasons other than vessels turning to scalloping because of its high value. The fact that Cape Cod landings also show a decrease in diversity when trawl landings were analyzed also helps to reinforce the idea that specialization is occurring in the fishery to a certain degree. The overall results involving the landings data, however, especially when Point Judith is considered, do not entirely support the findings of the surveys.

One possible explanation for the relatively high level of diversity observed in the analyses of landings data is that, although fishermen have been dealing with substantial changes to their occupation due to regulations and have been experiencing restrictions with regard to the flexibility in their decision making, they were still able to diversify and possibly did so in response to these changes. As was extensively discussed in Chapter II, diversification in the fishery is one of the most important strategies in fishermen's adaptation to change. The results of analyses of variance investigating fluctuations in landings of some of the most important species for the studied region are in agreement with the idea that some level of diversification has occurred in the past couple of decades.

The data analyzed clearly show that, especially in New Bedford and Point Judith, landings for cod, winter flounder, yellowtail flounder, and haddock, which constitute some of the most important fishery resources in New England, were in an ascending path until around 2001. After that, landings started to decline significantly, possibly as a consequence of measures following the first Conservation Law 
Foundation lawsuit against NMFS. In 2004, landings showed a more dramatic decrease, likely associated with the implementation of Amendment 13 to the groundfish fishery that imposed drastic reductions in groundfish landings, in particular cod, winter flounder, and yellowtail flounder. After 2004, landings for these species seemed to have stabilized, however, with a slight tendency to decrease.

Although a great deal of fluctuation was observed in landings for most of the major species of fish, the data suggest that while landings for cod, winter flounder, yellowtail flounder, and haddock showed an overall decrease over the years, other species groups such as monkfish, winter flounder, and American plaice in New Bedford; wolf fish and dogfish in New Bedford and Cape Cod; and butterfish and ilex squid in Point Judith; showed, in general, increasing trends. In Point Judith, although subject to intense fluctuations, the species group comprised by summer flounder, scup, black sea bass, loligo squid, tilefish, and hakes showed an increase in landings in the past decade inversely mirroring the trend observed for landings of cod, winter flounder, yellowtail flounder, and haddock.

These findings suggest that, although fishermen believe their levels of flexibility to be decreasing as a result of regulations, as the decline in groundfish landings suggest, they were still able to diversify throughout the period from 1994 until 2012 and therefore remain in business. This ability to diversify could be an indication that the ports studied have adapted as opposed to transformed, suggesting favorable levels of resilience. Adaptation through diversification could also explain the relatively higher Shannon Index scores in Point Judith when compared to the other two ports. In the words of one captain interviewed in Point Judith: 
Point Judith is much more diversified. [It is] very unique. [That is] the strength [of the port]. I fished in many ports [and] this is the most diversified port.

(Captain, personal communication, Point Judith, April 2012)

Other statements from Point Judith fishermen support the idea of adaptive diversification occurring in the port:

Boats used to work on groundfish, not so much squid. There was a time when $50 \%$ was groundfish. It turned to squid. (Captain/owner, personal communication, Point Judith, October 2012)

I used to fish yellowtail, cod, haddock. Switched to squid, mackerel, butterfish. (Captain/owner, personal communication, Point Judith, September 2012)

Butterfish used to be huge. The market went down and now squid is the new 'butter.' That's what's great about Point Judith. We adapt, catch other species. [But] we used to have more flexibility; use different mesh sizes, fish for groundfish. Now it's more restricted. (Captain, personal communication, Point Judith, October 2012)

The last statement shows that, although it seems that fishermen in Point Judith have adapted to changes by diversifying the fishery, fishermen in the port share the general sentiment that a great deal of their flexibility has been reduced as a result of regulations. A statement from one crew member also exemplifies this sentiment:

Point Judith used to be diversified. [You] could jump onto other fisheries when you had to. Scallops [have] a good market price [but] permits are expensive. Before, you could afford to get a scallop license. Nowadays [they] cost millions of dollars. A lot of people would like to have scallop permits but [they] can't afford it. (Crew member, personal communication, Point Judith, September 2012)

The general frustration expressed by fishermen may not yet be observable in landings diversity patterns, but that does not mean they will not occur in the future. The data shows that fishermen were able to diversify to a certain degree and cope with significant changes from 1994 through 2012, but their strong belief that their flexibility to exploit different species and use different gear types has been compromised by regulations can be seen as an indication that regulations which 
negatively affect diversity are likely to hinder fishermen's ability to cope with change in the future.

\subsubsection{Hypothesis II}

The second hypothesis developed states that a reduction in flexibility and diversity in the fishery has the potential for negatively affecting individual and community resilience. This hypothesis proved to be challenging to support because results involving the indicator of individual resilience used (the scale developed by Marshall and Marshall 2007) did not show significant correlational patterns that could be used to clearly support or reject this hypothesis. The most important quantitative finding supporting the idea behind the second hypothesis was the results of a comparison between multispecies and shellfish gear types, in which multispecies fishermen presented significantly lower scores in one of the components of resilience - Perception of Risk.

Other findings of this study suggest that multispecies fishermen have been more significantly affected by regulations that impact their ability to diversify. Results from landings data showed that in New Bedford and Cape Cod, Shannon Index scores for trawl fishermen have decreased over the years. In addition, results involving supplementary questions used to investigate more objectively fishermen's opinions on changes to their ability to diversify, which were specifically focused on multispecies gear users, show undeniably that fishermen believe regulations to have reduced their flexibility to exploit different species and use different gear types. These results, combined with the lower levels of resilience found for multispecies gear users in the 
component Perception of Risk, create a promising argument in support of the second hypothesis.

Qualitative data that was indirectly obtained while conducting interviews are, nonetheless, the most compelling evidence that a decrease in diversity in the fishery negatively impact individual and community resilience. The following statements exemplify some of the effects that a decrease in diversity can have on individual and community aspects that are closely associated with the resilience concept, such as financial and psychological well-being:

Now there are quotas for each species of fish. This is putting everyone out of business. (Crew, personal communication, New Bedford, August 2013)

Now we have to target species that we have quota for. But we have to buy quota. (Captain, personal communication, New Bedford, August 2013)

To diversify today we would have to buy new licenses and new gear. It's very expensive. (Crew, personal communication, Hyannis, August 2013)

Before we had to do whatever the season would call for. Now we are not allowed. I feel sorry for the younger. My boy wants [to fish] but it's not feasible. (Captain/owner, personal communication, Provincetown, August 2013)

Before you could choose what species you wanted. Now we have to call to ask to go squid fishing, apply for observers, and prepare trip reports. We have to think in advance. If trip reports are not in, they suspend your license. The job itself is tough enough. We are fishermen not paperwork people. (Captain, personal communication, Point Judith, May 2013)

They tell us what we can fish and what we can't. The fish is out there. It's hard, we have no control. (Crew, personal communication, New Bedford, January 2013)

If it keeps the way it is, soon the waterfront will be gone. We support a lot of people. (Captain, personal communication, New Bedford, November 2012)

Regulations are believed to impact fishermen's adaptability in a variety of ways. Some fishermen reported that they have failed to qualify for quota for certain 
species that they could target and benefit from in the future, therefore decreasing their flexibility, because they were targeting different species during specified qualifying years, sometimes for conservation reasons:

I was fishing for monkfish when they did the groundfish allocations - staying away from groundfish. I didn't get any groundfish (Captain/owner, personal communication, New Bedford, November 2012)

Government changed groundfishing days, took availability away. Now we're fishing for squid. If we could go groundfishing we'd be making more money now. (Crew, personal communication, Point Judith, July 2013)

The possibility that fishermen may not qualify for quota for certain species poses a threat to their future adaptation. Nowadays, when available, permits for certain species represent a substantial investment. Moreover, a great deal of fishermen reported that they already depend on leasing or buying quota from other fishermen in order to land a catch that yields favorable revenue. These constraints to adaptive flexibility pose a threat to fishermen's resilience and potentially to the resilience of the resource itself. As it was previously mentioned in this study, the same argument that exists in favor of in-fisheries diversification with the goal of 'spreading the risk' can be applied to the impacts of fishing on the fish populations. The more specialized the fishing fleet are, the more pressure they are likely to put on those specific resources. This statement from a New Bedford fisherman exemplifies the environmental threat of specialization:

Before you could fish for other things, now you can't and you beat those fisheries to death. (Crew, personal communication, New Bedford, August 2013)

Wild populations of fish and shellfish are subject to natural fluctuations, diseases, and the threat of climate change. New Bedford's evident high dependency on scallops, for example, although it currently leads to high levels of subjective resilience 
among shellfish fishermen due to high market values and a consequent general sense of security, is potentially disastrous in the hypothetical event of a scallop population collapse. The findings of this study, although not conclusive with regard to the impacts that specialization has had in the social resilience of fishermen and their communities, provide some insight on the potential effects it could have if diversification is not accounted for in the future.

\subsection{Other potentially important findings}

Results from this study yielded other noteworthy findings not directly related to the hypotheses developed but that provide information on social aspects of New England fisheries that could potentially be useful in the policy making process, especially in the context of social impact assessments. Results regarding the job satisfaction variables as well as patterns of correlation found among different demographic and fishing related variables and variables of job satisfaction and resilience constitute some of the most interesting outcomes.

\subsubsection{Job Satisfaction}

The nine job satisfaction variables used in this study have long been applied in fisheries social sciences studies since Pollnac and Poggie (1988) first proposed their use and stressed the importance of the concept when considering adaptation and change in fishing communities (see Bavinck et al. 2012). The three components of job satisfaction (Basic Needs, Social and Psychological Needs, and Self-Actualization) have remained relatively stable in analyses involving the job satisfaction variables in developed and developing countries throughout the decades (Binkley 1995, Pollnac et 
al. 2001). The findings of this study corroborate previous analyses on the job satisfaction components and emphasize the robustness of this measure.

Results of comparisons between the different ports studied showed that the only significant differences regarding job satisfaction were found between New Bedford and Cape Cod for the Social and Psychological Needs component. As it has been previously illustrated by the different fishery attributes characterizing each port, New Bedford and Cape Cod represent extreme opposites with regard to many aspects of the fishery, such as vessel and crew size, and, most importantly in this context, average trip length. The three questions highly correlated in the Social and Psychological Needs component deal with fishermen's satisfaction with the time spent away from home, the physical fatigue and healthfulness of the fishing job, issues heavily based on the effects that farther and longer fishing trips can have on fishermen. For this reason, it is not unforeseen that fishermen from New Bedford would have significantly lower scores on the Social and Psychological Needs component when compared to Cape Cod. The relationships described above also explain the negative correlation found between the component Fishing Occupation Attributes, which includes aspects of the occupation such as trip length and crew size, and the Social and Psychological Needs component. Analyses involving the other two components of job satisfaction (Basic Needs and Self-Actualization) did not result in significant differences when the three ports were compared.

The only additional significant result regarding the job satisfaction measure involves the Basic Needs component and categories of gear type. In this analysis, shellfish gear fishermen presented higher levels of job satisfaction in the component 
when compared to the other two gear type categories multispecies and trap gear. The Basic Needs component is highly linked to fishermen's satisfaction with their monetary gains from fishing, and the substantial contribution from scallop fishermen in the shellfish gear category likely explains their higher levels of satisfaction with the Basic Needs component. Analysis involving the other two components of job satisfaction and gear type categories did not show any significant results.

All these findings strengthen the argument extensively discussed in the literature (Apostle et al. 1985, Gatewood and McCay 1990, Binkley 1995, Pollnac and Poggie 2006) regarding fishermen’s prevailing high levels of occupational attachment, especially considering that satisfaction with regard to Self-Actualization, a component deemed as having a particularly important role in fishermen’s job satisfaction, maintain high levels across different ports and fishery types. These results suggest that, due to their high levels of job satisfaction, especially with regard to the SelfActualization component, fishermen in general would likely be reluctant to leave the occupation of fishing despite adversity, an idea that has been previously discussed in the literature (Binkley 1995, Pollnac et al. 2001, Crawford 2002) and is supported by the findings of this study. As discussed in Chapter II, this would decrease their resilience in the face of change.

\subsubsection{Correlations between variables}

The job satisfaction component Social and Psychological Needs was significantly correlated with a number of different variables. The negative correlation between this component and Occupation Attributes can be explained, as previously 
discussed, by the relationship between average trip length and its consequent effects on time spent away from home and strenuous physical work. This relationship is also likely to explain indirectly the correlation between Social and Psychological Needs and the component Gear Use and Education. Scallop fishermen were predominantly single gear users and were also primarily found in the port of New Bedford, where levels of formal education were significantly lower when compared to the other two ports, which explains the clustering of the two variables multiple gear use and education in the first place. New Bedford was also the port with significant lower levels of satisfaction with the component Social and Psychological Needs. These interrelationships most likely influenced the correlation between the components Gear Use and Education and Social and Psychological Needs.

The component Social and Psychological Needs was also correlated with the job satisfaction variables willingness to advise a young person to enter fishing and willingness to be a fisherman if had life to live over. The job satisfaction component Basic Needs was also correlated with willingness to advise a young person to enter fishing. These results suggest that fishermen with higher levels of satisfaction, especially with regard to fishing attributes determining time spent away and physical stress, as well as with monetary gains and overall safety of the job, are more likely to advise other people to fish and also to say they would become fishermen if they could, hypothetically, live their lives again. Interestingly, although fishermen present high and stable levels of satisfaction with the component Self-Actualization, it is the monetary and psychological and physical aspects of fishing that influence such significant choices. These results partially contradict previous studies involving the 
same job satisfaction components, which have often showed a significant relationship between Self-Actualization and the variable willingness to advise a young person to enter fishing (Seara 2010, Sall 2012, Monnereau and Pollnac 2012). It is not clear at this moment what influenced the different results obtained in this study. The two variables willingness to advise a young person to enter fishing and willingness to be a fisherman if had life to live over were also strongly correlated with each other.

The job satisfaction component Basic Needs was correlated with both resilience components Perception of Risk and Ability to Cope. These results suggest that fishermen highly satisfied with their monetary gains present a general sense of security with regard to the future. The Ability to Cope component encompasses the general idea of preparedness for the future and confidence in success. The Perception of Risk component deals with fishermen's perceptions of their options for the future in the face of drastic changes that may impede their ability to fish. Results suggest that financial security is an important aspect influencing fishermen's subjective perception of their ability to handle changes, probably because fishermen with higher levels of satisfaction regarding their income are most likely to have savings and the ability to invest in future sources of income in a situation where they are unable to fish. This general feeling of security may also explain why fishermen with high levels of satisfaction with the Basic Needs component and high scores in the Ability to Cope component are more willing to advise a young person to enter fishing.

The resilience component Adaptation to Change and the job satisfaction variable willingness to be a fisherman if had life to live over were also found to be correlated. Adaptation to Change is the resilience component that captures fishermen's 
subjective perception of their ability to adapt to changes that have occurred in the past as well as to potential changes that could occur in the future. These results suggest that fishermen who perceive their ability to adapt to changes with confidence are more likely to positively evaluate the idea of being a fisherman if they had their lives to live over.

In part, the results obtained with the correlation analyses suggest that monetary gains from fishing play a very important role in fishermen's perception of their ability to adapt and cope with change. One important way that a decrease in diversity in the fishery is likely to impact fishermen directly is by negatively affecting their incomes. Kasperski and Holland (2013) showed that a decrease in diversity in the U.S. west coast fisheries led to a substantial decrease in vessel revenue. The authors described these impacts in the context of loss of flexibility and resilience in the fishery. The correlations found between satisfaction with income and subjective levels of resilience suggest that a decrease in diversity that affects revenue negatively could result in lower levels of perceived ability to adapt to change, i.e. a decrease in resilience among fishermen.

The correlation found between aspects of job satisfaction and resilience can also help understand changes that have occurred in the fisheries in the past. A study comparing levels of job satisfaction in the ports of Point Judith and New Bedford for three time periods 1977, 2007 and 2009/10 showed that satisfaction with the components Basic Needs and Social and Psychological Needs have decreased significantly throughout the years (Seara 2012). Levels of subjective resilience for some of the components created by the Marshall and Marshall (2007) scale used in 
this study were positively correlated with both job satisfaction components, suggesting a possible decrease in subjective levels of resilience for Point Judith and New Bedford throughout the years.

Findings described and discussed in the present study primarily contribute to the overall understanding of New England fishermen's perceptions of the impacts that changes to the fishing occupation can have on their ability to cope and adapt. Results suggest that diversification of catch is an important adaptation strategy among New England fishermen but it also indicates that flexibility has been compromised to a certain extent. Fishermen expressed a strong belief that their ability to diversify target species and gear types have been reduced as a consequence of regulations, especially due to permit and quota requirements, which has and could diminish adaptability in future scenarios. These findings indicate that impacts on fishery diversity should receive much more consideration during the fishery management process.

The links observed between aspects of job satisfaction among fishermen and levels of perceived resilience, combined with previous findings that show a decrease in levels of job satisfaction among fishermen throughout time in two of the ports studied, suggests that levels of subjective resilience, and therefore fishermen's perception of their adaptability, could have decreased as well. Impacts on well-being and overall perception of the ability to adapt can have an impact on fishermen's willingness to comply and cooperate in the management process (Marshall and Marshall 2007); therefore it is in the interest of policy-makers to maximize resilience and well-being among fishermen. 


\subsection{Conclusions}

This study was designed with the main objective of responding the following research question: "have management practices reduced diversity in New England fisheries thus negatively affecting individual and community resilience?” In an effort to answer this question, data on landings occurring between 1994 and 2012 by vessels homeported in three main ports and fishing regions in New England - New Bedford, Point Judith, and Cape Cod - were analyzed for catch composition diversity using the Shannon Index and compared with data obtained through face-to-face surveys with 157 fishermen from the same ports and regions.

Results of analyses show that fishermen perceived a significant reduction in fishery diversity to have occurred as a result of impacts caused by regulations in the past couple of decades, despite the fact that analyses involving landings data showed a significant decrease in diversity only for New Bedford and a slight decreasing trend for New Bedford and Cape Cod when trawl gear landings were analyzed separately. The latter results can be in part explained by the analyses of landings fluctuation for some of the most important species in the studied region, suggesting that diversification has occurred, possibly as a mean of adaptation to change, which possibly contributed to maintaining stable levels of diversity in landings. It is undeniable, however, that fishermen interviewed strongly believe their flexibility to have been compromised.

This apparent disparity between results involving the two main types of data analyzed in this research raises interesting questions. The present study was not designed to understand, in depth, the rationale behind fishermen's perception of 
diversity loss, but rather to capture whether or not they believed their flexibility to diversify had changed throughout their fishing experience and the general reason for the change. It is possible that this limitation of the research design could have led to an oversimplification of fishermen's perception of change. However, it is also possible that fishermen expressed a concern for potential future impacts in the face of drastic changes to current important fish stocks, considering that they have lost flexibility to diversify due to regulations - something that would not yet be observable in landings trends. In any case, the results obtained provide promising opportunities for further investigations regarding New England's fishermen's perceptions of changes in diversity and changes to catch composition through time. One significant contribution would be assessing in more depth the rationale behind fishermen's perception of changes in flexibility to diversify and understanding their projections for the future.

Results regarding impacts that changes in fishery diversity can have on fishermen and fishing community resilience, although suggestive of a positive relationship, were not entirely conclusive. Statements by fishermen interviewed showed a relationship between diversity and adaptability, which is not clearly observed in the analyses of the data. Partially, these results can be attributed to the lack of robust measurements for individual and community resilience to changes in the fishery. The measurement chosen in this study - the scale developed by Marshall and Marshall (2007) - constitutes one of the very few attempts at operationalizing resilience at the individual level in the fishery context. It is possible that the measure employed failed to capture levels of resilience associated with the specific context of the present study. It is also possible that the inability to control for other factors that 
influence subjective levels of adaptability to change distorted the correlation between diversity and subjective resilience.

The correlation between diversity in the fishery and resilience of fishermen and fishing communities, although symptomatic, remains essentially anecdotal and hypothetical. There is great potential for further analyses of the relationship between changes to diversity in the fishery and fishermen's ability to cope. Correlations between fishermen's subjective levels of resilience and changes in fishery diversity could be further evidenced in studies involving a larger geographical scope and comparisons between larger samples of different fishery types to capture in more detail different possible effects of diversity on the adaptability of fishermen. Future research examining changes through time in subjective resilience among fishermen that could be compared with changes in the fishery would be beneficial to help understand fluctuations in perception of levels of adaptability in the future.

Other potential future investigations that would help clarify the issues studied involve the relationship between fluctuations in catch composition diversity and variables of economic nature such as market value for fish and total revenue from landings. These investigations would help understand factors influencing diversity and adaptability in the fisheries. Another possible way to advance the understanding of the relationships between fishery diversity and resilience in the fishery would be to investigate the effects of specialization on fish populations. In addition to evidence found in the literature, results of this study also support the need for further research on the subject. 
Although, partly, the results of this study serve to further stress the complexity and convolution of the relationships involving change and adaptation in New England fisheries, they also provide information that could be used to initiate important discussions in future research involving fishery diversity and resilience in fishing communities. This research did not benefit from previous attempts to measure and correlate diversity and resilience in the fisheries because studies of that nature are essentially not available - the literature linking the concept of diversity and resilience is mostly in the theoretical realm. The results of this investigation, highly explorative in essence, clearly indicate, however, the importance of the issue studied to those who are affected the most by them: the fishermen. Perhaps the most important contribution of this study to research in fisheries social sciences are the questions it evokes and a foundation to possibly clarifying the effects of changes in fishery diversity on fishermen’s and fishing communities’ resilience in the future. 


\section{APPENDIX I}

Questionnaire

\section{LOCATION:}

INTERVIEWER:

DATE:

\section{A. Demographics/Catch composition}

1. Where do you live? (town, state) 1.a. How long have you been living there?

2. What is your current position on the boat? (If more than one, ask the most frequent).

\begin{tabular}{|l|l|}
\hline Captain & \\
\hline Owner & \\
\hline Captain/owner & \\
\hline Crew & \\
\hline Mate & \\
\hline
\end{tabular}

\section{Crew size:}

3. Does the boat you fish on have a federal license? Yes __ No__ 3.a Type:

4. Does the boat you fish on belong to a sector? Yes No

5 . What gear(s) do you use specifically?

5.a. Do you use more than one type of gear on one same boat? Yes No

5.b. If YES, describe:

6 . What is the average trip length?

7. How many years of fishing experience do you have?

8. How long have you been fishing out of [current port]?

8.a. How long on current boat?

9. What do you fish for now/past year?

9.a. Which of these represents the greatest volume (not price)?

9.b. Which is second?

10. How has the composition of species changed over the years? Yes No

10.a. If yes, how?

10.b. Can you tell me approximately when the change took place and why?

11. How old are you?

12. How many years of formal education have you had?

13. How many boats have you fished on since you began fishing?

14. Do you have any relatives currently in the fishery? Yes No _ _ Number

14.a. Any relatives fishing on the same boat as you? Yes No __ Number

14.b. How many generations of your family have fished including you? 
15. What is your marital status? 15.a If married, does your partner have an occupation? Yes No

16. Do you currently have any occupations besides fishing? Yes No 16.a If yes, which one(s)?

17. Based on the different categories below, what would your total income be?

\begin{tabular}{|l|l|}
\hline Income categories & Response \\
\hline Under 10,000 & \\
\hline $10,000-14,999$ & \\
\hline $15,000-19,999$ & \\
\hline $20,000-24,999$ & \\
\hline $25,000-29,999$ & \\
\hline $30,000-34,999$ & \\
\hline $35,000-39,999$ & \\
\hline $40,000-44,999$ & \\
\hline $45,000-49,999$ & \\
\hline $50,000-59,999$ & \\
\hline $60,000-74,999$ & \\
\hline $75,000-99,999$ & \\
\hline $100,000-124,999$ & \\
\hline $125,000-149,999$ & \\
\hline $150,000-199,999$ & \\
\hline Over 200,000 & \\
\hline
\end{tabular}

\section{B. Resilience}

Level of agreement with the statements below:

18. I have many options available if I decide to no longer be a fisher.

1 strongly disagree $\quad 2$ disagree $\quad 3$ neutral 4 agree 5 strongly agree

19. I am confident that I could get work elsewhere if I needed to.

1 strongly disagree $\quad 2$ disagree $\quad 3$ neutral 4 agree 5 strongly agree

20. I am too young to retire and too old to find work elsewhere.

1 strongly disagree $\quad 2$ disagree $\quad 3$ neutral 4 agree 5 strongly agree

21. I would be nervous trying something else.

5 strongly disagree $\quad 4$ disagree $\quad 3$ neutral 2 agree 1 strongly agree

22. I can cope with small changes in industry.

1 strongly disagree $\quad 2$ disagree $\quad 3$ neutral 4 agree 5 strongly agree

23. I have planned for my financial security.

1 strongly disagree $\quad 2$ disagree $\quad 3$ neutral 4 agree 5 strongly agree

24. Every time there is a change I plan a way to make it work for me.

1 strongly disagree $\quad 2$ disagree $\quad 3$ neutral 4 agree 5 strongly agree 
25. I am more likely to adapt to change compared to other fishers.

1 strongly disagree $\quad 2$ disagree $\quad 3$ neutral 4 agree 5 strongly agree

26. I do not think I am competitive enough to survive much longer.

5 strongly disagree $\quad 4$ disagree $\quad 3$ neutral 2 agree 1 strongly agree

27. I am confident things will turn out well for me.

1 strongly disagree $\quad 2$ disagree $\quad 3$ neutral 4 agree 5 strongly agree

28. If there are any more changes I will not survive much longer.

5 strongly disagree $\quad 4$ disagree $\quad 3$ neutral 2 agree 1 strongly agree

29. I am interested in learning new skills outside the industry.

1 strongly disagree $\quad 2$ disagree $\quad 3$ neutral 4 agree 5 strongly agree

C. Job Satisfaction

How satisfied are you with the following items related to the job of fishing?

30. Your actual earnings?

1 Verydissatisfied 2Dissatisfied 3Neutral4Satisfied 5Very satisfied

31. Predictability of your earnings?

1Very dissatisfied 2Dissatisfied 3Neutral4Satisfied 5Very satisfied

32. Job safety?

1Verydissatisfied 2Dissatisfied 3Neutral4Satisfied 5Very satisfied

33. Time spent away from home?

1Verydissatisfied 2Dissatisfied 3Neutral4Satisfied 5Very satisfied

34. Physical fatigue of the job?

1Very dissatisfied 2Dissatisfied 3Neutral4Satisfied 5Very satisfied

35. Healthfulness of the job?

1Verydissatisfied 2Dissatisfied 3Neutral4Satisfied 5Very satisfied

36. Adventure of the job?

1Very dissatisfied 2Dissatisfied 3Neutral4Satisfied 5Very satisfied

37. Challenge of the job?

1Very dissatisfied 2Dissatisfied 3Neutral4Satisfied 5Very satisfied

38. Opportunity to be your own boss?

1Very dissatisfied 2Dissatisfied 3Neutral4Satisfied 5Very satisfied

39. Would you advise a young person to enter fishing? No___ Yes__

40. Would you still fish if you had your life to live over? No__ Yes_ 


\section{APPENDIX II}

Supplemental questionnaire

\section{LOCATION:}

\section{INTERVIEWER:}

DATE:

1. Port:

2. How many year of fishing experience?

3. How many years fishing out of the current port?

4. (If fished in different place before) Where did you fish before?

5. Position on the boat:

\begin{tabular}{|l|l|}
\hline Captain & \\
\hline Owner & \\
\hline Captain/owner & \\
\hline Crew & \\
\hline Mate & \\
\hline
\end{tabular}

Does the boat belong to a sector:

$$
\text { Yes_ }
$$
No

6. Gears used:

7. Principal species targeted:

8. Age:

9. Education:

10. On a scale ranging from 1 to 15 how much flexibility do you as a fisherman have to exploit different species (i.e. switch between different species if needed) today?

$\begin{array}{lccccccccccccc}1 & 2 & 3 & 4 & 5 & 6 & 7 & 8 & 9 & 10 & 11 & 12 & 13 & 14 \\ \text { (NOT FLEXIBLE) } & & & & & & & & & & & 15 \\ \text { (VERY FLEXIBLE) }\end{array}$

11. On a scale ranging from 1 to 15 how much flexibility did you as a fisherman have to exploit different species (i.e. switch between different species if needed) when you first began fishing?

$$
\begin{array}{lccccccccccccc}
1 & 2 & 3 & 4 & 5 & 6 & 7 & 8 & 9 & 10 & 11 & 12 & 13 & 14 \\
\text { (NOT FLEXIBLE) }
\end{array}
$$

12. On a scale ranging from 1 to 15 how much flexibility do you as a fisherman have to use different gear types (i.e. switch gear types if needed) today?

$\begin{array}{lccccccccccccc}1 & 2 & 3 & 4 & 5 & 6 & 7 & 8 & 9 & 10 & 11 & 12 & 13 & 14 \\ \text { (NOT FLEXIBLE) } & & & & & & & & & & & 15 \\ \text { (VERY FLEXIBLE) }\end{array}$

13. On a scale ranging from 1 to 15 how much flexibility did you as a fisherman have to different gear types (i.e. switch gear types if needed) when you first began fishing?

$$
\begin{array}{lccccccccccccc}
1 & 2 & 3 & 4 & 5 & 6 & 7 & 8 & 9 & 10 & 11 & 12 & 13 & 14 \\
\text { (NOT FLEXIBLE) } & & & & & & & & & & & 15 \\
\text { (VERY FLEXIBLE) }
\end{array}
$$

\section{If responses reflect changes through time:}

14. In your opinion, when did this change begin to occur?

15. In your opinion, why did this change occur? 
APPENDIX III

Albacore Tuna

American Eel

American Plaice Flounder

Atlantic Halibut

Atlantic Herring

Atlantic Mackerel

Atlantic Salmon

Barndoor Skates

Bay Scallops

Big Eye Tuna

Black Sea Bass

Blackfin Tuna

Blue Back Herring

Blue Crab

Bluefin Tuna

Bluefish

Blueline Tilefish

Bonito

Butterfish

Clearnose Skates

Cod

Conch

Conger Eel

Dolphin

Frigate Mackerel

Golden Tilefish

Goldface Tilefish

Haddock

Horseshoe Crab

Illex Squid

Jonah Crab

King Mackerel

King Whiting

Little Skates

Little Tuna

Lobster

Loligo Squid

Menhaden

Mix Red \& White Hake
Monkfish

Mussels

Ocean Pout

Ocean Quahog

Octopus

Offshore Hake

Other Shellfish

Other Shellfish

Oyster

Periwinkles

Pollock

Quahog

Red Crab

Red Hake

Red Porgy

Redfish

Sand Tilefish

Scup

Sea Cucumber

Sea Scallops

Sea Urchin

Silver \& Offshore Hake

(Mix)

Silver Hake

Skates

Skip Jack Tuna

Smooth Dogfish

Smooth Skates

Spanish Mackerel

Spiny Dogfish

Spotted Weakfish

Steelhead Trout

Striped Bass

Summer Flounder

Surf Clam

Swordfish

Tautog

Thorny Skates

Tilefish (NK)
Wahoo

Weakfish

Whelk

White Hake

Winter Flounder

Winter Skates

Winter Skates

Witch Flounder

Wolf Fish

Yellow Perch

Yellowfin Tuna

Yellowtail Flounder 
APPENDIX IV

\begin{tabular}{lllll}
\hline \multicolumn{5}{c}{ In-State/Out-State Residence (rows) by Port (columns) } \\
\hline & Point Judith (N) & New Bedford (N) & Cape Cod (N) & Total (N) \\
\hline In-State/Port Town & 8 & 14 & 10 & 32 \\
In-State/Different Town & 42 & 20 & 13 & 75 \\
Out-State & 1 & 7 & 1 & 9 \\
Total & $\mathbf{5 1}$ & $\mathbf{4 1}$ & $\mathbf{2 4}$ & $\mathbf{1 1 6}$ \\
\hline
\end{tabular}

Point Judith:

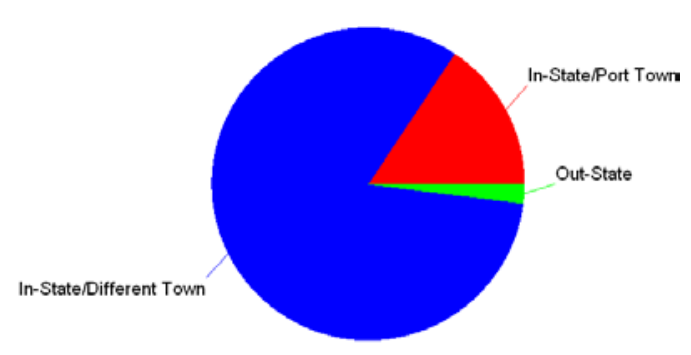

In-State/Out-State Residence

New Bedford:

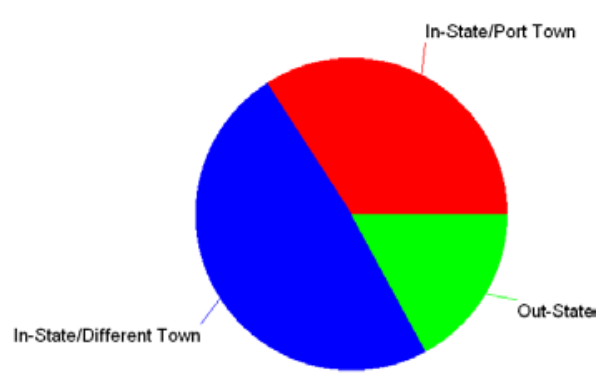

In-State/Out-State Residence

\section{Cape Cod:}

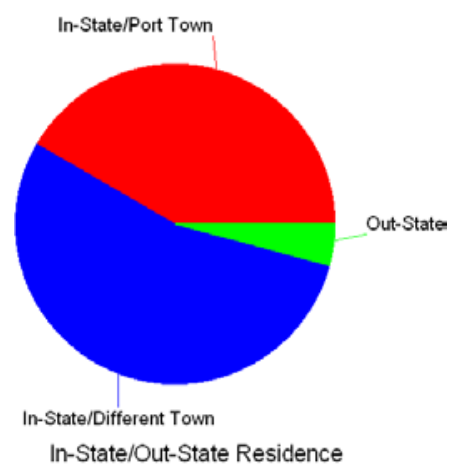




\section{APPENDIX V}

Occupations besides fishing mentioned by respondents:

\begin{tabular}{lc}
\hline Occupation & Frequency of response \\
\hline Part-time musician & 1 \\
Engineer & 1 \\
Boat building/repair & 1 \\
Carpentry & 3 \\
Construction & 3 \\
Farming & 1 \\
House painting & 1 \\
Tree farming & 1 \\
Journalist & 1 \\
Mechanic/fiberglass & 2 \\
Contractor cable company & 2 \\
Truck driving & 1 \\
Paramedic & 1 \\
Artist & 1 \\
Building trade & 1 \\
Real estate agent & 1 \\
Odd jobs & 1 \\
\hline
\end{tabular}




\section{APPENDIX VI}

Combinations of primary (rows) and secondary (columns) gear types for the overall sample:

\begin{tabular}{lllllllllll}
\hline & Trawl & Traps & Dredge & Gillnet & Fish Pots & $\begin{array}{l}\text { Rod \& } \\
\text { Reel }\end{array}$ & $\begin{array}{l}\text { Mid- } \\
\text { Water } \\
\text { Trawl }\end{array}$ & $\begin{array}{l}\text { Traps + } \\
\text { Rod \& } \\
\text { Reel }\end{array}$ & Fly Net & Total \\
\hline Trawl & 0 & 0 & $10(36 \%)$ & 0 & 0 & $1(3.6 \%)$ & $1(3.6 \%)$ & 0 & $1(3.6 \%)$ & $\mathbf{1 3 ( 4 7 \% )}$ \\
Traps & 0 & 0 & 0 & $2(7.2 \%)$ & $2(7.2 \%)$ & $2(7.2 \%)$ & 0 & 0 & 0 & $\mathbf{6 ( 2 2 \% )}$ \\
Dredge & $5(17.9 \%)$ & $1(3.6 \%)$ & 0 & 0 & 0 & 0 & 0 & 0 & 0 & $\mathbf{6 ( 2 2 \% )}$ \\
Gillnet & $1(3.6 \%)$ & $1(3.6 \%)$ & 0 & 0 & 0 & 0 & 0 & $1(3.6 \%)$ & 0 & $\mathbf{3 ( 1 1 \% )}$ \\
Total & $\mathbf{6 ( 2 1 . 5 \% )}$ & $\mathbf{2 ( 7 . 2 \% )}$ & $\mathbf{1 0}(\mathbf{3 6 \% )}$ & $\mathbf{2 ( 7 . 2 \% )}$ & $\mathbf{2 ( 7 . 2 \% )}$ & $\mathbf{3 ( 1 1 \% )}$ & $\mathbf{1 ( 3 . 6 \% )}$ & $\mathbf{1 ( 3 . 6 \% )}$ & $\mathbf{1 ( 3 . 6 \% )}$ & $\mathbf{2 8 ( 1 0 0 \% )}$ \\
\hline
\end{tabular}




\section{APPENDIX VII}

Primary species landed (volume) for all ports combined:

\begin{tabular}{ll}
\hline Species & Frequency of response \\
\hline Scallops & $24(22.7 \%)$ \\
Squid & $18(17 \%)$ \\
Lobster & $9(8.5 \%)$ \\
Scup & $6(5.7 \%)$ \\
Skates & $6(5.7 \%)$ \\
Crab & $5(4.7 \%)$ \\
Surf Clams & $4(3.8 \%)$ \\
Flounder & $4(3.8 \%)$ \\
Dogfish & $4(3.8 \%)$ \\
Haddock & $3(2.8 \%)$ \\
Winter Flounder & $2(1.9 \%)$ \\
Quahog & $2(1.9 \%)$ \\
Fluke & $2(1.9 \%)$ \\
Groundfish & $2(1.9 \%)$ \\
Cod & $2(1.9 \%)$ \\
Whiting & $2(1.9 \%)$ \\
Striped Bass & $2(1.9 \%)$ \\
Bluefish & $2(1.9 \%)$ \\
Conch & $1(0.9 \%)$ \\
Squid and Scup (equally important) & $1(0.9 \%)$ \\
Redfish & $1(0.9 \%)$ \\
Tuna & $1(0.9 \%)$ \\
Skates and Dogfish (equally important) & $1(0.9 \%)$ \\
Striped Bass and Bluefish (equally important) & $1(0.9 \%)$ \\
Depends & $1(0.9 \%)$ \\
Total & $\mathbf{1 0 6 ( 1 0 0 \% )}$ \\
\hline
\end{tabular}

Secondary species landed (volume) for all ports combined:

\begin{tabular}{ll}
\hline Species & Frequency of response \\
\hline None & $18(17 \%)$ \\
Fluke & $11(1.9 \%)$ \\
Monkfish & $10(9.6 \%)$ \\
Lobster & $9(8.7 \%)$ \\
Scup & $7(6.7 \%)$ \\
Groundfish & $6(5.8 \%)$ \\
Cod & $6(5.8 \%)$ \\
Tuna & $6(5.8 \%)$ \\
Squid & $4(3.8 \%)$ \\
Crab & $4(3.8 \%)$ \\
Whiting & $3(2.9 \%)$ \\
Skates & $3(2.9 \%)$ \\
Scallops & $2(1.9 \%)$ \\
Flounder & $2(1.9 \%)$ \\
Pollock & $2(1.9 \%)$ \\
Bluefish & $2(1.9 \%)$ \\
Surf Clams & $2(1.9 \%)$ \\
Yellowtail Flounder & $2(1.9 \%)$ \\
Conch & $1(0.9 \%)$ \\
Striped Bass and Surf Clams (equally important) & $1(0.9 \%)$ \\
Quahog & $1(0.9 \%)$ \\
Fluke and Scup (equally important) & $1(0.9 \%)$ \\
Depends & $1(0.9 \%)$ \\
Total & $\mathbf{1 0 4}(\mathbf{1 0 0} \%)$ \\
\hline
\end{tabular}


Primary species landed (volume) for Point Judith:

\begin{tabular}{ll}
\hline Species & Frequency of response \\
\hline Squid & $15(37.5 \%)$ \\
Scup & $6(15 \%)$ \\
Skates & $4(10 \%)$ \\
Lobster & $4(10 \%)$ \\
Crab & $4(10 \%)$ \\
Whiting & $2(5 \%)$ \\
Fluke & $2(5 \%)$ \\
Groundfish & $1(2.5 \%)$ \\
Scallops & $1(2.5 \%)$ \\
Squid and Scup (equally important) & $1(2.5 \%)$ \\
Total & $\mathbf{4 0 ( 1 0 0 \% )}$ \\
\hline
\end{tabular}

Secondary species landed (volume) for Point Judith:

\begin{tabular}{ll}
\hline Species & Frequency of response \\
\hline Fluke & $9(23.7 \%)$ \\
Scup & $7(18.4 \%)$ \\
Lobster & $6(15.8 \%)$ \\
Groundfish & $4(10.5 \%)$ \\
Whiting & $3(7.8 \%)$ \\
Squid & $3(7.8 \%)$ \\
Crab & $2(5.3 \%)$ \\
Skates & $1(2.6 \%)$ \\
Monkfish & $1(2.6 \%)$ \\
Fluke and Scup (equally important) & $1(2.6 \%)$ \\
None & $1(2.6 \%)$ \\
Total & $\mathbf{4 0 ( 1 0 0 \% )}$ \\
\hline
\end{tabular}

Primary species landed (volume) for New Bedford:

\begin{tabular}{ll}
\hline Species & Frequency of response \\
\hline Scallops & $18(43.9 \%)$ \\
Flounder & $4(9.8 \%)$ \\
Haddock & $3(7.3 \%)$ \\
Lobster & $2(4.9 \%)$ \\
Squid & $2(4.9 \%)$ \\
Winter Flounder & $2(4.9 \%)$ \\
Quahog & $2(4.9 \%)$ \\
Surf Clams & $1(2.4 \%)$ \\
Skates & $1(2.4 \%)$ \\
Crab & $1(2.4 \%)$ \\
Groundfish & $1(2.4 \%)$ \\
Cod & $1(2.4 \%)$ \\
Redfish & $1(2.4 \%)$ \\
Conch & $1(2.4 \%)$ \\
Depends & $1(2.4 \%)$ \\
Total & $\mathbf{4 1 ( 1 0 0 \% )}$ \\
\hline
\end{tabular}


Secondary species landed (volume) for New Bedford:

\begin{tabular}{ll}
\hline Species & Frequency of response \\
\hline None & $10(24.4 \%)$ \\
Monkfish & $9(21.9 \%)$ \\
Cod & $5(12.2 \%)$ \\
Lobster & $2(4.9 \%)$ \\
Crab & $2(4.9 \%)$ \\
Scallops & $2(4.9 \%)$ \\
Surf Clams & $2(4.9 \%)$ \\
Yellowtail Flounder & $2(4.9 \%)$ \\
Flounder & $2(4.9 \%)$ \\
Groundfish & $1(2.4 \%)$ \\
Pollock & $1(2.4 \%)$ \\
Fluke & $1(2.4 \%)$ \\
Conch & $1(2.4 \%)$ \\
Depends & $1(2.4 \%)$ \\
Total & $\mathbf{4 1 ( 1 0 0 \% )}$ \\
\hline
\end{tabular}

Primary species landed (volume) for Cape Cod:

\begin{tabular}{ll}
\hline Species & Frequency of response \\
\hline Scallops & $5(20 \%)$ \\
Dogfish & $4(16 \%)$ \\
Surf Clams & $3(12 \%)$ \\
Lobster & $3(12 \%)$ \\
Bluefish & $2(8 \%)$ \\
Striped Bass & $2(8 \%)$ \\
Skates & $1(4 \%)$ \\
Squid & $1(4 \%)$ \\
Cod & $1(4 \%)$ \\
Tuna & $1(4 \%)$ \\
Skates and Dogfish (equally important) & $1(4 \%)$ \\
Striped Bass and Bluefish (equally important) & $1(4 \%)$ \\
Total & $\mathbf{2 5 ( 1 0 0 \% )}$ \\
\hline & \\
Secondary species landed (volume) for Cape Cod: & \\
\hline Species & Frequency of response \\
\hline None & $7(28 \%)$ \\
Tuna & $6(24 \%)$ \\
Skates & $2(8 \%)$ \\
Bluefish & $2(8 \%)$ \\
Fluke & $1(4 \%)$ \\
Groundfish & $1(4 \%)$ \\
Cod & $1(4 \%)$ \\
Lobster & $1(4 \%)$ \\
Squid & $1(4 \%)$ \\
Pollock & $1(4 \%)$ \\
Striped Bass and Surf Clams (equally important) & $1(4 \%)$ \\
Total & $1(4 \%)$ \\
& $\mathbf{2 5 ( 1 0 0 \% )}$ \\
\hline
\end{tabular}




\section{APPENDIX VIII}

By port chi square analyses:

Advise Young to Enter Fishing by port:

\begin{tabular}{lllll}
\hline & Point Judith & New Bedford & Cape Cod & Total \\
\hline No & $28(23.9 \%)$ & $26(22.2 \%)$ & $16(13.7 \%)$ & $70(59.8 \%)$ \\
Maybe/Depends & $6(5.1 \%)$ & $4(3.4 \%)$ & $2(1.7 \%)$ & $12(10.3 \%)$ \\
Yes & $17(14.5 \%)$ & $11(9.4 \%)$ & $7(5.9 \%)$ & $35(29.9 \%)$ \\
Total & $\mathbf{5 1}$ & $\mathbf{4 1}$ & $\mathbf{2 5}$ & $\mathbf{1 1 7}(\mathbf{1 0 0 \% )}$ \\
\hline \multicolumn{5}{c}{$\chi^{\mathbf{2}} \mathbf{( 4 )}=\mathbf{0 . 9 7}, \mathbf{p}>\mathbf{0 . 0 5}$} \\
\hline
\end{tabular}

Fish if Had Life to Live Over by port:

\begin{tabular}{lllll}
\hline & Point Judith & New Bedford & Cape Cod & Total \\
\hline No & $15(12.8 \%)$ & $11(9.4 \%)$ & $3(2.6 \%)$ & $29(24.8 \%)$ \\
Maybe/Depends & $3(2.6 \%)$ & $2(1.7 \%)$ & $2(1.7 \%)$ & $7(5.9 \%)$ \\
Yes & $33(28.2 \%)$ & $28(23.9 \%)$ & $20(17.1 \%)$ & $81(69.2 \%)$ \\
Total & $\mathbf{5 1}$ & $\mathbf{4 1}$ & $\mathbf{2 5}$ & $\mathbf{1 1 7}(\mathbf{1 0 0 \% )}$ \\
\hline \multicolumn{5}{c}{$\chi^{\mathbf{2}} \mathbf{( 4 )}=\mathbf{2 . 9 9 , \mathbf { p } > \mathbf { 0 . 0 5 }}$} \\
\hline
\end{tabular}

By primary gear type chi square analyses:

Advise Young to Enter Fishing by primary gear type:

\begin{tabular}{lllll}
\hline & Multispecies & Traps & Shellfish & Total \\
\hline No & $47(40.2 \%)$ & $9(7.7 \%)$ & $14(11.9 \%)$ & $70(59.8 \%)$ \\
Maybe/Depends & $4(3.4 \%)$ & $4(3.4 \%)$ & $4(3.4 \%)$ & $12(10.3 \%)$ \\
Yes & $17(14.5 \%)$ & $5(9.4 \%)$ & $13(5.9 \%)$ & $35(29.9 \%)$ \\
Total & $\mathbf{6 8}$ & $\mathbf{1 8}$ & $\mathbf{3 1}$ & $\mathbf{1 1 7}(\mathbf{1 0 0} \%)$ \\
\hline \multicolumn{5}{c}{$\chi^{2} \mathbf{( 4 )}=\mathbf{8 . 4 5}, \mathbf{p}>\mathbf{0 . 0 5}$} \\
\hline
\end{tabular}

Fish if Had Life to Live Over by primary gear type:

\begin{tabular}{lllll}
\hline & Multispecies & Traps & Shellfish & Total \\
\hline No & $18(15.4 \%)$ & $5(4.3 \%)$ & $6(5.1 \%)$ & $29(24.8 \%)$ \\
Maybe/Depends & $6(5.1 \%)$ & $0(0.0 \%)$ & $1(0.8 \%)$ & $7(5.9 \%)$ \\
Yes & $44(37.6 \%)$ & $13(11.1 \%)$ & $24(20.5 \%)$ & $81(69.2 \%)$ \\
Total & $\mathbf{6 8}$ & $\mathbf{1 8}$ & $\mathbf{3 1}$ & $\mathbf{1 1 7}(\mathbf{1 0 0} \%)$ \\
\hline \multicolumn{5}{r}{$\chi^{\mathbf{2}} \mathbf{( 4 )}=\mathbf{3 . 4}, \mathbf{p}>\mathbf{0 . 0 5}$} \\
\hline
\end{tabular}

Basic Statistics on the two job satisfaction variables Advise Young to Enter Fishing and Fish if Had Life to Live Over:

\begin{tabular}{lcc}
\hline & Advise Young to Enter Fishing & Fish if Had Life to Live Over \\
\hline N of Cases & 117 & 117 \\
Mean & 0.701 & 1.444 \\
SD & 0.903 & 0.865 \\
\hline
\end{tabular}


APPENDIX IX

\begin{tabular}{|c|c|c|}
\hline Species & $\begin{array}{l}\text { Frequency } \\
\text { of response }\end{array}$ & $\%$ \\
\hline Squid & 28 & $(15.8 \%)$ \\
\hline Fluke & 19 & $(10.7 \%)$ \\
\hline Groundfish & 19 & (10.7\%) \\
\hline Scup & 16 & $(9.0 \%)$ \\
\hline Monkfish & 9 & $(5.1 \%)$ \\
\hline Scallops & 9 & $(5.1 \%)$ \\
\hline Tuna & 9 & (5.1\%) \\
\hline Dogfish & 8 & $(4.5 \%)$ \\
\hline Bluefish & 8 & $(4.5 \%)$ \\
\hline Lobsters & 8 & $(4.5 \%)$ \\
\hline Whiting & 5 & $(2.8 \%)$ \\
\hline Flounder & 5 & $2.8 \%)$ \\
\hline Skates & 5 & $(2.8 \%)$ \\
\hline Cod & 5 & $(2.8 \%)$ \\
\hline Sea Bass & 3 & $(1.7 \%)$ \\
\hline Haddock & 3 & $(1.7 \%)$ \\
\hline Butterfish & 2 & $(1.1 \%)$ \\
\hline Black Sea Bass & 2 & $(1.1 \%)$ \\
\hline Surf Clams & 2 & $(1.1 \%)$ \\
\hline Striped Bass & 2 & $(1.1 \%)$ \\
\hline Pollock & 2 & $(1.1 \%)$ \\
\hline Weakfish & 1 & $(0.6 \%)$ \\
\hline Bonito & 1 & $(0.6 \%)$ \\
\hline Crabs & 1 & $(0.6 \%)$ \\
\hline Mahi Mahi & 1 & $(0.6 \%)$ \\
\hline Lobster Bait & 1 & $(0.6 \%)$ \\
\hline Herring & 1 & $(0.6 \%)$ \\
\hline Tilefish & 1 & $(0.6 \%)$ \\
\hline Whelk & 1 & $(0.6 \%)$ \\
\hline
\end{tabular}




\section{APPENDIX X}

T tests comparing level of perceived flexibility to exploit different species today and when respondent first began fishing by age group:

Age $<50$

Perceived flexibility to exploit different species:

\begin{tabular}{lll}
\hline & Mean & N \\
\hline Flexibility today & 5.357 & 28 \\
Flexibility when began fishing & 10.857 & 28 \\
\hline \multicolumn{2}{c}{$\boldsymbol{t}(\mathbf{2 7})=\mathbf{- 5 . 1 8 , \boldsymbol { p } < \mathbf { 0 . 0 0 1 }}$} \\
\hline
\end{tabular}

Perceived flexibility to exploit different gear types:

\begin{tabular}{lll}
\hline & Mean & N \\
\hline Flexibility today & 7.259 & 27 \\
Flexibility when began fishing & 10.556 & 27 \\
\hline \multicolumn{2}{c}{$\mathbf{t ( 2 6 )}=\mathbf{- 3 . 4 9 ,} \boldsymbol{p}<\mathbf{0 . 0 1}$} \\
\hline
\end{tabular}

\section{Age $>50$}

Perceived flexibility to exploit different species:

\begin{tabular}{lll}
\hline & Mean & N \\
\hline Flexibility today & 5.588 & 34 \\
Flexibility when began fishing & 12.882 & 34 \\
\hline \multicolumn{2}{c}{$\mathbf{t ( 3 3 ) = - \mathbf { 7 . 5 8 } , \boldsymbol { p } < \mathbf { 0 . 0 0 1 }}$} \\
\hline
\end{tabular}

Perceived flexibility to exploit different gear types:

\begin{tabular}{lll}
\hline & Mean & N \\
\hline Flexibility today & 7.394 & 33 \\
Flexibility when began fishing & 11.394 & 33 \\
\hline \multicolumn{2}{c}{$\mathbf{t ( 3 2 )}=\mathbf{- 3 . 4 1 ,} \boldsymbol{p}<\mathbf{0 . 0 1}$} \\
\hline
\end{tabular}




\section{APPENDIX XI}
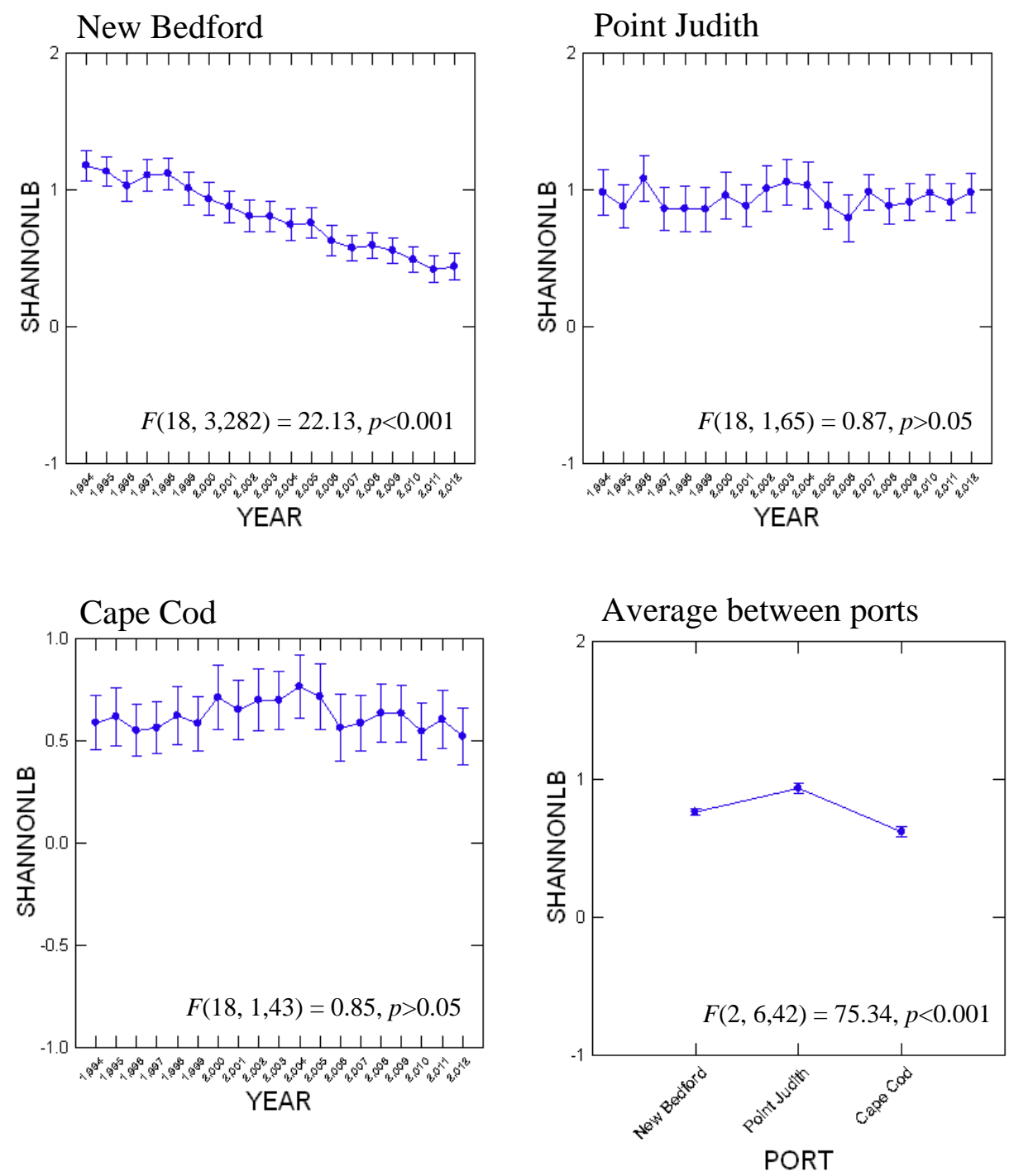
APPENDIX XII

Scree Plot

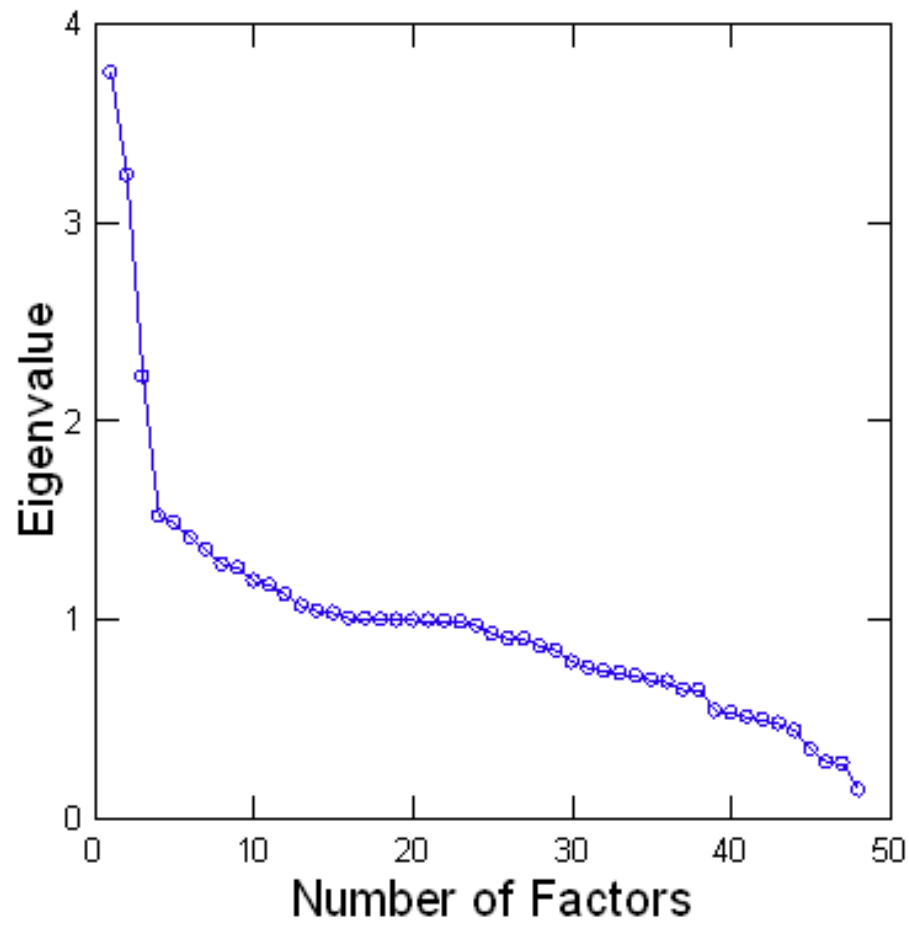


Variable transformations:

REM - - Following commands were produced by the LET dialog:

LET ALL_SKATES $=$ SKATLB+L_SKATLB+W_SKATLB+B_SKATLB+SM_SKATLB+TY_SKATLB+CN_SKATLB

LET ALL_TILE = GF_TILELB+BL_TILELB+S_TILELB+G_TILELB+NK_TILELB

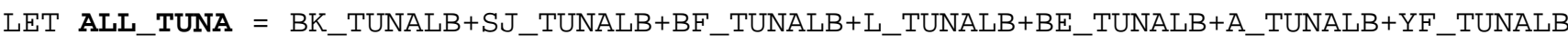

LET ALL_HAKE = SO_HAKELB+0_HAKELB+S_HAKELB+R_HAKELB+W_HAKELB+MIX_HAKELB

LET ALL_DOG = SM_DOGLB+SY_DOGLB

LET ALL_MACK = F_MACKLB+K_MACKLB+AT_MACKLB+SP_MACKLB

LET ALL_CRAB = B_CRABLB+R_CRABLB+J_CRABLB

LET ALL_WEAK = WEAKLB+S_WEAKLB

LET ALL_HERR = BLUBKHERLB+AT_HERLB

REM - - End of commands from the LET dialog 


\begin{tabular}{|c|c|c|c|c|c|c|c|c|c|c|c|c|c|c|c|c|c|c|}
\hline & 1 & 2 & 3 & 4 & 5 & 6 & 7 & 8 & 9 & 10 & 11 & 12 & 13 & 14 & 15 & 16 & 17 & 18 \\
\hline MONKLB & 0.035 & 0.024 & 0.018 & 0.042 & 0.019 & -0.134 & 0.045 & 0.026 & $\begin{array}{c}-0.680 \\
\end{array}$ & -0.014 & 0.050 & -0.091 & -0.045 & -0.151 & -0.127 & 0.058 & -0.088 & -0.024 \\
\hline BLUELB & -0.005 & 0.467 & -0.011 & -0.027 & 0.001 & -0.585 & 0.022 & 0.017 & 0.002 & 0.036 & 0.025 & -0.106 & 0.168 & 0.064 & -0.068 & 0.016 & 0.011 & -0.002 \\
\hline BONITLB & 0.007 & -0.096 & -0.018 & 0.032 & 0.005 & -0.732 & -0.039 & -0.013 & -0.026 & -0.068 & -0.025 & 0.009 & -0.074 & -0.052 & 0.047 & -0.018 & -0.015 & 0.002 \\
\hline BUTTERLB & -0.025 & 0.489 & -0.015 & 0.080 & 0.004 & -0.021 & -0.007 & 0.001 & 0.002 & -0.518 & 0.001 & -0.049 & 0.031 & -0.037 & 0.118 & 0.010 & 0.006 & -0.005 \\
\hline CODLB & 0.662 & -0.042 & 0.010 & 0.008 & 0.011 & -0.013 & 0.289 & 0.017 & -0.176 & 0.030 & 0.018 & -0.424 & -0.020 & -0.012 & 0.035 & 0.016 & -0.007 & -0.003 \\
\hline DOLPHLB & 0.001 & -0.001 & -0.645 & -0.001 & -0.051 & 0.016 & -0.015 & 0.000 & -0.004 & 0.016 & -0.076 & 0.026 & -0.010 & -0.003 & 0.000 & -0.010 & 0.004 & 0.003 \\
\hline W_FLOUNDLB & 0.836 & -0.003 & 0.014 & 0.000 & 0.012 & -0.028 & 0.092 & 0.011 & -0.075 & 0.047 & -0.013 & -0.049 & 0.039 & -0.033 & -0.081 & 0.015 & 0.000 & -0.003 \\
\hline S_FLOUNDLB & 0.070 & 0.637 & 0.006 & -0.019 & 0.010 & -0.039 & -0.033 & 0.004 & -0.043 & 0.102 & 0.025 & 0.046 & 0.113 & 0.081 & -0.480 & 0.003 & -0.019 & 0.003 \\
\hline WH_FLOUNDLB & 0.205 & 0.050 & 0.014 & 0.002 & 0.002 & 0.044 & 0.184 & -0.005 & -0.800 & 0.006 & -0.023 & 0.036 & 0.010 & 0.047 & 0.023 & -0.014 & 0.106 & 0.010 \\
\hline Y_FLOUNDLB & 0.695 & 0.107 & 0.008 & 0.025 & 0.008 & 0.017 & -0.104 & 0.003 & -0.219 & -0.078 & 0.022 & 0.160 & -0.004 & 0.001 & -0.064 & -0.003 & -0.012 & 0.004 \\
\hline AP_FLOUNDLB & 0.212 & 0.028 & 0.011 & 0.002 & 0.001 & 0.035 & 0.179 & 0.001 & -0.816 & -0.006 & -0.025 & 0.033 & 0.011 & 0.025 & 0.022 & -0.011 & -0.035 & 0.008 \\
\hline HADDLB & 0.514 & 0.026 & 0.001 & 0.008 & -0.003 & 0.007 & 0.476 & 0.005 & -0.163 & -0.016 & -0.005 & 0.058 & -0.044 & 0.022 & 0.036 & -0.010 & 0.018 & 0.009 \\
\hline AT_HALLB & 0.109 & 0.086 & 0.007 & -0.027 & 0.047 & 0.050 & 0.302 & -0.012 & -0.058 & 0.084 & -0.205 & -0.009 & 0.006 & -0.156 & 0.113 & 0.023 & -0.009 & -0.016 \\
\hline K_WHITLB & -0.045 & 0.017 & 0.005 & -0.005 & -0.002 & 0.067 & -0.075 & -0.003 & -0.153 & 0.031 & 0.025 & -0.005 & 0.061 & 0.142 & 0.052 & -0.023 & 0.784 & 0.008 \\
\hline MENHLB & 0.028 & 0.017 & -0.003 & -0.482 & -0.020 & 0.038 & -0.016 & 0.009 & 0.001 & 0.090 & 0.073 & 0.038 & -0.006 & 0.109 & 0.085 & 0.022 & -0.105 & -0.006 \\
\hline REDLB & -0.082 & -0.015 & -0.011 & 0.010 & -0.011 & 0.014 & 0.787 & 0.000 & -0.084 & -0.029 & 0.023 & 0.076 & 0.021 & 0.043 & -0.045 & -0.015 & 0.002 & 0.006 \\
\hline O_POUTLB & 0.026 & -0.026 & 0.003 & 0.029 & 0.002 & 0.154 & -0.015 & 0.005 & 0.000 & -0.062 & 0.002 & -0.080 & 0.771 & -0.127 & 0.030 & 0.005 & -0.036 & -0.004 \\
\hline POLLLB & 0.209 & -0.040 & -0.003 & 0.009 & -0.004 & -0.005 & 0.781 & 0.006 & -0.194 & -0.002 & 0.017 & -0.169 & -0.025 & 0.026 & 0.029 & 0.000 & 0.006 & 0.000 \\
\hline SCUPLB & -0.039 & 0.675 & 0.008 & -0.046 & -0.002 & -0.083 & 0.041 & 0.019 & 0.041 & 0.127 & 0.034 & 0.024 & 0.111 & 0.114 & -0.266 & 0.003 & 0.009 & 0.005 \\
\hline BS_BASSLB & -0.011 & 0.620 & 0.011 & -0.020 & 0.001 & -0.048 & 0.025 & 0.001 & 0.005 & 0.060 & -0.006 & 0.037 & 0.031 & 0.039 & -0.091 & -0.002 & 0.000 & 0.004 \\
\hline S_BASSLB & -0.017 & 0.003 & -0.011 & -0.009 & 0.024 & -0.050 & -0.004 & 0.084 & 0.064 & 0.027 & 0.056 & 0.040 & 0.020 & 0.781 & 0.066 & 0.006 & -0.048 & 0.046 \\
\hline SWORDLB & 0.003 & 0.031 & -0.880 & 0.002 & 0.018 & 0.041 & -0.021 & -0.012 & -0.011 & -0.024 & 0.007 & -0.015 & 0.057 & -0.040 & -0.002 & -0.007 & 0.002 & 0.000 \\
\hline TAUTLB & -0.009 & 0.061 & 0.012 & -0.002 & 0.004 & -0.285 & 0.007 & -0.009 & 0.024 & 0.028 & 0.004 & 0.060 & 0.679 & 0.085 & -0.012 & 0.001 & 0.011 & 0.004 \\
\hline WAHOOLB & 0.003 & 0.002 & -0.930 & -0.005 & 0.013 & 0.033 & -0.016 & -0.007 & -0.012 & 0.012 & -0.006 & 0.007 & 0.018 & -0.027 & -0.004 & -0.010 & 0.005 & 0.002 \\
\hline WOLFLB & 0.133 & 0.069 & 0.010 & -0.062 & 0.003 & 0.068 & -0.067 & 0.005 & -0.290 & 0.151 & 0.006 & -0.485 & -0.014 & -0.021 & 0.304 & 0.016 & 0.008 & -0.008 \\
\hline LOBSLB & 0.020 & -0.072 & 0.006 & 0.067 & -0.131 & 0.016 & 0.007 & 0.022 & 0.010 & -0.009 & -0.722 & 0.067 & -0.029 & 0.092 & 0.014 & -0.001 & -0.004 & 0.012 \\
\hline QUAHLB & -0.009 & -0.010 & 0.006 & 0.006 & 0.000 & -0.007 & 0.003 & -0.790 & 0.016 & -0.004 & 0.013 & -0.017 & -0.020 & 0.022 & -0.009 & -0.003 & 0.009 & -0.001 \\
\hline O_QUAHLB & 0.001 & 0.000 & 0.005 & -0.001 & 0.000 & -0.006 & 0.003 & 0.003 & 0.014 & 0.014 & 0.019 & 0.014 & 0.006 & -0.071 & 0.011 & -0.547 & -0.008 & -0.065 \\
\hline S_CLAMLB & -0.007 & -0.010 & 0.008 & 0.009 & 0.007 & 0.005 & -0.004 & -0.007 & 0.024 & 0.002 & 0.018 & 0.009 & -0.007 & -0.015 & 0.015 & -0.801 & 0.013 & 0.047 \\
\hline CONCHLB & -0.005 & -0.002 & 0.003 & -0.002 & 0.001 & 0.002 & -0.004 & -0.788 & 0.002 & 0.013 & 0.001 & 0.023 & 0.026 & 0.029 & 0.009 & 0.001 & -0.024 & 0.006 \\
\hline MUSSLB & -0.001 & 0.005 & 0.003 & -0.013 & -0.842 & 0.000 & 0.002 & -0.004 & 0.001 & 0.004 & 0.082 & -0.017 & 0.003 & -0.031 & 0.002 & 0.005 & 0.000 & -0.004 \\
\hline OCTOPLB & -0.037 & 0.029 & 0.003 & -0.035 & -0.003 & 0.079 & -0.077 & -0.018 & -0.150 & 0.042 & 0.015 & 0.004 & 0.083 & 0.130 & 0.052 & -0.026 & -0.580 & 0.001 \\
\hline
\end{tabular}




\begin{tabular}{|c|c|c|c|c|c|c|c|c|c|c|c|c|c|c|c|c|c|c|}
\hline & 1 & 2 & 3 & 4 & 5 & 6 & 7 & 8 & 9 & 10 & 11 & 12 & 13 & 14 & 15 & 16 & 17 & 18 \\
\hline OYSTLB & -0.002 & -0.002 & 0.003 & 0.002 & 0.003 & 0.003 & -0.001 & -0.006 & 0.013 & 0.006 & 0.013 & 0.007 & -0.001 & $\begin{array}{c}-0.059 \\
\end{array}$ & 0.012 & 0.040 & 0.005 & 0.984 \\
\hline PERIWLB & 0.136 & 0.006 & 0.004 & -0.021 & -0.005 & 0.007 & -0.030 & -0.016 & 0.079 & 0.053 & 0.026 & 0.116 & 0.088 & -0.110 & 0.064 & 0.143 & 0.117 & -0.095 \\
\hline B_SCALLB & -0.019 & -0.011 & -0.002 & 0.018 & 0.010 & 0.040 & 0.013 & -0.117 & 0.014 & -0.025 & -0.002 & -0.019 & -0.053 & 0.294 & 0.006 & 0.103 & 0.029 & -0.089 \\
\hline S_SCALLB & -0.228 & -0.154 & 0.022 & 0.070 & 0.039 & 0.031 & 0.059 & 0.058 & 0.121 & 0.083 & 0.368 & 0.308 & -0.079 & -0.362 & 0.208 & 0.154 & -0.013 & -0.077 \\
\hline L_SQUILB & 0.064 & 0.696 & 0.003 & 0.056 & 0.006 & -0.025 & -0.014 & 0.003 & -0.067 & -0.347 & 0.009 & 0.006 & -0.037 & -0.031 & 0.136 & 0.002 & -0.027 & -0.002 \\
\hline I_SQUILB & 0.013 & -0.001 & 0.003 & -0.113 & 0.004 & 0.001 & -0.004 & 0.007 & 0.000 & -0.826 & 0.007 & 0.016 & 0.021 & 0.044 & -0.046 & 0.011 & 0.011 & -0.001 \\
\hline OTHERLB & -0.066 & 0.025 & 0.012 & -0.039 & 0.070 & -0.022 & 0.023 & 0.003 & 0.019 & 0.015 & -0.672 & 0.003 & 0.009 & -0.124 & 0.012 & 0.051 & -0.005 & -0.026 \\
\hline ALL_SKATES & 0.086 & 0.044 & 0.010 & 0.026 & 0.010 & 0.028 & -0.044 & 0.000 & -0.068 & 0.002 & 0.013 & -0.064 & -0.049 & -0.078 & -0.777 & 0.025 & 0.007 & -0.011 \\
\hline ALL_TILE & 0.088 & 0.555 & 0.000 & 0.036 & -0.003 & -0.028 & -0.038 & -0.005 & -0.072 & -0.118 & 0.010 & 0.065 & -0.118 & -0.075 & 0.020 & -0.001 & -0.020 & -0.002 \\
\hline ALL_TUNA & -0.019 & -0.030 & -0.401 & 0.004 & 0.014 & -0.076 & 0.038 & 0.017 & 0.039 & -0.008 & 0.069 & -0.018 & -0.043 & 0.052 & 0.009 & 0.027 & -0.008 & -0.005 \\
\hline ALL_HAKE & -0.023 & 0.629 & 0.007 & -0.026 & 0.012 & 0.014 & 0.014 & -0.002 & -0.003 & 0.019 & -0.052 & -0.131 & -0.039 & -0.080 & 0.233 & 0.003 & 0.017 & -0.006 \\
\hline ALL_DOG & -0.066 & -0.052 & -0.009 & 0.053 & 0.000 & -0.040 & 0.046 & 0.003 & 0.107 & -0.060 & 0.058 & -0.761 & 0.033 & 0.004 & -0.131 & 0.024 & 0.005 & -0.010 \\
\hline ALL_MACK & -0.020 & -0.035 & 0.002 & -0.795 & 0.001 & -0.016 & 0.002 & 0.002 & 0.009 & -0.280 & 0.003 & 0.005 & 0.001 & -0.012 & -0.041 & 0.001 & 0.015 & 0.000 \\
\hline ALL_CRAB & -0.019 & -0.018 & -0.014 & 0.009 & -0.841 & 0.004 & -0.011 & 0.006 & 0.018 & 0.002 & -0.139 & 0.017 & -0.008 & 0.003 & 0.008 & 0.002 & -0.001 & 0.001 \\
\hline ALL_WEAK & 0.014 & 0.386 & -0.010 & -0.029 & -0.002 & -0.581 & -0.015 & 0.007 & -0.027 & 0.062 & 0.016 & 0.033 & 0.120 & 0.035 & -0.020 & 0.007 & 0.048 & -0.001 \\
\hline ALL_HERR & -0.035 & 0.006 & 0.005 & -0.697 & 0.018 & -0.027 & 0.011 & -0.006 & 0.024 & 0.028 & -0.073 & -0.027 & -0.015 & -0.118 & -0.035 & -0.016 & 0.074 & 0.004 \\
\hline
\end{tabular}

"Variance" Explained by Rotated Components

\begin{tabular}{llllllllllllllllll}
\hline $\mathbf{1}$ & $\mathbf{2}$ & $\mathbf{3}$ & $\mathbf{4}$ & $\mathbf{5}$ & $\mathbf{6}$ & $\mathbf{7}$ & $\mathbf{8}$ & $\mathbf{9}$ & $\mathbf{1 0}$ & $\mathbf{1 1}$ & $\mathbf{1 2}$ & $\mathbf{1 3}$ & $\mathbf{1 4}$ & $\mathbf{1 5}$ & $\mathbf{1 6}$ & $\mathbf{1 7}$ & $\mathbf{1 8}$
\end{tabular}

\begin{tabular}{llllllllllllllllll}
\hline 2.167 & 3.124 & 2.221 & 1.404 & 1.448 & 1.393 & 1.753 & 1.273 & 2.119 & 1.277 & 1.218 & 1.245 & 1.195 & 1.071 & 1.234 & 1.011 & 1.013 & 1.002
\end{tabular}

Percent of Total Variance Explained

\begin{tabular}{llllllllllllllllll}
\hline 1 & 2 & 3 & 4 & 5 & 6 & 7 & 8 & 9 & 10 & 11 & 12 & 13 & 14 & 15 & 16 & 17 & 18
\end{tabular}

\begin{tabular}{lllllllllllllllllll}
\hline 4.516 & 6.508 & 4.626 & 2.925 & 3.017 & 2.903 & 3.652 & 2.651 & 4.414 & 2.660 & 2.538 & 2.593 & 2.489 & 2.231 & 2.571 & 2.105 & 2.109 & 2.087
\end{tabular} 


\section{APPENDIX XIII}

Mussels/Crabs:
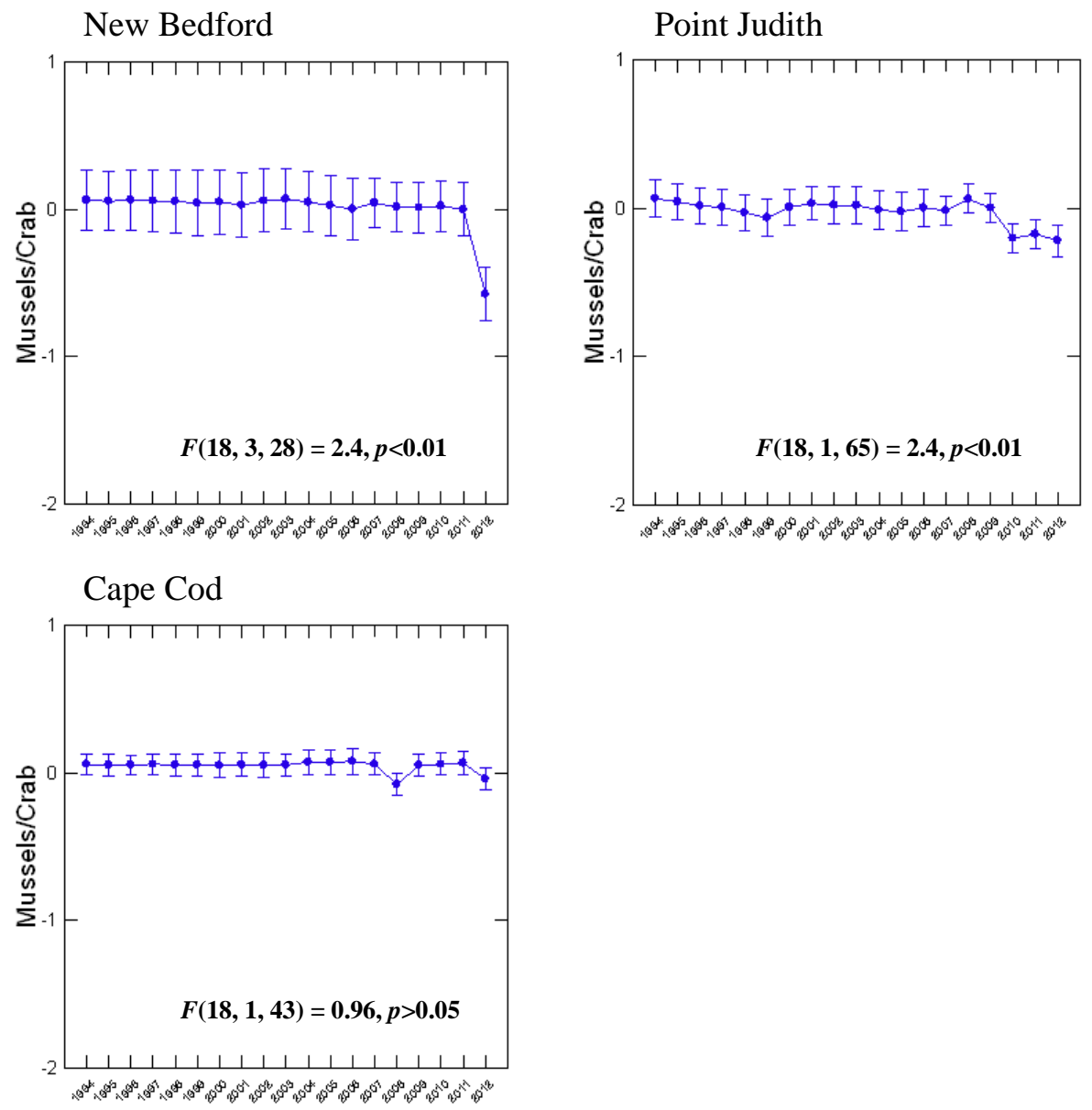
Bluefish/Bonito/Weakfish:

New Bedford

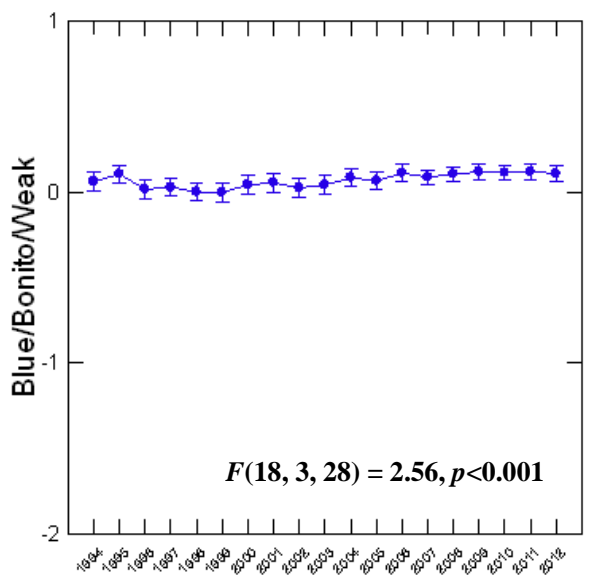

Cape Cod

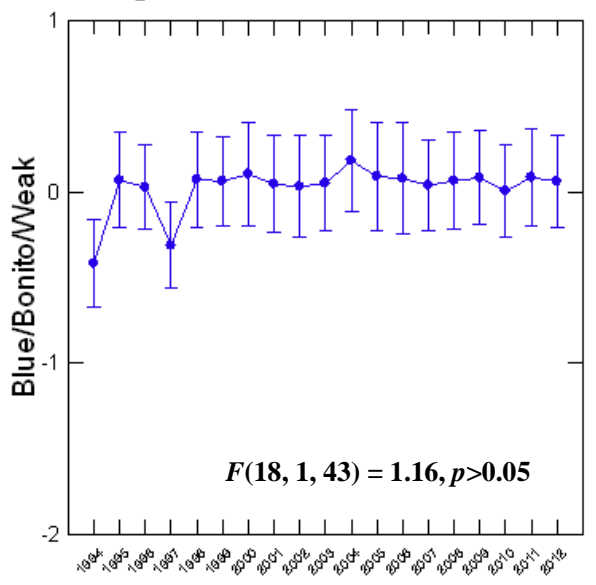

Point Judith

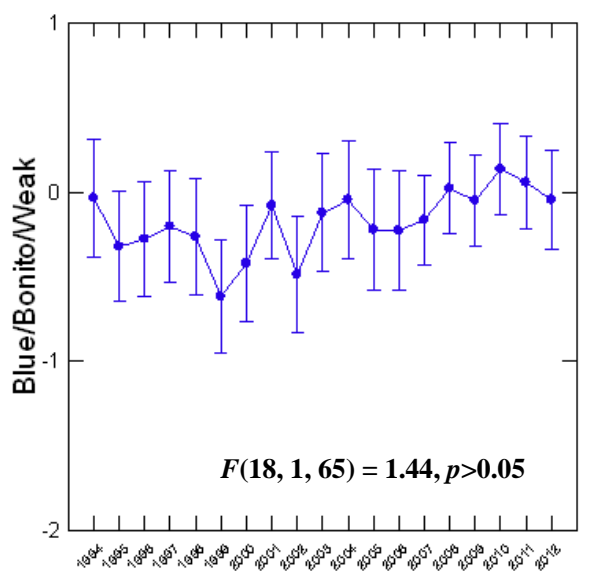


Lobster/Other/Scallops:
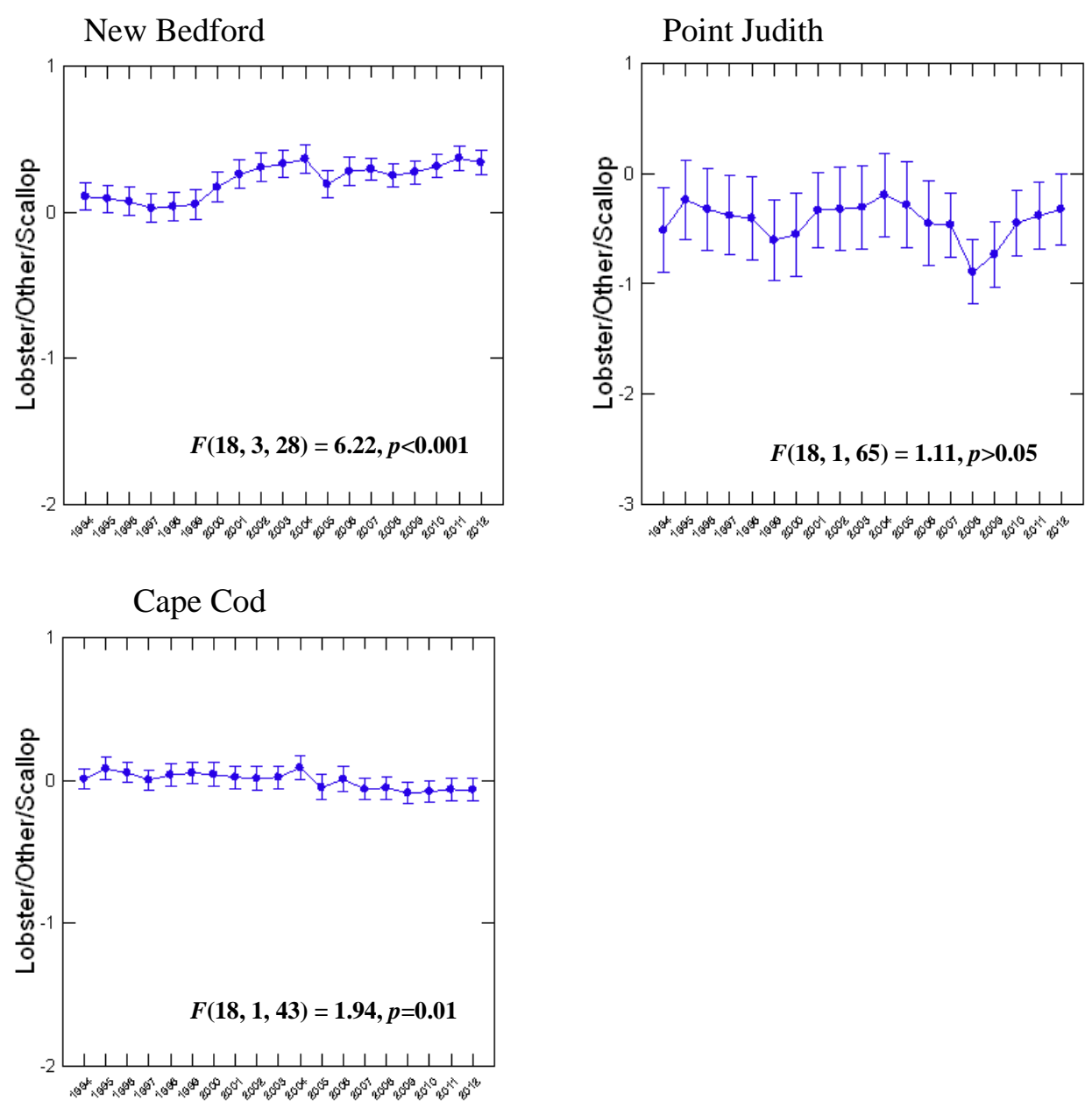
Skates:
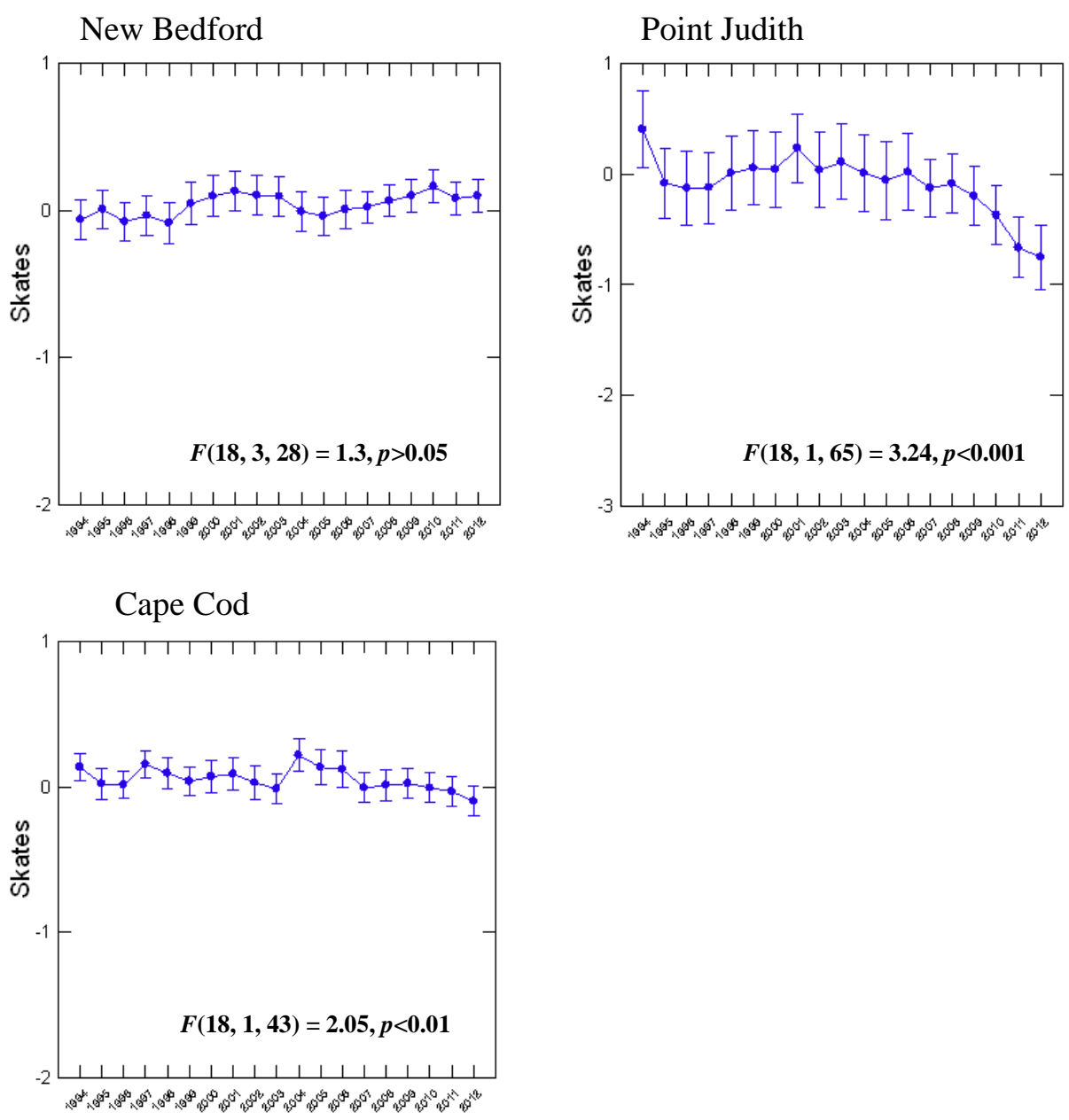
Ocean Quahog/Surf Clams:
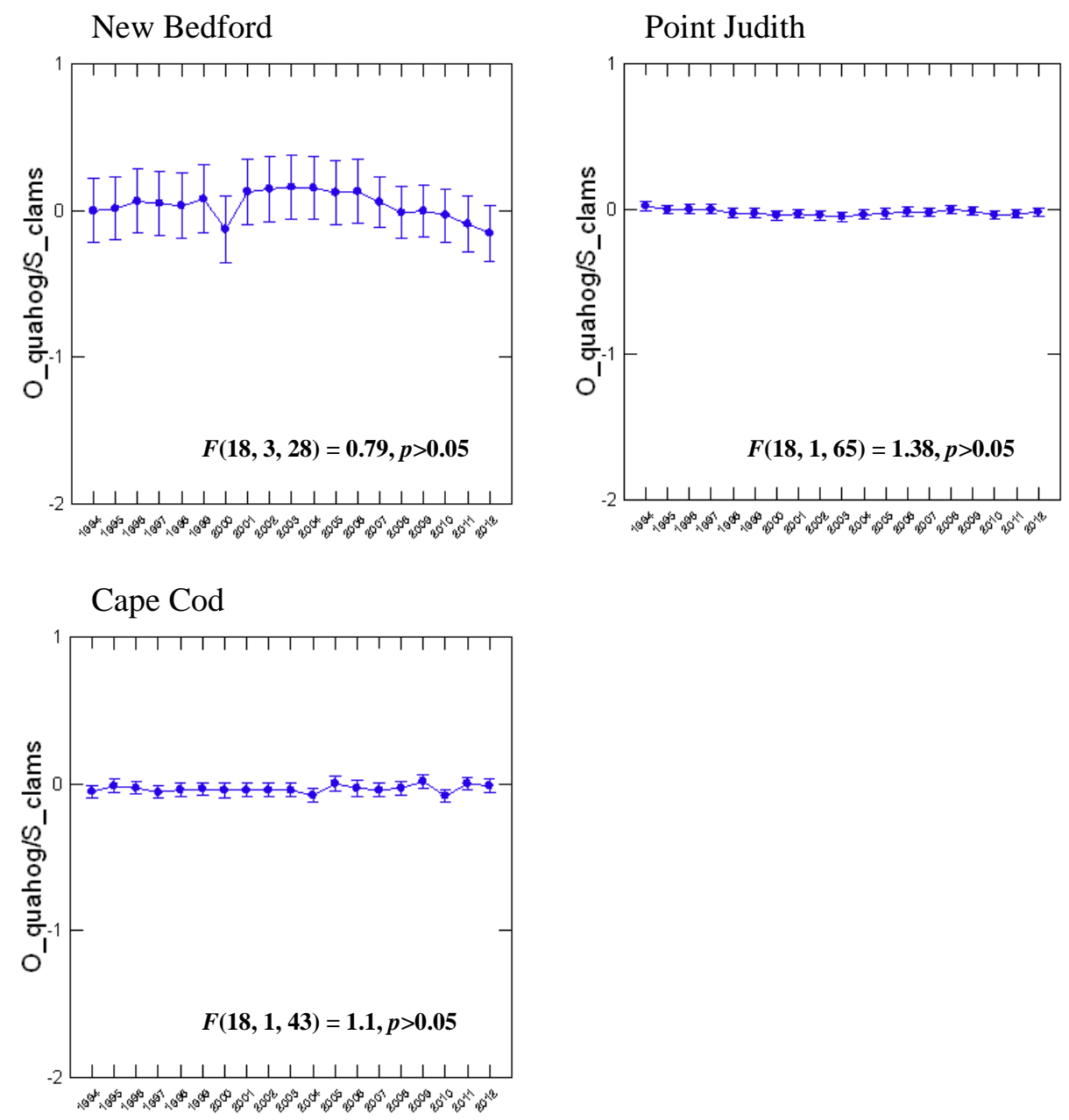


\section{BIBLIOGRAPHY}

Abel, Nick, David H M Dumming, and John M Anderies. "Collapse and Reorganization in Social-Ecological Systems: Questions, Some Ideas, and Policy Implications." Ecology and Society 11, no. 1 (2006): 1-25.

Abesamis, Nadia P, Collen Corrigan, Mark Drew, Stuart Campbell, and Giselle Samonte. "Social Resilience: A Literature Review on Building Resilience into Human Marine Communities in and around Mpa Networks," Global Conservation Program USAID, Arlington, USA, 2006. 41 p.

Acheson, J M, R B Pollnac, J J Poggie, and J A Wilson. "Study of Social and Cultural Aspects of Fisheries Management in New England under Extended Jurisdiction," National Science Foundation and University of Maine, Washington, D. C. and Orono, ME, NSF grant AER77-06018, 1980. 389 p.

Acheson, James. The Lobster Gangs of Maine. Durham, NH: University Press of New England, 1988.

Acheson, James M. "Anthropology of Fishing." Annual Review of Anthropology 10 (1981): 275-316.

Adger, Niel, Terry P Hughes, Carl Folke, Stephen Carpenter, and Johan Rockstrom. "Social-Ecological Resilience to Coastal Disasters ". Science 309 (2005): 1036-40.

Adger, W Niel. "Social and Ecological Resilience: Are They Related?". Progress in Human Geography 24, no. 3 (2000): 347-64.

Allen, Craig R, Joseph J Fontaine, Kevin L Pope, and A S Garmestani. "Adaptive Management for a Turbulent Future." Journal of Environmental Management 92 (2011): 1339-45.

Allison, Edward, and Frank Ellis. "The Livelihoods Approach and Management of Small-Scale Fisheries." Marine Policy 25 (2001): 377-88.

Allison, Edward H, Neil L Andrew, and Jamie Oliver. "Enhancing the Resilience of Inland Fisheries and Aquaculture Systems to Climate Change." Journal of Semi-Arid Tropical Agricultural Research 4, no. 1 (2007): 1-35.

Anthony, Vaughn C. "The New England Groundfish Fishery after 10 Years under the Magnuson Fishery Conservation and Management Act." North American Journal of Fisheries Management 10, no. 2 (1990): 175-84.

Apollonio, Spencer, and Jacob J Dykstra. An Enormous, Immensely Complicated Intervention: Groundfish, the New England Fishery Management Council, and the World Fisheries Crisis. Montgomery, AL: E-Book Time, LLC, 2008. 246 p. 
Apostle, R L, L Kasdan, and A Hanson. "Work Satisfaction and Community Attachment among Fishermen in Southwest Nova Scotia." Canadian Journal of Fish Aquatic Sciences 42 (1985): 256-67.

Armitage, Derek, and Ryan Plummer. "Adaptive Capacity and Environmental Governance," In "Springer Series on Environmental Management." New York, NY: Springer, 2010.

Baelde, P. "Fisher's Description of Changes in Fishing Gear and Fishing Practices in the Australian South East Trawl Fishery." Marine and Freshwater Research 52 (2001): 411-17.

Baskaran, R, and J L Anderson. "Atlantic Sea Scallop Management: An Alternative Rights-Based Cooperative Approach to Resource Sustainability." Marine Policy 29, no. 4 (2005): 357-69.

Bavinck, Maarten, Richard Pollnac, Iris Monnereau, and Pierre Failler. "Introduction to the Special Issue on Job Satisfaction in Fisheries in the Global South." Social Indicators Research 109, no. 1 (2012): 1-6.

Beisner, B E, D T Haydon, and K Cuddington. "Alternative Stable States in Ecology." Front Ecol Environ 1, no. 7 (2003): 376-82.

Béné, Christophe. "Are Fishers Poor or Vulnerable? Assessing Economic Vulnerability in Small-Scale Fishing Communities." The Journal of Development Studies 45, no. 6 (2009): 911-33.

Berkes, F, and C Folke. Linking Social and Ecological Systems: Management Practices and Social Mechanisms for Building Resilience. Cambridge, UK: Cambridge University Press, 1998.

Berkes, F, T P Hughes, R S Steneck, J A Wilson, D R Bellwood, B Crona, C Folke, et al. "Globalization, Roving Bandits, and Marine Resources." Science 311 (2006): 1557-58.

Berkes, Fikret. "Rethinking Community-Based Conservation." Environment and Ecology 18, no. 3 (2004): 621-30.

Bernard, H Russel. Research Methods in Anthropology - Qualitative and Quantitative Approaches. Fourth Edition ed. Lanham, MD: Altamira Press, 2006. 803 p.

Binkley, Marian. Risks, Dangers, and Rewards in the Nova Scotia Offshore Fishery. Montreal, Canada: McGill-Queen's University Press, 1995.

Brodziak, Jon, Steve X Cadrin, Christopher M Legault, and Steve A Murawski. "Goals and Strategies for Rebuilding New England Groundfish Stocks." Fisheries Research 94, no. 3 (2008): 355-66. 
Bruk-Lee, Valentina, Haitham A Khoury, Ashley E Nixon, Angeline Goh, and Paul E Spector. "Replicating and Extending Past Personality/Job Satisfaction MetaAnalyses." Human Performance 22, no. 2 (2009): 156-89.

Cape Cod Commercial Fishermen's Alliance. 2013. "Cape Cod Fisheries Trust." Accessed October 20, 2013. http://capecodfishermen.org/fisheries-trust.

Carpenter, Steve, Brian Walker, Marty Anderies, and Nick Abel. "From Metaphor to Measurement: Resilience of What to What?". Ecosystems 4 (2001): 765-81.

Chambers, Robert, and Gordon Conway. Sustainable Rural Livelihoods: Practical Concepts for the 21st Century. Brighton, England: Institute of Development Studies, 1992. $42 \mathrm{p}$.

Chein, I. "An Introduction to Sampling ". In Research Methods in Social Relations, edited by C Selltiz, L S Wrightsman and S W Cook. New York, NY: Holt, Rinehart and Winston, 1976. 483 p.

Christensen, Anne-Sofie, and Jesper Raakjaer. "Fishermen's Tactical and Stretegic Decisions: A Case Study of Danish Demersal Fisheries." Fisheries Research 81 (2006): 258-67.

Cinner, Joshua, T R McClanahan, and A Wamukota. "Differences in Livelihoods, Socioeconomic Characteristics, and Knowledge About the Sea between Fishers and Non-Fishers Living near and Far from Marine Parks on the Kenyan Coast." Marine Policy 34 (2010): 22-28.

Colburn, Lisa, S Abbott-Jamieson, and P Clay. "Anthropological Applications in the Management of Federally Managed Fisheries: Context, Institutional History, and Prospectus." Human Organization 65, no. 3 (2006): 231-39.

Costello, Christopher, Steven D Gaines, and John Lynham. "Can Catch Shares Prevent Fisheries Collapse?". Science 321, no. 5896 (2008): 1678-81.

Coulthard, Sarah. "Can We Be Both Resilient and Well, and What Choices Do People Have? Incorporating Agency into Resilience Debate from a Fisheries Perspective." Ecology and Society 17, no. 1 (2012): 1-4.

Crane, Todd A. "Of Models and Meanings: Cultural Resilience in Social-Ecological Systems." Ecology and Society 15, no. 4 (2010): 16.

Crawford, Brian. 2002. "Seaweed Farming: And Alternative Livelihood for SmallScale Fishers?" University of Rhode Island, Accessed July 22, 2013. www.crc.uri.edu/download/Alt_Livelihood.pdf.

Crocker, Michael. Sharing the Ocean: Stories of Science, Politics, and Ownership. Gardiner, ME: Tilbury House Publishers, 2008. 160 p. 
Cutter, Susan L, Lindsey Barnes, Melissa Berry, Christopher Burton, Elijah Evans, Eric Tate, and Jennifer Webb. "A Place-Based Model for Understanding Community Resilience to Natural Disasters." Global Environmental Change 18 (2008): 598-606.

Cutter, Susan L, Christopher T Emrich, Jennifer J Webb, and Daniel Morath. "Social Vulnerability to Climate Variability Hazards: A Review of the Literature," Oxfam America, 2009. 44 p.

Davidson, Debra J. "The Applicability of the Concept of Resilience to Social Systems: Some Sources of Optimism and Nagging Doubts." Society \& Natural Resources 23, no. 12 (2010): 1135-49.

Dell'Apa, Andrea, Lisa Schiavinato, and Roger A Rulifson. "The Magnuson-Stevens Act (1976) and Its Resuthorizations: Failure or Success for the Implementation of Fishery Sustainability and Management in the U.S.?". Marine Policy 36, no. 3 (2012): 673-80.

Dennett, D. Darwins Dangerous Idea: Evolution and the Meanings of Life. New York: Simon and Schuster, 1995. 586 p.

Derissen, Sandra, Martin F Quaas, and Stefan Baumgartner. "The Relationship between Resilience and Sustainability of Ecological-Economic Systems." Ecological Economics 70 (2011): 1121-28.

Doak, D F, D Bigger, E K Harding, M A Marvier, R E O'Malley, and D Thomson. "The Statistical Inevitability of Stability-Diversity Relationships in Community Ecology." The American Naturalist 151 (1998): 264-76.

Doeringer, P, P L Moss, and D G Terkla. The New England Fishing Economy: Jobs, Income and Kinship. Amherst, MA: University of Massachusetts Press, 1986.

Dublin, H T, A R E Sinclair, and McGlade J. "Elephants and Fire as Causes of Multiple Stables States in the Serengeti-Mara Woodlands." Journal of Animal Ecology 59 (1990): 1147-64.

Ebbin, Syma A. "Institutional and Ethical Dimensions of Resilience in Fishing Systems: Perspectives from Co-Managed Fisheries in the Pacific Northwest." Marine Policy 32 (2009): 264-70.

Edwards, Steven F. "Rent-Seeking in the U.S. Atlantic Sea Scallop Fishery." Marine Resource Economics 16 (2002): 263-75.

Ellis, Frank. Rural Livelihood Diversity in Developing Countries. Oxford, UK: Oxford University Press, 2000. 296 p.

Elton, E J, and M J Gruber. "Risk Reduction and Portfolio Size: An Analytical Solution." The Journal of Business 50 (1977): 415-37. 
Folke, Carl, Stephen Carpenter, Brian Walker, Marten Scheffer, Thomas Elmqvist, L H Gunderson, and C S Holling. "Regime Shifts, Resilience, and Biodiversity in Ecosystem Management." Annu. Rev. Ecol. Evol. Syst. 35 (2004): 557-81.

Folke, Carl. "Resilience: The Emergence of a Perspective for Social-Ecological Systems Analyses." Global Environmental Change 16 (2006): 14.

Freund, J E. Modern Elementary Statistics. Englewood Cliffs, NJ: Prentice-Hall, Inc., 1960. $576 \mathrm{p}$.

Gallopín, Gilberto. "Linkages between Vulnerability, Resilience, and Adaptive Capacity." Global Environmental Change 16 (2006): 293-303.

Gatewood, J B, and B J McCay. "Comparison of Job Satisfaction in Six New Jersey Fisheries." Human Organization 49, no. 1 (1990): 14-25.

Gersuny, Carl, and J J Poggie. "Harbor Improvements and Fishing at Point Judith." Rhode Island History 32 (1973): 23-32.

- Fishermen of Galilee: The Human Ecology of a New England Coastal Community. Marine Bulleting Series Vol. 17, Kingston, RI: University of Rhode Island, 1974. 117 p.

Gibbs, Mark T. "Resilience: What Is It and What Does It Mean for Marine Policymakers?". Marine Policy 33 (2009): 322-31.

Ginkel, Rob van. Coastal Cultures: An Anthropology of Fishing and Whaling Traditions. Amsterdam: Spinhuis Publishers, 2007. 240 p.

Glazier, E W. Hawaiian Fishermen. Belmont, CA: Thompson Wadsworth Co., 2007. $160 \mathrm{p}$.

Griffith, David, and Manuel Valdes Pizzini. Fishers at Work, Workers at Sea: A Puerto Rican Journey through Labor and Refuge. Philadelphia, PA: Temple University Press, 2002. 280 p.

Gunderson, L H, and C S Holling. "Resilience and Adaptive Cycles." In Panarchy: Understanding Transformations in Human and Natural Systems, edited by L H Gunderson and C S Holling. Washington, D.C., USA: Island Press, 2002. 536 p.

Ha, Tran Thi Phung, and Han van Dijk. "Fishery Livelihoods and (Non-)Compliance with Fishery Regulations - a Case Study in Ca Mau Province, Mekong Delta, Viet Nam." Marine Policy 38 (2013): 417-27.

Hall-Arber, Madeleine, Chris Dyer, J J Poggie, James McNally, and Renee Gagne. "New England Fishing Communities," MIT Sea Grant College Program, Cambridge, MA, 2001. 426 p. 
Hanazaki, Natalia, Fikret Berkes, Cristiana S Seixas, and Nivaldo Peroni. "Livelihood Diversity, Food Security and Resilience among the Caiçara of Coastal Brazil." Human Ecology 41, no. 1 (2013): 153-64.

Hartley, Troy W. "Fishery Management as a Governance Network: Examples from the Gulf Od Maine and the Potential for Communication Network Analysis Research in Fisheries." Marine Policy 34 (2010): 1060-67.

Healey, M C, and T Hennessey. "The Paradox of Fairness: The Impact of Escalating Complexity on Fishery Management." Marine Policy 22, no. 2 (1998): 109-18.

Healey, Michael C. "Resilient Salmon, Resilient Fisheries for British Columbia, Canada." Ecology and Society 14, no. 1 (2009): 1-13.

Hennessey, T, and M Healey. "Ludwig's Ratchet and the Collapse of New England Groundfish Stocks." Coastal Management 28 (2000): 187-213.

Hilborn, R, T P Quinn, D E Schindler, and D E Rogers. "Biocomplexity and Fisheries Sustainability." Proceedings of the National Academy of Science 100 (2003): 6564-68.

Holland, Daniel S, Patricia Pinto da Silva, and Joshua Wiersma. "A Survey of Social Capital and Attitudes toward Management in the New England Groundfish Fishery," U.S. Department of Commerce, Northeast Fisheries Science Center, Reference Document 10-12, 2010.

Holling, C S. "Principles of Insect Predation." Annual Review of Entomology 6 (1961): 163-82.

_. "Resilience and Stability of Ecological Systems." Annual Review of Ecology and Systematics 4 (1973): 22.

—_. "What Barriers? What Bridges?". In Barriers and Bridges to the Renewal of Ecosystems and Institutions, edited by L H Gunderson, C S Holling and S S Light. New York: Columbia University Press, 1995. 3-34 p.

__. "Engineering Resilience Versus Ecological Resilience." In Engineering within Ecological Constraints edited by P Schulze. Washington DC: National Academy Press, 1996. 31-44 p.

Holling, C S, L H Gunderson, and G Peterson. "Sustainability and Panarchies." In Panarchy: Understanding Transformations in Human and Natural Systems, edited by L H Gunderson and C S Holling. Washington, D. C., USA: Island Press, 2002. 536 p.

Hoss, D E, G E Bath, F A Cross, and J V Merriner. "U.S. Atlantic Coastal Fisheries How Effective Have Management Plans Been in Maitaining "Sustainable 
Fisheries"?". Limnologica - Ecology and Management of Inland Waters 29, no. 3 (1999): 227-32.

Jackson, Jeremy B C, Michael X Kirby, Wolfgang H Berger, Karen A Bjorndal, Louis W Botsford, B J Bourque, R H Bradbury, et al. "Hisotrical Overfishing and the Recent Collapse of Coastal Ecosystems." Science 293 (2001): 629-38.

Jacob, Steve, Priscilla Weeks, Benjamin Blount, and Michael Jepson. "Development and Evaluation of Social Indicators of Vulnerability and Resiliency for Fishing Communities in the Gulf of Mexico." Marine Policy 37, no. 1 (2013): 86-95.

Jin, Di, Eric Thunberg, Hauke Kite-Powell, and Kevin Blake. "Total Factor Productivity Change in the New England Groundfish Fishery: 1964-1993." Journal of Environmental Economics and Management 44 (2002): 540-56.

Johnson, Kris H, Kristiina A Vogt, Heidi J Clark, Oswald J Schmitz, and Daniel J Vogt. "Biodiversity and the Productivity and Stability of Ecosystems." TREE 11, no. 9 (1996): 372-77.

Jones, P S J, W Qiu, and E M De Santo. "Governing Marine Protected Areas: SocialEcological Resilience through Institutional Diversity." Marine Policy 41 (2013): 5-13.

Kasperski, S, and D S Holland. "Income Diversification and Risk for Fishermen ". Proceedings of the National Academy of Science 100, no. 6 (2013): 2076-81.

Kates, Robert W, William C Clark, Robert Corell, Michael J Hall, Carlo C Jaeger, Ian Lowe, James J McCarthy, et al. "Environment and Development: Sustainability Science." Science 292 (2001): 641-42.

Kitts, Andrew, Evan Bing-Sawyer, John Walden, Chad Demarest, Matthew McPherson, Peter Christman, Scott Steinback, Julia Olson, and Patricia Clay. "2010 Final Report on the Performance of the Northeast Multispecies (Groundfish) Fishery (May 2010-April 2011) " U.S. Department of Commerce, Northeast Fisheries Science Center, Reference Document 11-19, 2011. 97 p.

Klein, Richard J T, Robert J Nicholls, and Frank Thomalla. "Resilience to Natural Hazards: How Useful Is This Concept?". Environmental Hazards 5 (2003): 3545.

Knapp, G. "The Chignik Salmon Cooperative." In Case Studies in Fisheries SelfGovernance edited by R Townsend, R Shotton and H Uchida. Rome, Italy: FAO, 2008.

Knowlton, N. "Thresholds and Multiple Stable States on Coral Reef Community Dynamics." American Zoology 32 (1992): 674-82. 
Koellner, T, and O J Schmitz. "Biodiversity, Ecosystem Function, and Investment Risk." BioScience 56 (2006): 977-85.

Krantz, Lasse. "The Sustainable Livelihood Approach to Poverty Reduction: An Introduction," International Development Cooperation Agency, Stockholm, Swedish, 2001. 44 p.

Labaree, Jonathan M. "Sector Management in New England's Groundfish Fishery: Dramatic Change Spurs Innovation," Gulf of Maine Research Institute, 2012. $13 \mathrm{p}$.

Laycock, W A. "Stable States and Thresholds of Range Condition on North American Rangelands: A Viewpoint." Journal of Rangelands Management 44 (1991): 427-33.

Lebel, Louis, John M Anderies, Bruce Campbell, Carl Folke, Steve Hatfield-Dodds, Terry P Hughes, and James Wilson. "Governance and the Capacity to Manage Resilience in Regional Social-Ecological Systems." Ecology and Society 11, no. 1 (2006): 1-21.

Lewontin, R C. "The Meaning of Stability." In Diversity and Stability of Ecological Systems. Brookhaven, NY: Brookhaven Symposia in Biology, 1969.

Macinko, Seth, and William Whitmore. "A New England Dilemma: Thinking Sectors Through," Massachusetts Division of Marine Fisheries, Kingston, RI, 2009. 81 p.

Magnuson Fishery Conservation and Management Act of 1996. U.S. Public Law 104297. 104th Congress, 11 October 1996.

Majerus, M E N. Melanism: Evolution in Action. Oxford, UK: Oxford University Press, 1998. 364 p.

Maler, Karl-Goran. "Sustainable Development and Resilience in Ecosystems." Environ Resource Econ 39 (2008): 17-24.

Marschke, Melissa, and Fikret Berkes. "Exploring Strategies That Build Livelihood Resilience: A Case from Cambodia." Ecology and Society 11, no. 1 (2006): 116.

Marshall, N A, D M Fenton, P A Marshall, and S G Sutton. "How Resource Dependency Can Influence Social Resilience within a Primary Resource Industry." Rural Sociology 72, no. 3 (2007): 359-90.

Marshall, Nadine A, and Paul A Marshall. "Conceptualizing and Operationalizing Social Resilience within Commercial Fisheries in Northern Australia." Ecology and Society 12 (2007): 14. 
Marshall, Robert J. "Emotive Commitment to Fishing: A Sociological Exploration of Three New England Fishing Communities." Master's thesis, University of Rhode Island, 1973.

May, R M. "Will a Large Complex Ecosystem Be Stable?". Nature 238 (1972): 41314.

_. "Thresholds and Breakpoints in Ecosystems with a Multiplicity of States." Nature 269 (1977): 471-77.

McCay, Bonnie J. "Emergence of Institutions for the Commons: Contexts, Situations, and Events." In The Drama of the Commons, edited by E Ostrom et al. Washington, D.C.: National Academy Press, 2002. 361-533 p.

Miller, Fiona, Henny Osbahr, Emily Boyd, Frank Thomalla, Sukaina Bharwani, Gina Ziervogel, Brian Walker, et al. "Resilience and Vulnerability: Complementary or Conflicting Concepts?". Ecology and Society 15, no. 3 (2010): 1-25.

Minnegal, M, and P D Dwyer. "Managing Risk, Resisting Management: Stability and Diversity in a Southern Australian Fishing Fleet." Human Organization 67 (2008): 97-108.

Monnereau, Iris, and Richard Pollnac. "Which Fishers Are Satisfied in the Caribbean? A Comparative Analysis of Job Satisfaction among Caribbean Lobster Fishers." Social Indicators Research 109, no. 1 (2012): 95-118.

Morris, R F. "The Dynamics of Epidemic Spruce Budworm Populations." In Population Dinamics: New Approaches and Synthesis, edited by Naomi Cappuccino and Peter W Price. San Diego, CA: Academic Press, 1963. 322 p.

Moss, Philip, and D G Terkla. "Income and Employment Change in the New England Fishing Industry." Ocean Development \& International Law 15, no. 1 (1985): 37-59.

Murray, Grant, Teresa Johnson, Bonnie J McCay, Mike Danko, Kevin St. Martin, and Satsuki Takahashi. "Creeping Enclosure, Cumulative Effects and the Marine Commons of New Jersey." International Journal of the Commons 4, no. 1 (2010): 367-89.

NAFO. 2013. "History of Northwest Atlantic Fisheries - Icnaf Years." Accessed August 13, 2013. http://www.nafo.int/about/frames/about.html.

National Research Council. Review of Northeast Fishery Stock Assessments. Washington, D.C.: National Academy Press, 1998. 136 p.

NEFMC. 1981. "Interim Fishery Management Plan for Atlantic Groundfish." 
_ 1982. "Fishery Management Plan Final Environmental Impact Statement Regulatory Impact Review for Atlantic Sea Scallops (Placopecten Magellanicus)."

_ 1985. "Fishery Management Plan, Environmental Impact Statement, Regulatory Impact Review, and Initial Regulatory Flexibility Analysis for the Northeast Multispecies Fishery."

_ 1996. "Amendment 7 to the Northeast Multispecies (Groundfish) Fishery Fmp."

_. 2003. "Amendment 13 to the Northeast Multispecies Fishery Management Plan Including a Final Supplemental Environmental Impact Statement and an Initial Regulatory Flexibility Analysis - Volume 1: Management Anlternatives and Impacts."

— 2007. "Final Decision Document for Amendment 11 to the Scallop Fishery Mangement Plan (Fmp)."

—. 2013a. "About the Nefmc." Accessed August 10, 2013. http://www.nefmc.org/about/index.html.

_ 2013b. "Northeast Multispecies Fishery Management Plan."

_ . nd. "New England Fishery Management Council Seeks Your Comments on Conservation and Management of the Multispecies Fishery." Accessed July 22, 2013. http://www.gmri.org/upload/files/A18\%20scoping\%20doc.pdf.

NEFSC. 2012. "Brief History of the Groundfishing Industry of New England." Accessed September 18, 2013. http://www.nefsc.noaa.gov/history/stories/groundfish/grndfsh1.html.

New Bedford Whaling Museum. 2013. "Cultural Communities and Identities." Accessed September 17, 2013. http://www.whalingmuseum.org/learn/researchtopics/cultural-communities.

NOAA. 2006a. "Point Judith/Narragansett, Ri - Community Profile." Accessed September 15, 2013. http://www.nefsc.noaa.gov/read/socialsci/pdf/RI/point\%20judith-naragannsettri.pdf.

— 2006b. "Provincetown, Ma - Community Profile." Accessed September 20, 2013. http://www.nefsc.noaa.gov/read/socialsci/pdf/MA/provincetown-ma.pdf.

—. 2010. "Scallop General Category Ifq Program." Accessed July 24, 2013. http://www.nmfs.noaa.gov/sfa/domes_fish/catchshare/docs/scallop_general_ca tegory_ifq2010.pdf. 
_ _ 2013a. "2012 Commecial Fishery Landings by Port Ranked by Dollars." Office of Science and Technology, Accessed September 15, 2013. http://www.st.nmfs.noaa.gov/pls/webpls/MF_LPORT_YEARD.RESULTS.

_ 2013b. "Regional Fisheries Management Councils." Accessed August 10, 2013. http://www.nmfs.noaa.gov/sfa/reg_svcs/councils.htm.

_ 2013c. "Magnuson-Stevens Fishery Conservation and Management Act Reauthorized." Accessed August 16, 2013. http://www.nmfs.noaa.gov/msa2007/.

Nystrom, M, C Folke, and F Moberg. "Coral Reef Disturbance and Resilience in Human-Dominated Environment." Trends in Ecological Evolution 15 (2000): 413-17.

O'Neill, R V, D L De Angelis, J B Waide, and T F H Allen. A Hierarchical Concept of Ecosystems. Princetown, NJ: Princetown University Press, 1986. 253 p.

Olson, Julia. "Changing Property, Spatializing Difference: The Sea Scallop Fishery in New Bedford, Massachusetts." Human Organization 65, no. 3 (2006): 307-18.

_. "Understanding and Contextualizing Social Impacts from the Privatization of Fisheries: An Overview." Ocean \& Coastal Management 54 (2011): 353-63.

Olson, Julia, Patricia M Clay, and Patricia Pinto da Silva. "Putting Seafood in Sustainable Food Systems." Marine Policy 43 (Forthcoming 2013): 104-11.

Orleans, Laura, Kirsten Bendiksen, and Markham Starr. Voices from the Waterfront: Portrait of the New Bedford Fishing Industry. North Stonington, CT: Fowler Road Press, 2010.

Ostrom, Elinor, Joanna Burger, Christopher B Field, Richard B Norgaard, and David Policansky. "Revisiting the Commons: Local Lessons, Global Challenges." Science 284 (1999): 278-82.

Parkin, David, and Stanley Ulijaszek. Holistic Anthropology: Emergence and Convergence (Methodology and History in Anthropology). New York: Berghahn Books, 2007. 224 p.

Perrings, Charles. "Resilience and Sustainable Development." Environment and Development Economics 11 (2006): 417-27.

Peterson, G, C R Allen, and C S Holling. "Ecological Resilience, Biodiversity, and Scale." Ecosystems 1 (1998): 6-18.

PEW. 2011. "Managing Fish and Fishing in America's Oceans." Accessed August 15, 2013. http://www.pewenvironment.org/news-room/fact-sheets/managing-fish- 
and-fishing-in-americas-oceans-

328450?utm_source=\&utm_medium=RSS\&utm_campaign=RSSFeed.

Pimm, S L. The Balance of Nature?: Ecological Issues in the Conservation of Species and Communities. Chicago, IL: Chicago Press, 1984. 448.

Pitcher, Tony J. "Fisheries Managed to Rebuild Ecosystems? Reconstructing the Past to Salvage the Future." Ecological Applications 11, no. 2 (2001): 601-17.

Poggie, J J, R B Pollnac, and S Jones. "Perceptions of Vessel Safety Regulations: A Southern New England Fishery." Marine Policy 19, no. 5 (1995): 411-18.

Pollnac, Richard, Brian R Crawford, and Maharlina L G Gorospe. "Discovering Factors That Influence the Success of Community-Based Marine Protected Areas in the Visayas, Philippines." Ocean \& Coastal Management 44 (2001): 683-710.

Pollnac, Richard, Susan Abbott-Jamieson, Courtland Smith, Marc Miller, Patricia Clay, and Brian Oles. "Toward a Model for Fisheries Social Impact Assessment." Marine Fisheries Review 68 (2008): 1-4.

Pollnac, Richard, and John J Poggie. "Happiness, Well-Being and Psychocultural Adaptation to the Stresses Associated with Marine Fishing." Human Ecology Review 15, no. 2 (2008): 194-200.

Pollnac, Richard. "Using Multivariate Analysis to Select Indicators for Surveys in Fishing Communities." In NOAA Indicator Workshop. Miami, FL, 2010.

_ . "Using Multivariate Analysis to Select Indicators for Large Scale Surveys." In NOAA Well-being Indicator Workshop. Charleston, SC, 2011.

Pollnac, Richard B, and John J Poggie. "Economic Gratification Orientations among Small-Scale Fishermen in Panama and Puerto Rico." Human Organization 37, no. 4 (1978): 355-67.

. "The Structure of Job Satisfaction among New England Fishermen and Its Application to Fisheries Management Policy." American Anthropologist 90, no. 4 (1988): 888-901.

_ . "Job Satisfaction in the Fishery in Two Southeast Alaskan Towns." Human Organization 65, no. 3 (2006): 329-39.

Portman, Michelle, Di Jin, and Eric Thunberg. "The Connection between Fisheries Resources and Spatial Land Use Change: The Case of Two New England Fish Ports." Land Use Policy 28 (2011): 523-33. 
Rammel, C, and J C J M van der Bergh. "Evolutionary Policies for Sustainable Development: Adaptive Flexibility and Risk Minimizing." Ecological Economics 47 (2010): 121-33.

Redman, Charles L, Morgan J Grove, and Lauren H Kuby. "Integrating Social Science into the Long-Term Ecological Research (Lter) Network: Social Dimensions of Ecological Change and Ecological Dimensions of Social Change." Ecosystems 7 (2004): 161-71.

Repetto, Robert. "A Natural Experiment in Fisheries Management." Marine Policy 25 (2001): 251-64.

Resilience Alliance. 2009. "Assessing and Managing Resilience in Social-Ecological Systems: A Practitioner's Workbook " Accessed July 10, 2013. http://wiki.resalliance.org/index.php/Main_Page.

Robards, Martin D, and Joshua A Greenberg. "Global Constraints on Rural Fishing Communities: Whose Resilience Is It Anyways?". Fish and Fisheries 8 (2007): 14-30.

Rosenzweig, M L. "Paradox of Enrichment: Destabilization of Exploitation Ecosystems in Ecological Time." Science 171 (1971): 385-87.

Rudestam, Kjell Erik, and Rae R Newton. Surviving You Dissertation: A Comprehensive Guide to Content and Process. SAGE Publications, Inc., 2007.

Rummel, R J. Applied Factor Analysis. Evanston, IL: Northwestern University Press, 1970. 617 p.

Sall, Aliou. "Job Satisfaction in the Coastal Pelagic Fisheries of Senegal." Social Indicators Research 109, no. 1 (2012): 25-38.

Schikler, P. "Has Congress Made It Harder to Save the Fish? An Analysis of the Limited Access Provisions of the Magnuson-Stevens Fishery Conservation and Management Reauthorization Act of 2006." New York University of Environmental Law Journal 17 (2008): 908-35.

Schindler, Daniel E, Ray Hilborn, Brandon Chasco, Christopher Boatright, Thomas P Quinn, Lauren A Rogers, and Michael S Webster. "Population Diversity and the Portfolio Effect in an Exploited Species." Nature 465, no. 7298 (2010): 609-13.

Seara, Tarsila. "Impacts of Management on Social Stratification in Southern Massachusetts Fishing Communities as Related to Job Satisfaction and WellBeing." Master's thesis, University of Rhode Island, 2010. 
_ . "Job Satisfaction among Fishers through Time: The Importance of Comparable Indicators." In Society for Applied Anthropology. Denver, CO, 2012.

Sempier, T T, D L Swann, R Emmer, S H Sempier, and M Schneider. "Coastal Community Resilience Index: A Community Self-Assessment " MASGP-08014, 2010.

Sethi, Suresh. "Risk Management for Fisheries." Fish and Fisheries 11 (2010): 34165.

Sharp, Shayla, and Denise Lach. "Integrating Social Values into Fisheries Management: A Pacific Northwest Study." Fisheries 28, no. 4 (2003): 10-15.

Shelley, Peter. "Ten Years 'after the Fall': Litigation and Groundfish Recovery in New England." Ocean and Coastal Law Journal 7, no. 1 (2001): 21-27.

Sievanen, Leila, Brian Crawford, Richard Pollnac, and Celia Lowe. "Weeding through Assumptions of Livelihood Approaches in Icm: Seaweed Farming in the Philippines and Indonesia." Ocean \& Coastal Management 48, no. 3-6 (2005): 297-313.

Smith, Courtland L, and Patricia M Clay. "Measuring Subjective and Objective WellBeing: Analyses from Five Marine Commercial Fisheries." Human Organization 69, no. 2 (2010): 158-68.

Stokstad, Erik. "Privatization Prevents Collapse of Fish Stocks, Global Analyses Shows." Science 321, no. 5896 (2008): 1619.

Sutherland, J P. "Multiple Stable Points in Natural Communities." Am Nat 108 (1974): 859-73.

Thomas, D H. Figuring Anthropology New York, NY: Holt, Rinehart and Winston, 1976. $544 \mathrm{p}$.

Tilman, D, P B Reich, and J M H Knops. "Biodiversity and Ecosystem Stability in a Decade-Long Grassland Experiment." Nature 441 (2006): 629-32.

Turner, B L. "Vulnerability and Resilience: Coalescing or Paralleling Approaches for Sustainability Science?". Global Environmental Change 20 (2010): 570-76.

Vayda, Andrew, and Bonnie McCay. "New Directions in Ecology and Ecological Anthropology." Annual Review of Anthropology 4 (1975): 293-306.

Walker, Brian, Stephen Carpenter, John Anderies, Nick Abel, Graeme Cumming, Marco Janssen, Louis Lebel, et al. "Resilience Management in SocialEcological Systems: A Working Hypothesis for a Participatory Approach." Conservation Ecology 6, no. 1 (2002): 1-22. 
Walker, Brian, C S Holling, Stephen R Carpenter, and Ann Kinzig. "Resilience, Adaptability and Transformability in Social-Ecological Systems." Ecology and Society 9, no. 2 (2004): 1-9.

Weiss, Cindy. "Fishing for the Real Story of Cape Cod." UConn Today, October 31 2011http://today.uconn.edu/blog/2011/10/fishing-for-the-real-story-of-capecod/.

Whaling City Seafood Display Auction. nd. Accessed September 17, 2013. http://www.whalingcityauction.com/.

Whitmarsh, D J. "The Fisheries Treadmill." Land Economics 74 (1998): 422-27.

Worm, Boris, Ray Hilborn, Julia K Baum, Trevor A Branch, Jeremy S Collie, Christopher Costello, Michael J Fogarty, et al. "Rebuilding Global Fisheries." Science 325 (2009): 578-85.

Wright, T F, J R Eberhard, E A Hobson, M L Avery, and M A Russello. "Behavioral Flexibility and Species Invasions: The Adaptive Flexibility Hypothesis." Ethology Ecology \& Evolution 22, no. 4 (2010): 393-404. 